\title{
Copyright
}

by

Josiah Franklin Marineau

2016 
The Dissertation Committee for Josiah Franklin Marineau Certifies that this is the approved version of the following dissertation:

\section{Aiding Dependency: A Cross-National Analysis of Foreign Aid and Tax Compliance}

\section{Committee:}

Michael G. Findley, Supervisor

Terrence Chapman

Wendy Hunter

Patrick McDonald

Catherine Weaver 


\title{
Aiding Dependency: A Cross-National Analysis of Foreign Aid and Tax Compliance
}

by

Josiah Franklin Marineau, B.A.; M.A.

\author{
Dissertation \\ Presented to the Faculty of the Graduate School of \\ The University of Texas at Austin \\ in Partial Fulfillment \\ of the Requirements \\ for the Degree of
}

Doctor of Philosophy

The University of Texas at Austin

August 2016 


\section{Dedication}

This work is dedicated to the best friend I could have asked for over the past twelve years: Nicole Renae Marineau. 


\section{Acknowledgements}

I had the privilege to write this dissertation while studying as a graduate student at the University of Texas and living in the city of Austin, Texas. My time at the University of Texas would not have been as lively or fulfilling without the students who entered in the same class that I did, including Joseph Amick, Clare Brock, Benjamin Cook, Lewis Fallis, Derrick Goodrich, John Graeber, Henry Pascoe, Peter Harris, Stephen Joyce, Roberto Keller, Kristin Kelly, Jonathan Lewallen, Ryan Lloyd, John Meyer, Joshua Mishriky, Hillel Ofek, Daniel O’Toole, and Sahar Zubairy.

I also had the privilege of studying under many of the Government department faculty, including Drs. Catharine Boone, Terrence Chapman, Michael Findley, Wendy Hunter, Stephen Jessee, Tse-Min Lin, Patrick McDonald, Robert Moser, Peter Trubowitz, R. Harrison Wagner, Scott Wolford, and Kurt Weyland. Professors that I did not study under, but nevertheless learned much from, include Drs. Bruce Buchanan, Susanna Campbell, John Griffin, Paula Newberg, Catherine Weaver, and Rachel Wellhausen.

Two people have been instrumental in my development and progression through the doctoral program, and so deserve particular recognition. The first is Dr. Catherine Boone, who generously facilitated my work in Africa and served as a model of scholarly integrity. The second person is Dr. Michael Findley. This dissertation would not have been written, and almost certainly would not have been finished, without Dr. Findley's support and example.

I would like to thank my former students and colleagues at Innovations for Peace 
and Development, including Oliver Babcock, Ria Charabarty, Michael Cheroff, Catharine Cready, Ethan Hendrickson, Halley Ham, Rachel Hill, Jennifer Johnson, Megan Maldonado, Michelle Mueller, Mustafa Monk, Lindsay May Read, Bianca Remmie, Catie Sauer, Anna Scanlon, Juliette Sieve, Sierra Smith, Caroline Thomas, Raymond Weyandt, Eleanor Williams. I also thank Cyrus Huncharek.

For expertly guiding a naïve graduate student through the streets of Bujumbura, I would like to thank Audifax Bigirimana. Thank you, to Isaac Mulwoya, for sharing his home with a complete stranger. Thank you to Richard for driving me through Lilongwe.

My doctoral studies would not have been possible without the support from faculty at the Josef Korbel School of International Studies, including Drs. Alan Gilbert, Nader Hashemi, Martin Rhodes, Timothy Sisk, and Peter van Arsdale. Of special note are Drs. Barry Hughes, Mohammed Irfan, and Jonathan Moyer at the Pardee Center for International Futures.

At the University of Alaska, Fairbanks, I had the privilege of studying under Drs. Jonathan Rosenberg, James Gladden, and Amy Lovecraft, as well as the late Dr. Joseph Thompson. From my time at the University of Alaska, Anchorage, I would like to acknowledge Professors Kimberly Pace, James Muller, and Carl Shepro.

The process of completing my doctoral program took place in a vibrant community in Austin, Texas. I would like to thank Evan and Kristina Baehr, Micah Bruce, Peter Daniels, Amanda and Graeme Donaldson, George and Kallie Doubleday, Jon Fortenbury, John Griffin, Kendal Haug, Matthew Litschi, Mark Lush, David and Erin Magness, Scott McJunkin, Blake Parrish, Dan Perehoduk, Brittany Snyder, Todd 
Stewman, and Will Walker. Of particular note are my close friends Kevin, Luke, Daniel, Ricardo, and Adam. I would like to thank my friend David Abitbol for encouraging me to apply to the University of Texas. I could not have done it without you.

I would like to thank the Lamson family for their warmth and love over the years, including Jim, David, Chris, John, Laurie, Daniel, Bethy, Jessica, and Brian Lamson. I would also like to thank Cindy Strutz.

Finally, I would like the express my appreciation for my family, which first and foremost includes my Mom and Dad. Thank you both for your support. I would like to thank my brother Josh for the mentorship and guidance he has provided over the years. Thank you to Kim, Jacob, and Audrey Marineau, as well as Zimmel. Thank you to my sister Keylee, and to Rheanna, Gryffen, and Zephyr. Thank you to Michael, Dawn, and Joseph Blosser. I would like to thank my grandfather John Larsen and grandmother Juanita Bray, Donna Larsen and Paul Bray, Kay, William, William John, and Elizabeth Cook, Laura and Michael Stevenson, Sarah Tallwhiteman and Rebecca Holt, and Don, David, and Abby Larsen. Thank you to Zoey and Lulu for the memories.

The biggest thanks goes to the person who is the light of my day and the best friend I could ever ask for, Nicole Marineau. 


\title{
Aiding Dependency: A Cross-National Analysis of Foreign Aid and Tax Compliance
}

\author{
Josiah Franklin Marineau, PhD \\ The University of Texas at Austin, 2016
}

Supervisor: Michael G. Findley

This dissertation investigates whether foreign aid helps or hinders the development of state capacity through its influence on tax compliance. The dissertation argues that tax compliance is the product of a bargaining process between the state and citizenry, which aid can disrupt by lowering the incentive for states to collect taxes and the incentive for people to pay them. To test this argument, a new dataset of sub-national foreign aid in Uganda is used to show that aid lowers tax compliance. These findings are supported with data gathered during fieldwork in Uganda in April and May 2015, and then the findings are generalized through a cross-national analysis of the relationship between aid and tax compliance. 


\section{Table of Contents}

List of Tables ......................................................................................... xii

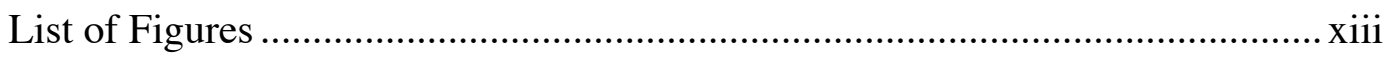

List of Illustrations .............................................................................

Chapter 1 Overview and Introduction............................................................

Overview of Dissertation ......................................................................

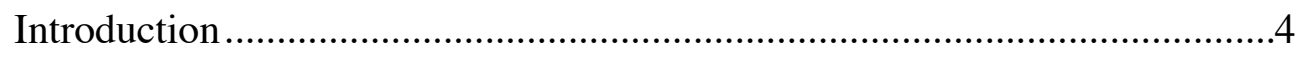

Foreign Aid, Taxation and State-building: What is the Connection? ............6

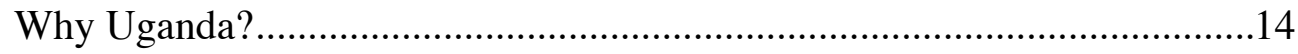

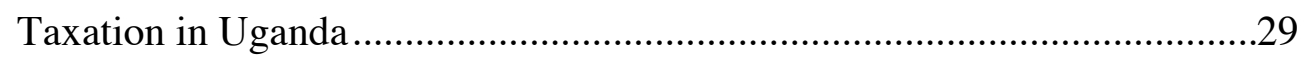

Explaining Uganda's Tax Revenues, 1989-1999.............................36

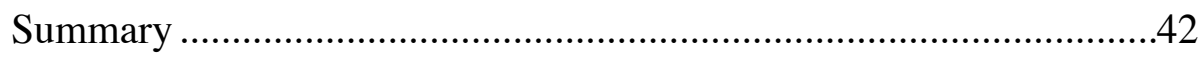

Foreign Aid Flows to Uganda ..............................................................42

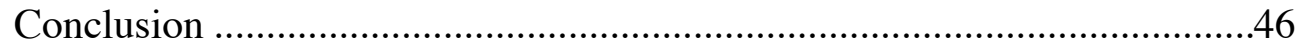

Chapter 2 Aiding Dependency: A Subnational Analysis of Foreign Aid and Tax

Compliance in Uganda.......................................................................48

State Capacity, Foreign Aid, and Tax Compliance....................................51

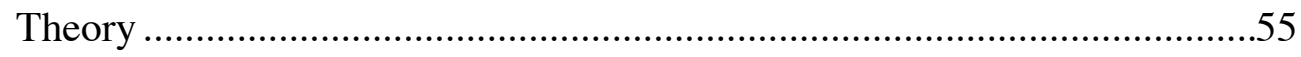

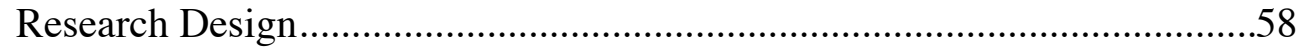

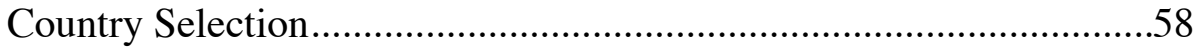

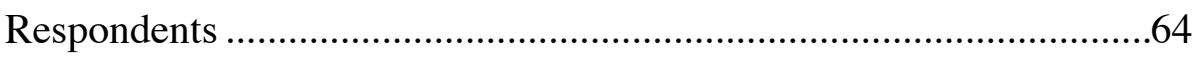

The Dependent Variable ...............................................................65

The Independent Variable ...............................................................67

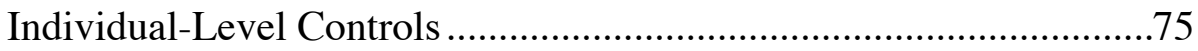

Measures of Attitudes towards Taxation ................................75

Additional Control Variables .................................................76

Addressing Project Location Allocation ............................................76

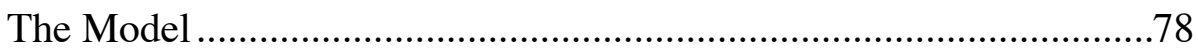

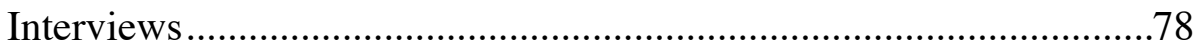

ix 
Results

Relationship Between Foreign Aid and Taxation in Uganda: Findings from Interviews. .86

Conclusion .94

Chapter 3 Aiding Dependency: A Cross-National Analysis of Foreign Aid and

Tax Compliance ............................................................................. 96

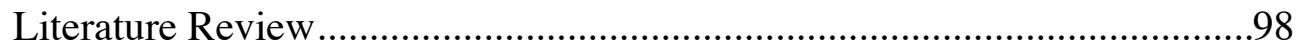

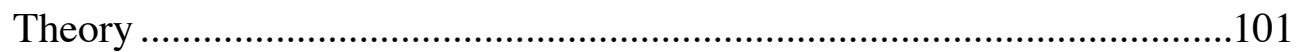

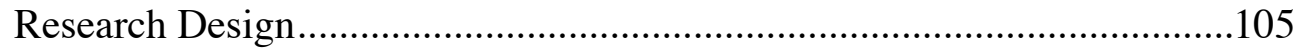

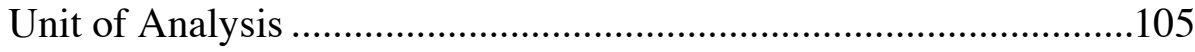

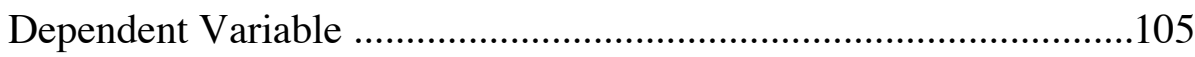

Explanatory Variable ............................................................106

Interaction Terms ................................................................106

Instrumental Variable.................................................................107

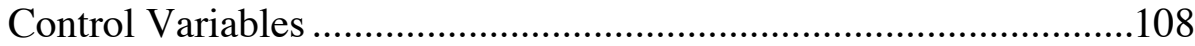

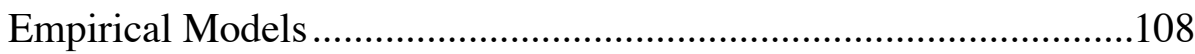

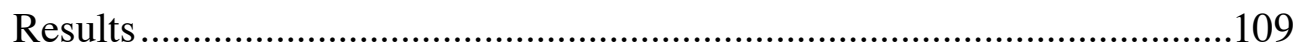

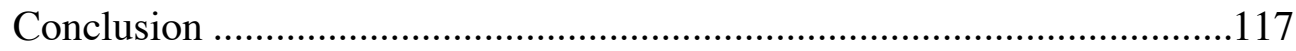

Chapter 4 Donor Motives and Aid Allocation in Uganda ................................119

Background: Aid and Elections in Uganda..............................................122

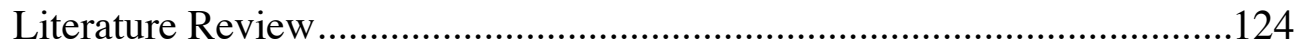

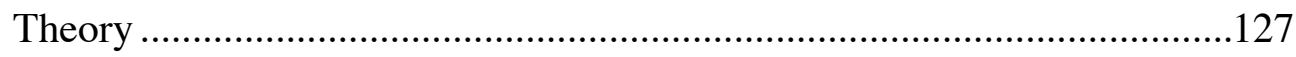

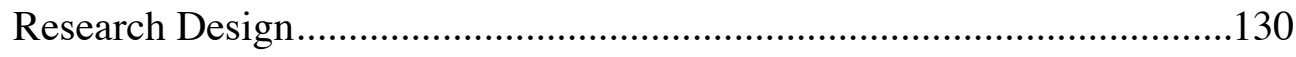

The Unit of Analysis ...................................................................130

The Dependent Variable ............................................................131

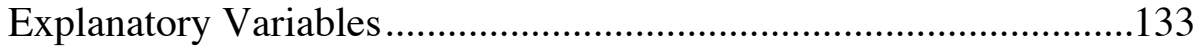

The Control Variables ...................................................................134

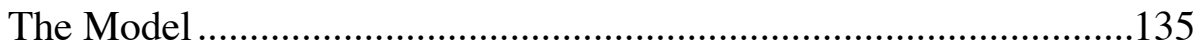

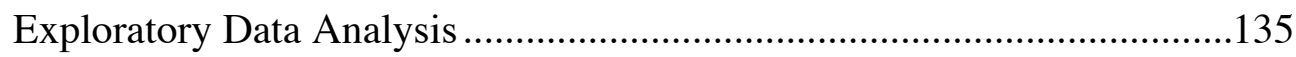

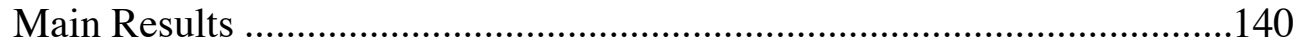

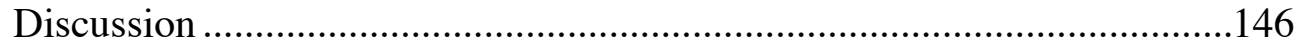




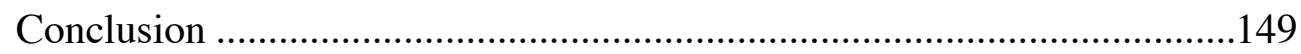

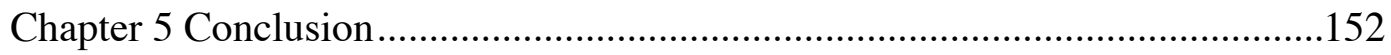

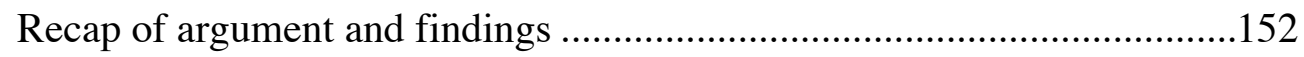

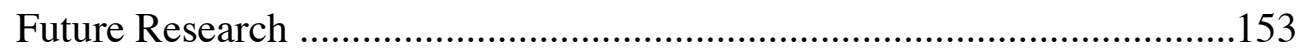

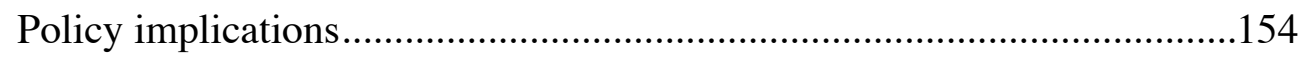

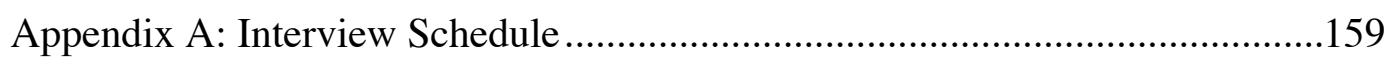

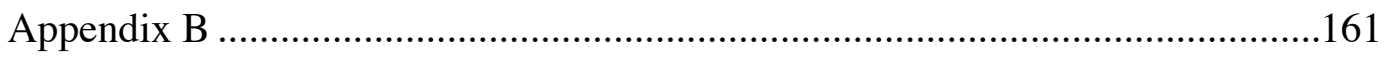

Wording of Questions Used as Independent Variables ..............................161

Wording for Questions Used in Need Index ..................................................163

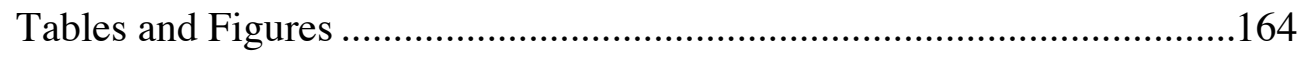

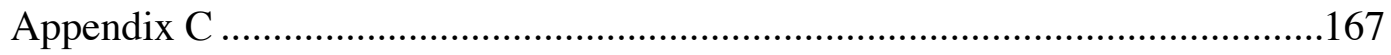

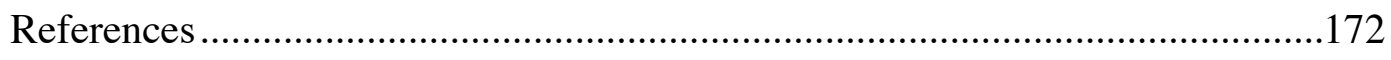

Vita 


\section{List of Tables}

Table 1. Precision Code Description ..................................................................18

Table 2. Frequency of Precision Codes ..........................................................19

Table 3. Project Locations by Primary Sector .................................................20

Table 4. Primary Sector by Precision Code …...............................................21

Table 5. Project Commitments by Sector ......................................................23

Table 6. Average Project Commitments per Sector by Location .........................25

Table 7. Aid Project Locations and Commitments by Donor.............................27

Table 8. Tax-GDP ratios in select African countries in the 1980s and 1990s .......30

Table 9. Summary of Respondents ............................................................64

Table 10. Summary of Reported Tax Compliance in Uganda............................66

Table 11. Logistic Regression Results for Refusal to Comply with Taxation .......80

Table 12. Multilevel Logistic Regression with Logged Aid..............................110

Table 13. Multilevel Multinomial Logistic Regression with Logged Aid...........114

Table 14. Instrumental Variable Results ..........................................................116

Table 15. Summary of Number of Project Locations by Donor ........................132

Table 16. Negative Binomial Results for Bilateral and Multilateral Donors ......141

Table 17. Negative Binomial Regression for Major Bilateral Donors ................143

Table 18. Negative Binomial Regression for Major Multilateral Donors ...........145

Table C1. Multilevel Logistic Regression with Country Projects ......................167

Table C2. Multilevel Multinomial Logistic Regression with Country Projects ..168

Table C3. Full Instrumental Variable Results................................................171 


\section{List of Figures}

Figure 1. GDP Decomposition by Year ..........................................................31

Figure 2: Tax Revenues in Uganda in 2015 US Dollars ..................................33

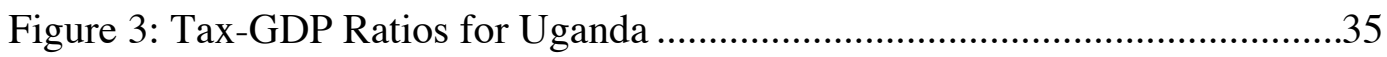

Figure 4. Composition of Ugandan Tax Revenue, 1988-2003 …........................38

Figure 5: Total Foreign Aid for Uganda and Sub-Saharan Africa, 1967-2012 ....43

Figure 6: Aid per Person for Uganda and Sub-Saharan Africa, 1967-2014 _.........44

Figure 7. Project Aid and Budget Support in Uganda, 2005-2014 ......................60

Figure 8. Quality of Governance Measures, 1996-2014 ...................................62

Figure 9. Proportion of Respondents Who Owed Taxes ..................................65

Figure 10. Aid Project Locations at County Level by Sector ..............................71

Figure 11. Project Commitments by Sector ..................................................72

Figure 12. Project Disbursements by Sector ................................................73

Figure 13. Coefficient Plot of Models 1-5 ....................................................84

Figure 14. Marginal Effect of Increasing Logged Aid on Predicted Probability

of Tax Refusal ........................................................................111

Figure 15. Interaction of Logged Aid and Ease of Evading Taxes.....................112

Figure 16. Bilateral Aid and NRM Control after 2006 ..................................136

Figure 17. Multilateral Aid and NRM Control after 2006 ..............................137

Figure 18. Bilateral Aid and NRM Control after 2011 ...................................138

Figure 19. Multilateral Aid and NRM Control after 2011 ..............................139

Figure B1. Relationship Between Tax Compliance and Tax Revenue................165

Figure B2. County Aid Projects by Sector.....................................................166

Figure C1. Marginal Effects of Increasing Aid Projects ..................................169

Figure C2. Interaction of Aid Projects and Ease of Evading Taxes ...................169 
Figure C3. Interaction of Lower State Services and Aid Projects 


\section{List of Illustrations}

Map 1. County-Level Aid Projects in Uganda.................................................69 


\section{Chapter 1 Overview and Introduction}

\section{OVERVIEW OF DISSERTATION}

How does foreign aid affect tax revenues in developing states? The generation of tax revenue is a core component of institutional development, because higher revenues allow for the greater distribution of public goods and imply that the state has the administrative ability to assess and collect taxes. I argue that aid lowers tax revenue by undermining the incentives for the state to collect taxes, while also leading to noncompliance among the citizenry due to the under-provision of public services by the state. While there have been studies of there have been studies of the effect of aid on tax revenues (Gupta et al. 2004, Clist and Morrissey 2011), I argue that a critical component of tax revenues is tax compliance- whether people pay the taxes that they are required to pay or owe. Insofar as tax revenues are a critical component of state capacity, tax compliance serves as the micro-foundations for state capacity. If aid is found to undermine tax compliance, it has negative implications for the relationship between aid and state-building more generally.

In the remainder of this chapter, I unpack the research question and main contribution of this dissertation in more detail. I then explain why Uganda is a useful case for this study, in that the country is a 'typical' developing country in many ways and also because of the availability of a rich dataset on aid allocations at the sub-national level. I then discus tax revenues in Uganda following 1989, and provide a miniature case study of tax revenues between 1989-1999. I conclude the chapter by providing further basic descriptive statistics on aid revenues in Uganda from 1989 to 2014, building on the 
presentation of aid in Uganda discussed earlier in the chapter.

The second chapter looks at the effects of sub-national aid flows on tax compliance. I argue that aid weakens the fiscal contract between citizens and states by decreasing the relative value of state-funded public services while undermining the incentive for the state to enforce taxation. I utilize new data on aid allocations at the local level in Uganda that provide an opportunity to test whether foreign aid lowers tax revenues. Using the 2012 Afrobarometer survey results for tax compliance in Uganda, I show that respondents in areas that have foreign aid projects are more likely to have refused to pay taxes. Drawing on 23 interviews and tax data collected during fieldwork in Uganda in April and May 2015, I find that while aid does not deter all tax revenue, it provides a means for the state to avoid taxing certain sectors of the country. The suspension of aid in 2011 and 2012 allows for an examination of the effects of changes in the independent variable: how the government of Uganda attempted to increase revenue when aid flows decrease.

The third empirical chapter expands upon the research question pursued in the first and second chapters to examine tax compliance in all developing countries that participated in the Afrobarometer survey. In this chapter I test the argument that aid deters government collection and enforcement of tax revenues in developing countries in 34 African countries, and examine the substitution and enforcement mechanisms that may drive this result. The findings suggest that aid does lower tax compliance, and evidence suggests that the enforcement mechanism is stronger than the substitution mechanism. 
The fourth and final chapter looks at the factors that shape sub-national aid allocation. Specifically, it includes a negative binomial regression model that estimates the effects of the 2006 and 2011 Ugandan elections on aid flows after the election. These findings show that bilateral donors are more likely to allocate aid to constituencies that elected parliamentary leaders from the governing party than multilateral donors. Among bilateral donors, the US is especially more likely to provide aid to these constituencies. I argue that, similarly to the literature on strategic interests and cross-national aid allocations, bilateral donors allocate aid within countries in a manner to bolster their influence on the recipient government policies. Yet donors allocate the aid sub-nationally to lower the risks of state capture and the public fallout that can result if the donor's home constituencies believe the donor is funding corrupt regimes.

In the conclusion of the dissertation, I summarize the main findings in each of the previous chapters, indicate new research questions to pursue, and suggest the policy implications of my research. One research question includes, how do recipient states shift their public spending priorities at the sub-national level in response to aid allocations? Regarding policy implications, my findings suggest the importance of foreign aid donors in investing in the capacity of the state to extract tax revenues and ensuring that aidfunded services do not substitute for state-supplied services. Donors should also consider conditioning the delivery of aid upon the meeting of agreed-upon improvements in tax collections within recipient countries.

This project makes several contributions to the study of foreign aid. First, it shows how aid, which has historically been studied at the cross-national level, can have 
important effects within recipient countries at the sub-national level. Thus, this project helps to demonstrate the sub-national effects of international processes. Second, it utilizes a new data on local foreign aid projects in Uganda that the author helped to collected. Third, it provides the first examination of the effect of foreign aid on tax compliance, both cross-nationally in chapter 3 and sub-nationally in chapter 2 . Finally, it suggests how aid may be problematic for state-building more generally by undermining tax compliance at the local level.

\section{INTRODUCTION}

Does foreign aid reduce tax revenues, and if so, how? Aid may reduce tax revenues by lowering the incentives for the state to enforce taxation: As aid serves as a source of resources that the state can rely upon to pay for state services, the state can avoid the costs associated with taxation while still functioning. The rest of this chapter unpacks the theoretical mechanisms discussed in later chapters and illustrates the extent to which key theoretical assumptions hold.

The answers to this question of how aid affects taxation are nuanced, and thus dealt at length in the remainder of this chapter. The basic answers are as follows:

- The tax-GDP ratio has been slowly increasing in Uganda over the past 30 years from around $6 \%$ in 1986 to about $13.2 \%$ in 2014 , although it is low compared to the regional average of $18 \%$ and has stayed roughly at the same level since the 
late 1990 s. ${ }^{1}$

- Uganda has received high levels of aid compared to the average sub-Saharan African country since emerging from civil war in 1986.

- Uganda has seen its level of foreign aid in the form of budget support decrease sharply in recent years, due to several aid-related corruption scandals. Donors are giving more of their aid in the form of project aid. In response to this, the government of Uganda has at least made gestures towards increasing tax revenues as a way to make up for the loss of budget support.

- Tax rates on certain sectors of the economy are quite high, so it is clear that foreign aid does not displace all tax effort. In particular, the small formal sectors of the economy are often taxed at a high rate. However, aid may provide the financial support so that developing states do not need to tax the more difficult areas of the economy, namely the informal and agricultural sectors.

- Donors are becoming more conscious of the importance of public financial reforms more generally and the importance of tax revenue. While these areas have typically been the purview of the IMF, some donors are starting to put more effort into strengthening these systems. Only time will tell if these efforts will offset any tendency for foreign aid to reduce tax revenues.

1 For example, the regional average includes the tax-GDP ratios for Kenya (18.8\% in 2014), Tanzania (17.6\% in 2014), and Rwanda (24.4\% in 2014)). These countries are used as a point of reference because they, with Uganda, for the East African Community (EAC), a regional trade group. Burundi is also a member of the EAC, but lacks reliable tax-GDP ratio statistics. 


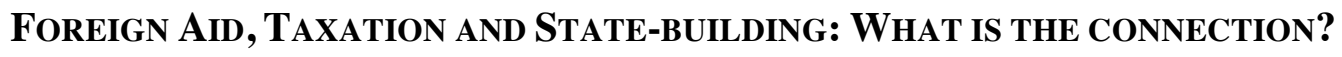

State capacity development, also known as state-building, is a critical goal that the international community has chosen to support. The 2005 Paris Declaration on Aid Effectiveness claims that "the capacity to plan, manage, implement, and account for results of policies and programmes, is critical for achieving development objectives" (para. 22). The 2008 Accra Agenda for Action also declared that "without robust capacity - strong institutions, systems, and local expertise - developing countries cannot fully own and manage their development processes" (para. 14). These statements highlight the close relationship that the international community sees between state-building and the ability for a country to achieve development objectives.

State capacity is "the degree of control that state agents exercise over persons, activities, and resources within their government's territorial jurisdiction" (McAdam et al. 2001, 78). The degree of control that a state exercises is "the probability that a command with a given specific content will be obeyed by a given group of persons" (Weber 1968, 53). Thus for Weber, compliance with the state's commands is a key attribute of state capacity. Ottervik $(2013,5-6)$ points out that research on the state tends to focus both on why people comply with the state and the means by which the state perpetuates itself. The first focus, on compliance, proceeds by attempting to explain individual compliance in terms of state legitimacy, quasi-voluntary compliance, and consent (Levi 1988). The second focus is exemplified by the call to 'Bring the State Back In', which has focused on the states ability to sustain itself (Evans et al. 1985). Ottervik notes that "these lines of research intersect the most clearly in the focus on the state as an 
aggregator of resources" $(2013,6)$. The ability of the state to raise revenues is this a key indicator of its ability to penetrate society and on its bureaucratic capability to collect those taxes.

However, a considerable body of work suggests that where the state accrues the revenues that it needs for sustenance shape the development of the state and its relationship with society. Kevin Morrison has drawn a critical distinction between nontax revenues and tax revenues, where non-tax revenues constitute natural resource rents, remittances from diasporas, and revenue from foreign actors (2014). Tax revenues are revenues generated from taxing citizens, domestic organization, and international actors seeking to business in the country. These non-tax revenues can contribute to what is known as the resource curse, in which access to non-tax revenues can inhibit democratization and allow for the maintenance of authoritarian regimes (Morrison 2012, see also Ross 1999, Smith 2008, and Ahmed 2012). Sarah Bermeo (2016) has challenged whether aid has the same relationship with as posited by scholars such as Morrison, alleging instead that any negative effects of aid are limited to the Cold War period.

Where these studies concur is the centrality of revenue mobilization to state development. As argued by Besley and Persson, "the power to tax lies at the heart of state development" $(51,2013)$. On the one hand, high tax revenues contribute to a stronger state that can deliver on pubic services such as defense and welfare-related spending. Since "revenues are necessary to fund the state's activities in a sustainable manner, the size and consistency of government revenues can tell us a lot about the level of capacity that exists within the state apparatus" (Moss et al. 2006, 10). On the other, the ability to 
tax effectively an indicator of state capacity, with high tax revenues suggesting that the state has successful penetrated the society it governs and has the bureaucratic efficiency to deliver the tax revenue into the state treasury. It is thus not surprising that the ability to raise revenues domestically is often used as an indicator of state capacity (Young 2009, Hendrix 2010).

Less work has explicitly worked on the ability of the state to enforce compliance with taxation. If tax revenues are key for state capacity, and tax compliance is important for raising tax revenues, then tax compliance serves as the microfoundations for state capacity (Ottervik 2013). Yet developing countries can encounter significant challenges to raising tax revenues and enforcing compliance.

Developing countries have both structural and institutional challenges to raising tax revenues. As described by Ardant, the structural challenges stem from the fact that many developing countries have agrarian economies, and extracting tax revenue from agrarian economies is difficult (1975). First off, much of the farming in agricultural economies is subsistence farming, in which the farmer lives off the produce of his or her land. The net product of the farming is often very limited once the farmer has consumed what he or she needs for daily living. Thus, little remains of the produce for taxation. Secondly, agricultural products can only be taxed if they are first turned into money, which in turn depends upon access to markets. ${ }^{2}$ Yet limited urban areas and poor roads can limit access of farmers to reach the markets in developing countries. Finally, the assessment of taxes is difficult because farmers often do not track the volume and value

\footnotetext{
2 Instead of collecting the tax as currency, states could possibly collect the taxes in-kind, but this would prove highly inefficient in agricultural economies do to the spoilage of the produce.
} 
of their produce. As explained by Brewer in comments on tax collection in early modern England that are remarkably application to contemporary developing countries in Africa,

All tax collectors face three major problems: those of measurement - assessing liability on the basis of wealth or output; of collection - persuading or coercing subjects and citizens to pay their taxes; and or remittance - getting money from the point of collection into the coffers of the state. All three are exceptionally difficult to accomplish not in a poor economy but in characterized by subsistence agriculture, by scatter, small-scale production, by local markets, poor communications and by exchange in kind rather than through cash or credit. $[1988,182]$

There are also institutional challenges to tax collection. Developing states often face serious problems regarding corruption, in which public funds are used to serve private purposes (Rose-Ackerman 1999). Corruption can fuel the loss of public revenues (Friedman et al. 2000), which in turn can lower the level of public services the state provides: Mauro (1998) finds that more corrupt states spend less on public services like education, because this sort of spending has less opportunities for government official to obtain a financial benefit. The lower levels of public spending and the poor quality of public services "discourages some individuals from using these services and reduces their willingness to pay for them (through tax evasion), which shrinks the tax base and diminishes the government's ability to provide quality public services" (Gupta, Davoodi, and Tiongson 2002, 111).

Additionally, the administrative capacity of the tax revenue authorities is often weak. The revenue authorities are often not given the power to prosecute tax evaders on a wide scale, and have little presence outside of the main urban areas. The lack of adequate transaction records for most businesses makes auditing their accounts near impossible, while the absence of a cadaster precludes implementing taxes on property. 
In the early modern period, states that today are considered 'developed' had to overcome many of the same challenges facing contemporary 'developing' states. How they did so is a topic that would take us too far afield from the discussion at hand. However, one difference between the early modern states and contemporary developing states, a difference that may limit the applicability of the early modern experience to the contemporary challenges that developing states face, is a large foreign aid industry that allocates billions upon billions of funds to these developing states.

Foreign aid is suspected of having a negative effect on the incentive for developing states to collect revenue, and thus serving to perpetuate the dependence of these states upon aid. Pritchard, Brun and Morrissey succinctly explain the potentially negative linkage between aid and taxes: "foreign aid, by providing governments with a ready source of non-tax revenue, may reduce incentives for governments to pursue politically costly domestic tax collection" $(2012,13)$. Scholars have argued that, like natural resources, foreign aid can deter the incentives for the state to raise revenues domestically. In a study of Somaliland, Eubanks (2012) argued that the fact that the government was ineligible to receive foreign aid spurred efforts towards raising domestic revenues.

Evidence for a negative relationship between foreign aid and tax revenues has been found in some cross-national studies. Grants in particular may be problematic in terms of their effect on incentives to mobilize domestic revenue, because unlike loans, they need not be repaid by the recipient state (Gupta et al. 2004). The fact that loans have requirements for repayment suggests that they may have a positive relationship with 
domestic revenue. This negative effect may be more prevalent in states with weaker states (Benedek at al. 2012). Institutional quality thus may be an intervening variable in the aid-tax revenue relationship, such that states with poor quality of bureaucracy have a negative relationship between aid and tax revenues (Brun et al. 2011).

However, the debate on the cross-national effect of aid on tax revenue has not been concluded. The positive finding has been criticized as the result of poor data quality with considerable missing observations, as well as the use of incorrect temporal framework (Clist and Morrissey 2011). Others have argued that the effect of aid on tax revenues is heterogenous across countries (Morrissey 2015). Prichard, in a review of the literature on aid and tax revenues, concludes that "there is no consistently significant relationship between aid and tax collection" $(2016,54)$.

The argument that aid may undermine tax collection hinges on the assumption that taxes are costly to collect. If there were no costs attached to tax collection, then an aid-recipient state would ostensibly seek to maximize its revenues by collecting both the rents that donors give in the form of foreign aid as well as the revenues it can generate by taxing its citizens.

What are the sources for these costs? One source that Pritchard, Brun and Morrissey allude to is the political costs of tax collection (2012). Rooted in the logic that citizens demand representation in exchange for taxation (Ross 2004), the idea is that states have to cede power in the form of accountability and transparency to the citizenry in exchange for extracting high levels of taxes. Foreign aid serves a source of 'free 
money' that subsidizes the state and enables it to avoid ceding power to the citizenry in the form of accountability (Bueno de Mesquita and Smith 2010).

A second source of the costs for tax collection is rooted in the agrarian nature of many aid-recipient countries. As mentioned above, collecting tax revenues is difficult in these countries, and the taxes collected from agriculture are often revenue-neutral or even negative due to the high administrative costs of tax assessment and collection. Aid may allow the state to avoid the costly effort to expand the tax base beyond the narrow wageearning sector of the economy, which is much easier to tax and indeed heavily relied upon as a source of domestic tax revenue.

As a way to avoid the costs associated with taxation, aid may displace tax revenue by allowing the state to invest less in tax enforcement. This allows the state to recoup the operational costs of taxation, but, more importantly, it allows the state to avoid incurring the political costs of taxation. Insofar as tax enforcement decreases, so do the costs associated with refusals to comply with taxation. ${ }^{3}$ Thus, aid can lower tax compliance by reducing the likelihood that the state will enforce taxation. This is called the enforcement mechanism. Secondly, aid may decrease tax compliance by providing services that compete and can even substitute for the state's provision of services. Aid may allow the state to redirect tax funds that it would have to spend on services and consume the funds privately or spend the funds on politically-expedient projects, with aid making up the

\footnotetext{
${ }^{3}$ Some studies of aid and tax revenue include squared aid in the right-hand side of the regression equation to account for potential non-linearity in the relationship between aid and tax revenues.
} 
difference. ${ }^{4}$ Yet by doing so, the state makes tax-paying less beneficial for taxpayers, insofar as they would have received the services from donors even if they had not paid taxes. This is called the substitution mechanism, whereby the substitution of aid-funded services for state-funded services lowers tax compliance.

One factor that the aid-taxation debate has left unaddressed is that not all sectors of the economy are equally costly to tax. As discussed, the agricultural sector is notoriously difficult to tax because of the difficulty of assessing the amount of tax owed and collecting the tax in the form of currency. However, the wage-earning portion of the economy, which is largely confined to the few large businesses in these countries and the public sector workforce, is much easier to tax. Indeed, the income taxes from this sector produce a large share of the domestic tax revenue. The aid-tax relationship likely does not affect this sector, except to provide more opportunities for taxation through the taxation of salaries of aid-related nonprofits and the importing of certain goods..$^{5}$

For the reasons discussed above, however, aid may prevent the state from seeking to tax the agricultural sector. First, the cost of doing so is often prohibitive, although the cost may be moderated by taxing agricultural associations that are charged with collecting taxes (Joshi and Ayee 2008). Second, since close to a majority of people in developing countries tend to work in this sector- the World Bank reports that just over

\footnotetext{
4 This assumes that taxpayers are unaware that the services they receive are afforded by aid. If they are aware, aid may lower tax compliance as the taxpayers would still receive services even if they did not pay for them through taxes.

5 The taxation of the foreign aid industry is a controversial topic in developing countries. Donors resist it, as they view their aid as in many cases already going to the government and otherwise benefitting the public at large. The exact laws that govern the taxation of aid-related projects and organizations are often vague. However, several of my interviews pointed to taxes related to the aid industry as a source of revenue for the government.
} 
$47 \%$ of the working population on average was employed in the agricultural sector in lower-middle income countries ${ }^{6}$ - thus it is the taxes on this sector that may be mostly likely to result in demands for greater accountability and transparency in the government. Finally, because agricultural workers make much less than the wage-earning sector, they are much more sensitive to any direct taxes and thus more likely to demand greater levels of public services in exchange for their taxes than the wage-earning sector. In sum, the effect of aid on taxes may depend on the sector of the economy.

As the rest of this section will demonstrate, Uganda is an ideal country in which to study the effects of foreign aid on tax revenues generally and tax compliance specifically because of the high levels of foreign aid the country has received since 1986, along with the difficulty the country as faced in raising tax revenues. I turn next to why Uganda is an ideal country for this study, turning next to a discussion of tax revenues in Uganda in detail, and then turn to foreign aid flows.

\section{WHY UGANDA?}

Uganda is an ideal country for studying the effects of foreign aid on tax compliance because in many ways, it has characteristics that are typical of developing countries. It lacks characteristics associated with "strategically important" countries, such as military alliances with world powers (Bueno de Mesquita and Smith 2009), the production of lucrative natural resources, location in a strategically vital area of the world (Berthélemy 2006), or high levels of trade and foreign direct investment (Alesina and

\footnotetext{
${ }^{6}$ http://data.worldbank.org/indicator/SL.AGR.EMPL.ZS, accessed 2 June 2016 at 4pm. Average calculated over the time period 1995-2014
} 
Dollar 2000). According to the Correlates of War dataset on military alliances, Uganda had a defense treaty with Sudan dating back to 1972, while signed a regional defense pact with several regional neighbors in 2006, including Angola, Burundi, Central African Republic, Democratic Republic of the Congo, Kenya, Sudan, Tanzania, and Zambia (Gibler 2009). In 2006, oil was discovered in the eastern shore of Lake Albert, which lies on the western border between Uganda and the Democratic Republic of Congo. The government of Uganda estimates the amount of oil reserves to be as high as 6.5 billion barrels. ${ }^{7}$ Yet oil production has not begun, and the expected date for oil production to begin has already been pushed back in several iterations from $2009^{8}$ to $2018^{9}$. Finally, Uganda's location as a land-locked country in Africa places it outside of many of the regions that donors have typically looked to with strategic interests, including the Middle East and Latin America for the US and eastern Asia for Japan (Berthélemy 2006).

Even given the presence of oil, Uganda joins the ranks of many other African countries that are oil-producers. At least 15 other Sub-Saharan countries currently produce oil, including Nigeria, Angola, Equatorial Guinea, South Sudan, Republic of Congo, Gabon, South Africa, Ghana, Chad, Cameroon, Cote d'Ivoire, Democratic Republic of the Congo, Niger, Mauritania, and Malawi. ${ }^{10}$ Other countries, such as Kenya, are known to have oil reserves but have not yet begun producing oil. So even insofar as

\footnotetext{
7 BBC. Uganda picks Tanzania for oil pipeline, drops Kenya plan. 23 April 2016. Accessed at: http://www.bbc.com/news/world-africa-36121081 on 15 June 2016 at 4pm.

8 See afrol News, Uganda becomes oil producer. 9 October 2009. Accessed at http://www.afrol.com/articles/21834 on 15 June 2016 at 4:12pm.

${ }^{9}$ BBC. Uganda picks Tanzania for oil pipeline, drops Kenya plan. 23 April 2016. Accessed at: http://www.bbc.com/news/world-africa-36121081 on 15 June 2016 at 4pm.

${ }^{10}$ African Vault. Top 20 Oil Producing Countries in Africa. No Date. Accessed at http://www .africanvault.com/oil-producing-countries-in-africa/ on 15 June 2016 at 5:55pm.
} 
the presence of oil reserves might shape donor behavior toward the country, it is not unique for having oil relative to many other countries in Sub-Saharan Africa.

Uganda does have several factors such as former colony status, democratic openness, and low GDP ${ }^{11}$ (Alesina and Dollar 2000) that are typically associated with higher levels of aid allocation, but it is not exceptional for possessing these features. Uganda does have a former colonizer (the United Kingdom), for example, but it is not unique for that fact and even rather shares its former British colony status with 18 other countries in Sub-Saharan Africa, including: Sudan, Nigeria, parts of Somalia, Botswana, Kenya, Tanzania, Ghana, parts of Cameroon, Egypt, the Gambia, Zambia, Malawi, Sierra Leone, South Africa, Namibia, Zimbabwe, Lesotho, and Swaziland. In addition, every other contemporary country in Sub-Saharan Africa is a former colony, except for Ethiopia.

In terms of democratic openness, Uganda scores similarly to the rest of the subcontinent. The Democracy Index complied by the Economist Intelligence Unit shows Uganda with a score of 5.22, and so labeling it as a "hybrid regime," which is more democratic than an authoritarian regime but less democratic than a "flawed democracy," according to the methodology of the index (2015). This score places Uganda slightly above the regional average score for Sub-Saharan Africa, 4.38, for 2015, which also falls within the category of hybrid regime. Freedom House ranks Uganda as Partly Free in 2015, a score that it assigns to $37 \%$ of all countries in Sub-Saharan Africa. ${ }^{12}$

\footnotetext{
${ }^{11}$ Uganda's GDP will be discussed in detail in the next section.

12 Freedom House, Country Status by Region, 1973-2016 and Country Rating and Status, 1973-2016. Both accessed at https://freedomhouse.org/report-types/freedom-world on 15 June 2016 at 5:29pm.
} 
Thus in many ways, Uganda is a typical aid-recipient country in Sub-Saharan Africa, and so the findings of an investigation of the relationship between aid and tax compliance are potentially generalizable to other aid-recipient countries. However, there are also particular aspects of Uganda that make it attractive for such a study as this. For one, I helped lead a team that collected a dataset on sub-national aid allocation in Uganda under the guidance of a methodology developed by Strandow et al. (2011). This dataset includes information on aid projects that were implemented at lower administrative levels within the country, and so present a unique opportunity to investigate the effects of foreign aid at the sub-national level. Foreign aid studies have traditionally been conducted at the cross-national level, and so overlook the considerable variation concerning where goes within countries.

The dataset contains information on a total of 2,458 aid project locations (the number of locations that an aid project reaches) for 569 separate aid projects that were implemented between 1988 and 2013. ${ }^{13}$ The aid project locations are identified by a precision code that indicates the level of 'exactness' in terms of the location information for the project. The precision codes range from the national level down to the city level:

13508 aid project locations lack temporal information. 
Table 1. Precision Code Description

\begin{tabular}{|l|l|}
\hline Precision & Precision Code Description \\
\hline 1 & Coordinates correspond to an exact location or populated place \\
\hline 2 & $\begin{array}{l}\text { Coordinates correspond to a location that is known to be within } \\
\text { 25km of the coordinates or a division smaller than ADM2 }\end{array}$ \\
\hline 3 & $\begin{array}{l}\text { Coordinates correspond to an ADM2 division (as defined by } \\
\text { GAUL) }\end{array}$ \\
\hline 4 & $\begin{array}{l}\text { Coordinates correspond to an ADM1 division (as defined by } \\
\text { GAUL) }\end{array}$ \\
\hline 5 & $\begin{array}{l}\text { Estimated coordinates of a large feature, such as rivers or national } \\
\text { parks }\end{array}$ \\
\hline 6 & $\begin{array}{l}\text { Coordinates correspond to the entire country, project operates in } \\
\text { sub-national locales but they are not known }\end{array}$ \\
\hline 8 & $\begin{array}{l}\text { Coordinates correspond to the entire country, it is likely that the } \\
\text { funding goes to a government ministry or financial institution }\end{array}$ \\
\hline
\end{tabular}

As described in table 1, precision code 1 refers to an exact location or populated place. In practice, this precision code will usually refer to a city or town although more specific locations can occur (e.g. a specific hospital, school, or airport). Precision code 2 refers to a location within 25 kilometers of the aid project, such as a project that is located in the periphery of an urban area. It can also refer to administrative level smaller than administrative level 2 (ADM2). Precision code 3 refers to projects at administrative level 2 (ADM2). Precision code 4 refers to projects administered at administrative level 1 (ADM1). Note that ADM1 is larger typically than ADM2. Precision code 5 refers to locations with boundaries that can cross administrative units, such as rivers and national parks. Precision code 6 refers to projects administered at the sub-national level, but the exact location is not known. Precision code 8 refers to projects administered at the national level. 
Table 2. Frequency of Precision Codes

\begin{tabular}{|l|r|r|r|}
\hline Precision & Frequency & Percent & Cumulative \\
\hline 1 & 727 & 29.58 & 29.58 \\
\hline 2 & 105 & 4.27 & 33.85 \\
\hline 3 & 1,334 & 54.27 & 88.12 \\
\hline 4 & 35 & 1.42 & 89.54 \\
\hline 5 & 5 & 0.2 & 89.75 \\
\hline 6 & 170 & 6.92 & 96.66 \\
\hline 8 & 82 & 3.34 & 100 \\
\hline
\end{tabular}

Table 2 shows the frequency of the different precision codes. By far the most numerous with 1,334 occurrences is precision code 3 (ADM2) which corresponds to the district level in Uganda. Precision code 3-level projects make up about 54\% of the dataset. The next most numerous is precision code 1 with 727 occurrences, constituting about $29 \%$ of the dataset. Precision code 6 is the third most frequent precision code, with 170 occurrences, and precision code 2 is the fourth most frequent with 105 occurrences. Precision codes 8,4 , and 5 are the least frequently occurring precision codes, with 82,35 , and 5 occurrences each. 
Table 3. Project Locations by Primary Sector

\begin{tabular}{|l|r|r|r|}
\hline Primary Sector & Frequency & Percent & Cumulative \\
\hline Accountability & 121 & 4.92 & 4.92 \\
\hline Agriculture & 203 & 8.26 & 13.18 \\
\hline Budget Support & 157 & 6.39 & 19.57 \\
\hline Education & 252 & 10.25 & 29.82 \\
\hline Energy and Mineral Development & 84 & 3.42 & 33.24 \\
\hline Health & 545 & 22.17 & 55.41 \\
\hline Information and Communication Technology & 11 & 0.45 & 55.86 \\
\hline Justice, Law, and Order Sector & 29 & 1.18 & 57.04 \\
\hline Public Administration & 2 & 0.08 & 57.12 \\
\hline Public Sector Management & 289 & 11.76 & 68.88 \\
\hline Security & 1 & 0.04 & 68.92 \\
\hline Social Development & 356 & 14.48 & 83.4 \\
\hline Tourism, Trade, and Industry & 17 & 0.69 & 84.09 \\
\hline Water and Environment & 280 & 11.39 & 95.48 \\
\hline Works and Transport & 111 & 4.52 & 100 \\
\hline
\end{tabular}

Table 3 shows the frequency of aid project locations by primary sector, which is the particular issue area that the aid project is intended to influence. The most frequently occurring aid sector is health, with 545 aid project locations $(22.17 \%$ of the total) devoted to health projects. The next most frequently occurring aid sector, constituting 356 aid project locations or $14.48 \%$ of the total, is social development, a broad category of projects that are aimed at improving livelihoods. Projects under the social development category include titles such as "Livelihoods and Local Economic Recovery in Acholi Sub-Region," "Poverty Reduction for Internally Displaced Persons (IDPS)", and “Women's Empowerment for Peace," among many other examples. The least frequently 
occurring sectors include public administration, with only 2 aid project locations, and security, with a sole aid project location in the bunch.

Table 4. Primary Sector by Precision Code

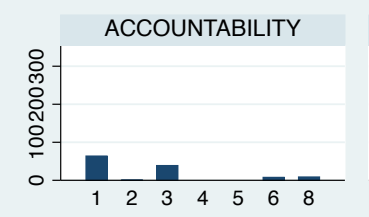

AGRICULTURE

BUDGET SUPPORT

EDUCATION
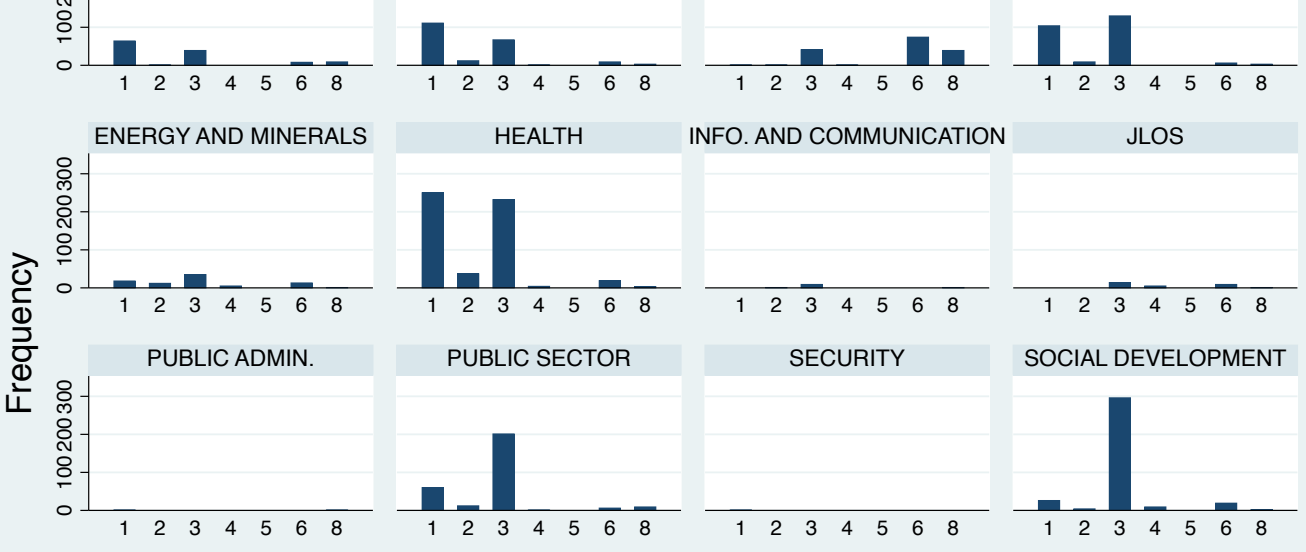

HEALTH

INFO. AND COMMUNICATION

JLOS
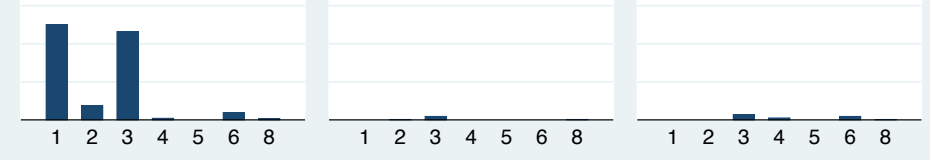

PUBLIC SECTOR

SECURITY

SOCIAL DEVELOPMENT
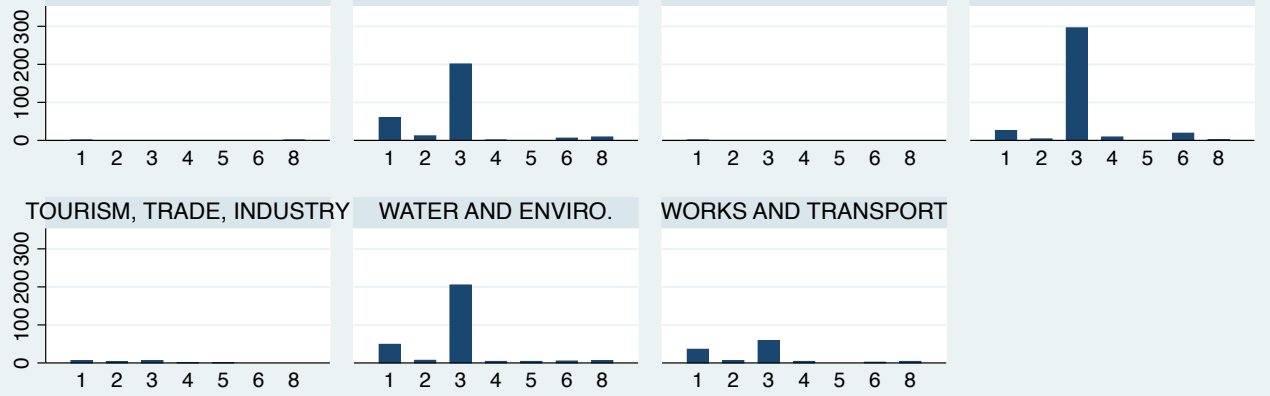

WATER AND ENVIRO.

WORKS AND TRANSPORT
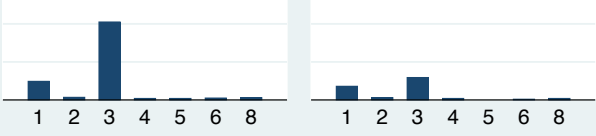

Sub-graphs organized by Primary Sector

Table 4 displays the primary aid sectors by precision code. The categories with the fewest occurrences of aid project locations, such as public administration and security, appear nearly empty because of the dearth of these projects in the dataset. Health projects make up the plurality of aid project locations at precision code 1 , constituting 250 of the 727 aid project locations at this level. Agricultural projects constitute the next most frequently occurring sector at the precision code 1 level, with 111 aid project locations at precision code 1 . Education projects are the third most 
frequently occurring projects at this level, with 104 aid project locations dealing with education. The only sectors that are completely unrepresented at the $1^{\text {st }}$ precision code level include justice, law, and order sector projects (JLOS) and information and communication technology. Projects at precision code level 2 are relatively infrequent, with only 105 aid project locations at this level in the dataset. Health projects again make up the plurality of aid project locations at this level, making up 37 of the 105 project locations. Precision code 3 is the most frequently occurring of the group, with 1,334 locations out of the total 2,458 . Social development projects are the most frequently occurring sector at this precision code level, with 296 project locations or $26.1 \%$ of the total. Health project are the second most frequently occurring sector at this precision code level, with 232 aid project locations related to health. Water and environment and public sector management are the third and fourth most frequently occurring aid projects at this precision code level, with 205 and 201 aid project locations respectively.

Precision codes 4 through 8 occur infrequently in the dataset, and so relatively few primary sectors are represented at these levels. However, some aid sectors such as budget support are predominantly located at higher precision code levels. 114 of budget support's total aid project locations are at precision code level 4 or higher. 15 of JLOS's 29 aid project locations are also at precision code level 4 or higher. One of the two public administration aid project locations is at precision code level 8 (the other is at precision code level 1). 
Table 5. Project Commitments by Sector

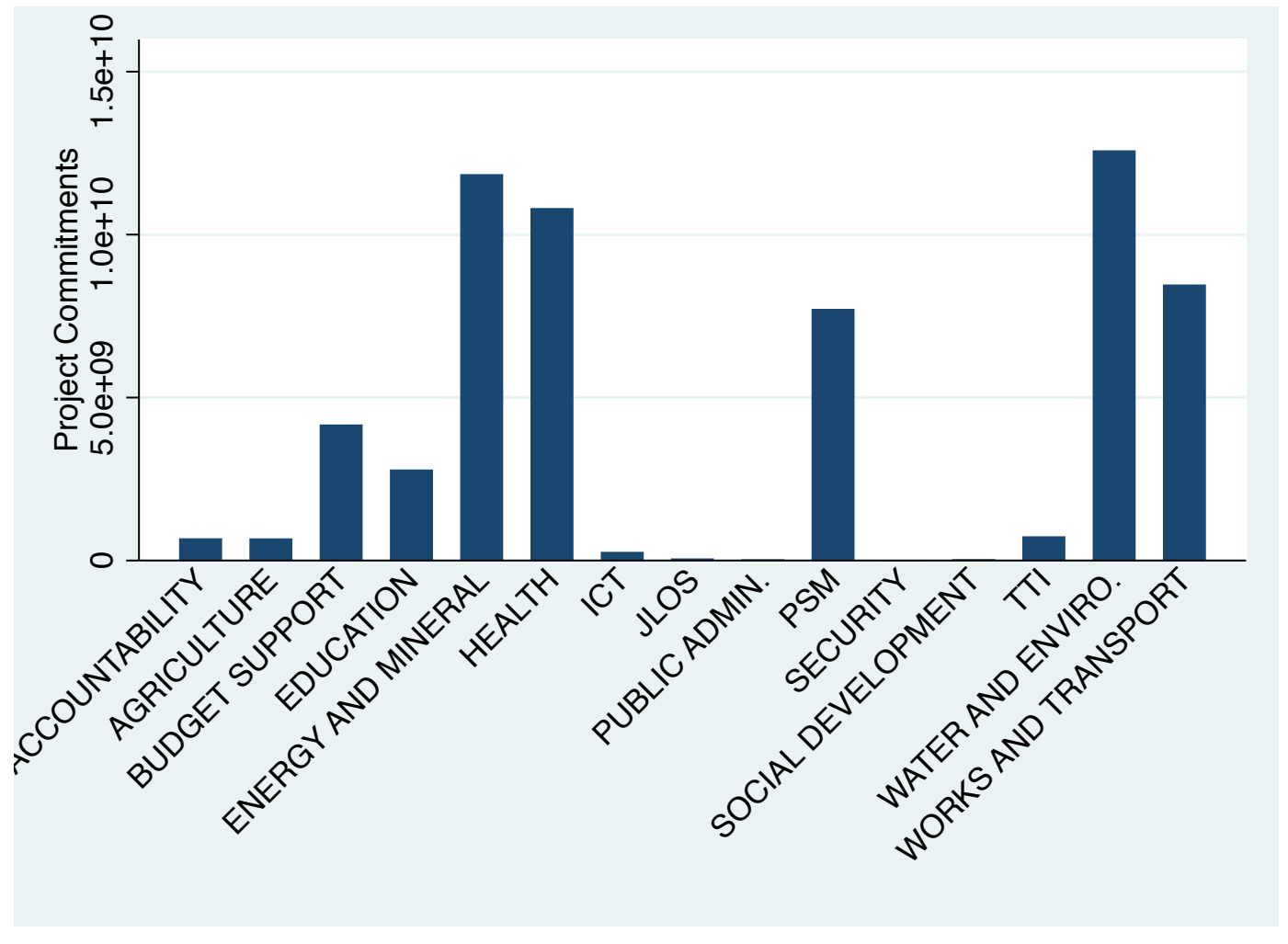

Note: ICT (Information and Communication Technology), JLOS (Justice, Law, and Order Sector), PSM (Public Sector Management), and TTI (Tourism, Trade, and Industry)

Table 5 shows the project commitments in current USD to the aid project locations by sector. Note that project commitments refers to the amount of money that a donor has committed to spending on behalf of a project, but that this number can differ from the amount that the donor actually spends on a project. Nevertheless, project commitments are still informative. The project commitments in this dataset total 
$60,730,000,000$ USD. The Water and Environment sector received the largest share of the project commitments, totaling some 12,570,000,000 USD. The Energy and Mineral Sector received the second largest share of commitments, with a total of $11,840,000,000$ USD. The Health sector has the third largest share of commitments $(10,800,000,000$ USD).

It is interesting to compare table 5 to table 3 , which displays the number of project locations by sector. Some project sectors with the relatively largest numbers of project locations have less in terms of committed dollars. The health sector, which is the largest in terms of the number of aid project locations, is only the third largest in terms of total committed values. Public Sector Management projects were the second-most frequent project by location, but are only the fifth largest by committed dollars $(7,703,000,000)$. Education projects are the third-most frequent by location, but seventh largest by committed dollars $(2,777,000,000)$. Conversely, some aid project sectors with relatively few locations have relatively more dollars committed to them. Works and Transportation had only 111 project locations, the seventh fewest number of locations by sector, but is the fourth largest sector by committed dollars $(8,454,000,000)$. Water and Environment projects have the third-most locations, but have the most in terms of committed dollars. The following table shows the average aid commitment per location by sector. 
Table 6. Average Project Commitments per Sector by Location

\begin{tabular}{|l|r|}
\hline Sector & $\begin{array}{l}\text { Average Commitments per } \\
\text { Location }\end{array}$ \\
\hline Accountability & $5,521,488$ \\
\hline Agriculture & $3,270,443$ \\
\hline Budget Support & $26,503,185$ \\
\hline Education & $11,019,841$ \\
\hline Energy and Mineral Development & $140,952,381$ \\
\hline Health & $19,816,514$ \\
\hline Information and Communication Technology & $22,972,727$ \\
\hline Justice, Law, and Order Sector & $1,720,141$ \\
\hline Public Administration & $12,216,044$ \\
\hline Public Sector Management & $26,653,979$ \\
\hline Security & $6,747,340$ \\
\hline Social Development & 77,854 \\
\hline Tourism, Trade, and Industry & $42,870,588$ \\
\hline Water and Environment & $44,892,857$ \\
\hline Works and Transportation & $76,162,162$ \\
\hline
\end{tabular}

Table 6 shows the average aid commitments per sector by location. Energy and Mineral Development aid projects by far receive the most dollars per location, with an average of just over 140 million USD per location. The sector that receives the secondmost commitments per location, Works and Transportation, receives almost half $(76,162,162$ USD) as much as Energy and Mineral Development projects. The sectors that receive the third and fourth largest average aid commitments by location are Water 
and Environment and Tourism, Trade, and Industry, with 44,892,857 USD and 42,870,588 USD respectively. 
Table 7. Aid Project Locations and Commitments by Donor

\begin{tabular}{|c|c|c|c|}
\hline Donor Name & $\begin{array}{l}\text { Project } \\
\text { Locations }\end{array}$ & $\begin{array}{l}\text { Total Aid } \\
\text { Commitment }\end{array}$ & $\begin{array}{l}\text { Aid per } \\
\text { Location }\end{array}$ \\
\hline $\begin{array}{l}\text { African Capacity Building } \\
\text { Foundation }\end{array}$ & 1 & $2,219,550$ & $2,219,550$ \\
\hline African Development Fund & 174 & $9,810,538,014$ & $56,382,402$ \\
\hline BADEA & 12 & $927,754,613$ & $77,312,884$ \\
\hline Austria & 70 & $72,868,434$ & $1,040,978$ \\
\hline Belgium & 21 & $279,510,309$ & $13,310,015$ \\
\hline Canada & 2 & $11,072,968$ & $5,536,484$ \\
\hline China & 33 & $318,776,724$ & $9,659,901$ \\
\hline Denmark/DANIDA & 108 & $1,127,222,890$ & $10,437,249$ \\
\hline European Investment Bank & 6 & $185,263,789$ & $30,877,298$ \\
\hline European Union & 200 & $3,007,532,961$ & $15,037,665$ \\
\hline Germany & 14 & $178,780,552$ & $12,770,039$ \\
\hline Iceland & 3 & $1,413,737$ & 471,246 \\
\hline IBRD & 2 & $3,424,635$ & $1,712,318$ \\
\hline $\begin{array}{l}\text { International Centre for Tropical } \\
\text { Agriculture }\end{array}$ & 3 & 405,145 & 135,048 \\
\hline $\begin{array}{l}\text { International Development } \\
\text { Association }\end{array}$ & 262 & $25,574,613,569$ & $97,613,029$ \\
\hline IFAD & 1 & $25,379,830$ & $25,379,830$ \\
\hline International Monetary Fund & 7 & $220,733,223$ & $31,533,318$ \\
\hline Ireland & 116 & $72,990,080$ & 629,225 \\
\hline Islamic Development Bank & 13 & - & - \\
\hline Japan & 165 & $5,642,027,962$ & $34,194,109$ \\
\hline Netherlands & 45 & $306,513,446$ & $6,811,410$ \\
\hline Norway & 214 & $598,890,629$ & $2,798,554$ \\
\hline OPEC & 1 & $10,000,000$ & $10,000,000$ \\
\hline Spain & 2 & - & - \\
\hline Sweden & 53 & - & - \\
\hline Switzerland & 3 & $21,984,214$ & $7,328,071$ \\
\hline United Kingdom & 258 & $1,323,525,383$ & $5,129,943$ \\
\hline United Nations Children's Fund & 1 & $157,564,608$ & $157,564,608$ \\
\hline UNDP & 130 & $7,063,975$ & 54,338 \\
\hline United States of America & 538 & $10,843,392,589$ & $20,155,005$ \\
\hline
\end{tabular}

Note: Islamic Development Bank, Spanish, and Swedish projects lack commitment information. 
Tables 1 through 6 described various aspects of the aid projects by frequency, number of locations, sector, and aid commitment. Table 7 shows the frequency of aid project locations by donor, including the average aid commitment per location by donor and the total aid committed by donor. The International Development Association, a member of the World Bank Group, is by far the largest donor agency in the data, with aid funds totaling more than 25.5 billion USD. With 262 project locations in Uganda, each project location averages about 97 million USD. The United States has allocated approximately 10.8 billion USD to Uganda, with a relatively small amount of aid per project location (20.1 million USD) due to the large number of aid project locations (538). The African Development Bank is the third largest donor, with some 9.8 billion USD in aid delivered to the country. It has 174 aid project locations throughout the country, with an average aid commitment of over 56 million USD per location.

There is considerable variation in the number of project locations, the amount of total dollars, and therefore the average amount of aid per location. The Arab Bank for Economic Development in Africa (BADEA), for example, has relatively few project locations (12) but its large overall aid commitment (over 927 million USD) results in a large amount of aid per location (over 77 million USD, the second-highest average). The US, on the other hand, with its large overall aid commitment and large number of aid locations results in a relatively small amount of aid per location (just over 20 million USD). Japan spends relatively more per location (over 34 million USD) than the US despite having a smaller aid commitment (5.6 billion USD) because it has fewer aid locations (165) than the US. There is an average of 79 aid project locations per donor, 
with an average total aid commitment of 2,249,313,475 USD and an average aid commitment per location of 23,559,056 USD.

Thus, Uganda is a typical developing country in many respects, and that allows for the results of this study to be generalized to similar countries. The detailed aid information at the sub-national level also makes the country an attractive object for study. The following sections of this chapter examine the taxes and aid flows in Uganda in a more detailed manner.

\section{TAXATION IN UGANDA}

This section will discuss the trends in tax collection over time, including the types of taxes collected, in Uganda. We start with a discussion of tax-GDP ratios in the 1980s and 1990s, and then turn to a detailed examination of the trends in tax collection and taxGDP ratios in the 2000s. The section concludes with a short case study of Uganda's taxGDP increase between 1989 to 1999, to understand both why the ratio increased during much of this period and also why it ceased to rise in the late 1990s and has stayed relatively stable since. 
Table 8. Tax-GDP ratios in select African countries in the 1980s and 1990s

$\begin{array}{lccc} & & \text { Average } & \\ & 1985-90 & 1991-96 & 1985-96 \\ \text { Uganda } & 5.8 & 7.8 & 6.8 \\ \text { Malawi } & 18.6 & 17 & 17.8 \\ \text { Kenya } & 19.9 & 22.7 & 21.3 \\ \text { Tanzania } & 14.3 & 12 & 13.2 \\ \text { Rwanda } & 9.9 & 7.6 & 8.8 \\ \text { Zambia } & 18.1 & 16.2 & 17 \\ \text { Zimbabwe } & 32.4 & 30.9 & 31.6 \\ \text { South Africa } & 24.4 & 25 & 24.7 \\ \text { Ghana } & 11.6 & 14.2 & 12.9 \\ \text { Sub-Saharan Africa } & 17.3 & 16.4 & 16.9 \\ \text { Source: Ghura } & & & \\ \text { (1998) } & & & \end{array}$

Table 8 shows the average tax-GDP ratio for Uganda and several other African countries. The tax-GDP is reported because it takes into account the size of the economy, and so provides a better basis for comparison across countries than by simply presenting net tax revenues, for instance. The other countries were selected either because they are in the same region as Uganda (e.g. Kenya, Tanzania) and so provide regional context, or they are a well-performing country in terms of their economy (Ghana, South Africa). Also included are the averages for sub-Saharan Africa as a whole.

Uganda faced considerable challenges in collecting taxes during this time. Indeed, from the countries presented in table 8, Uganda has the lowest tax-GDP ratio (6.8), while Rwanda's tax-GDP ratio is the next lowest (8.8). ${ }^{14}$ Uganda's low tax-GDP ratio is at least partly a result of the years of political instability and war that beset the country between 1971 and 1986 (Cawley and Zake 2010).

\footnotetext{
${ }^{14}$ In the original report (Ghura 1998), only Guinea-Bissau had a lower average tax-GDP ratio between 1985-1996 (6.2). The tax-GDP ratio for the Democratic Republic of the Congo was not included in the report, presumably from lack of reliable data.
} 
However, Uganda's tax-GDP ratio improved during the 1990s. As shown in table 8, the tax-GDP ratio improved from 5.8 between 1985 and 1990 to 7.8 between 1991 and 1996. Indeed, of the countries shown in table 8, the only other country to have an increase in its tax-GDP ratio during this time is Kenya, while the other countries, saw a decline from 18.6 to 17 percent.

Figure 1. GDP Decomposition by Year

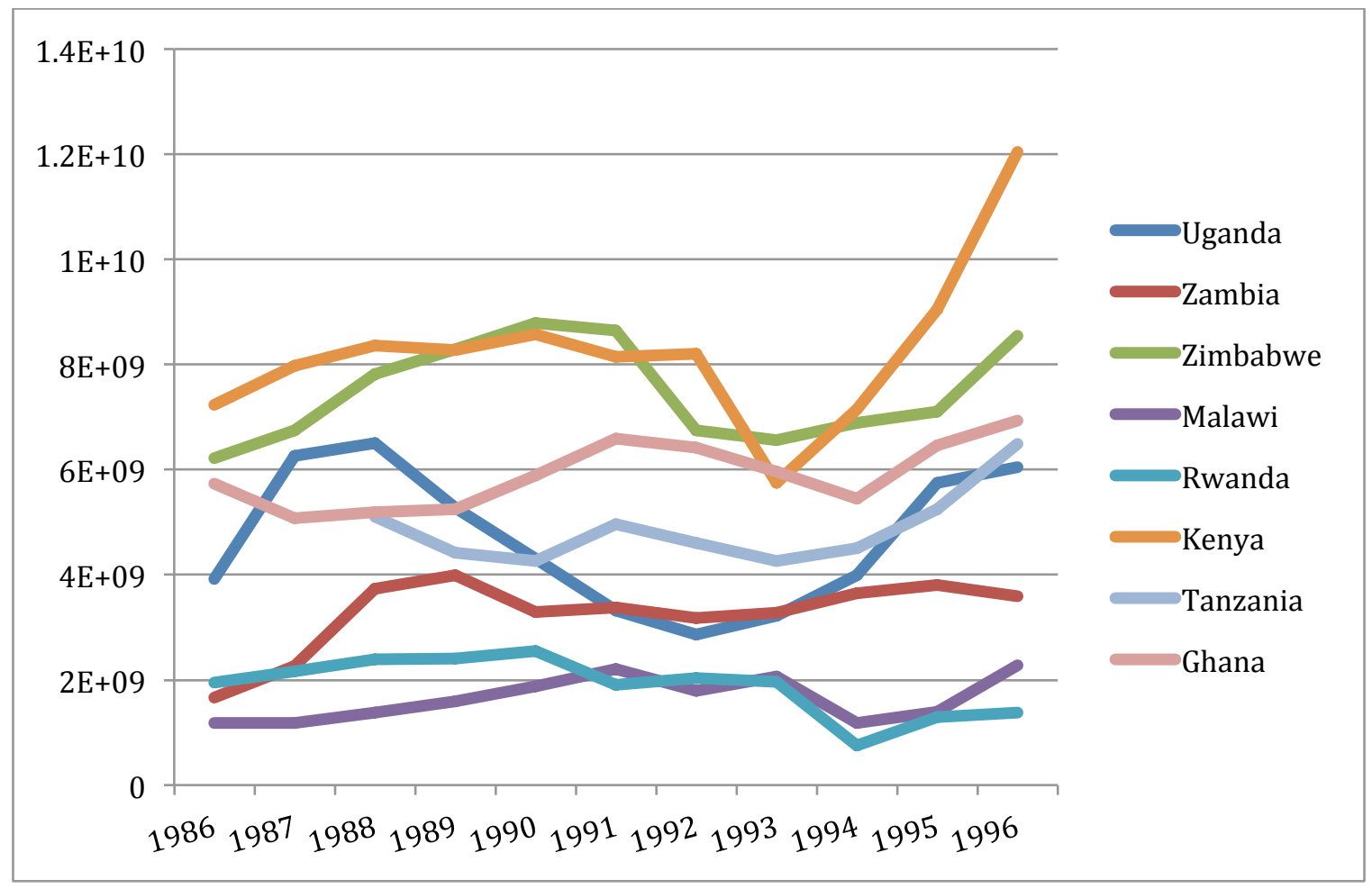

Source: World Bank World Development Indicators, 1986-1996 (Current USD). GDP shown in market prices.

To provide some context for the values in table 8 , figure 1 shows the GDP for these countries between 1986-1996. (Note that South Africa is not included in figure 1 because its GDP is quite large, and so including it in the chart would compress the lines representing the other countries' GDPs.) The GDPs presented in figure show wide 
variation in the both the level of GDP at the beginning of the time period in question and the amount of change in GDP over time. Kenya began this period of time with the highest GDP in 1986 (just under 8 billion USD) and ended with the highest (around 12 billion USD). However, it experienced a steep drop in its GDP between 1992 and 1993 (from 8.2 billion USD to 6 billion USD in dollar amounts), but began a sharp rise in 1994.

The middle countries in the middle of the chart include Zimbabwe, Ghana, Tanzania, and Uganda. Zimbabwe's economy actually became the largest in this group briefly, in 1990 and 1991, but then began to drop in 1992. The economy began to recover in 1994, and by 1996, the economy was just over 8.5 billion USD. Ghana's economy grew from 5 billion USD in 1986 to 6.6 billion in 1991. It then began a slow decline, reaching its nadir at 5.4 billion in 1994, and then rising to 6.9 billion USD in 1994. Tanzania's economy followed a similar pattern: It grew from 4.4 billion USD in 1989 to 4.9 billion USD in 1991, and then declined to 4.2 billion USD in 1993. Afterwards, it saw steady growth with the GDP climaxing at 6.5 billion USD in 1996. Uganda, however, saw more extreme patterns in its GDP compared to this group. Its GDP grew from just under 4 billion USD in 1986 to 6.5 billion USD in 1988, afterwards experiencing a long decline to 2.8 billion USD in 1992. From 1992 on, the economy began to grow again, peaking at just over 6 billion USD in 1996.

The countries of this group with the smallest GDPs include Zambia, Malawi, and Rwanda. All three of these countries began with a GDP of less than 2 billion USD in 1986, but display more variation in terms of their economic growth between 1986 and 
1996. Zambia's GPD totaled some 3.6 billion USD by 1996, Malawi's GDP was 2.3 billion USD, and Rwanda's was the smallest at 1.4 billion USD.

The takeaway from this analysis of the GDPs of these countries from 1986 to 1996 is that Uganda's economy was 'typical:' Not the smallest, and not the largest. Given the 'typical' of the economy, the low tax-GDP ratio is all the more perplexing. The problem regarding the low tax-GDP ratio is not the size of the GDP, but problems regarding the raising of taxes in the country. Nevertheless, there is small growth in the tax-GDP ratio, increasing from 5.8\% between 1986-1991 to 7.8\% between 1992 and 1996. The yearly total tax revenue in Uganda from 1997 to 2012 in 2015 US dollars is presented in Figure 2 below.

Figure 2: Tax Revenues in Uganda in 2015 US Dollars

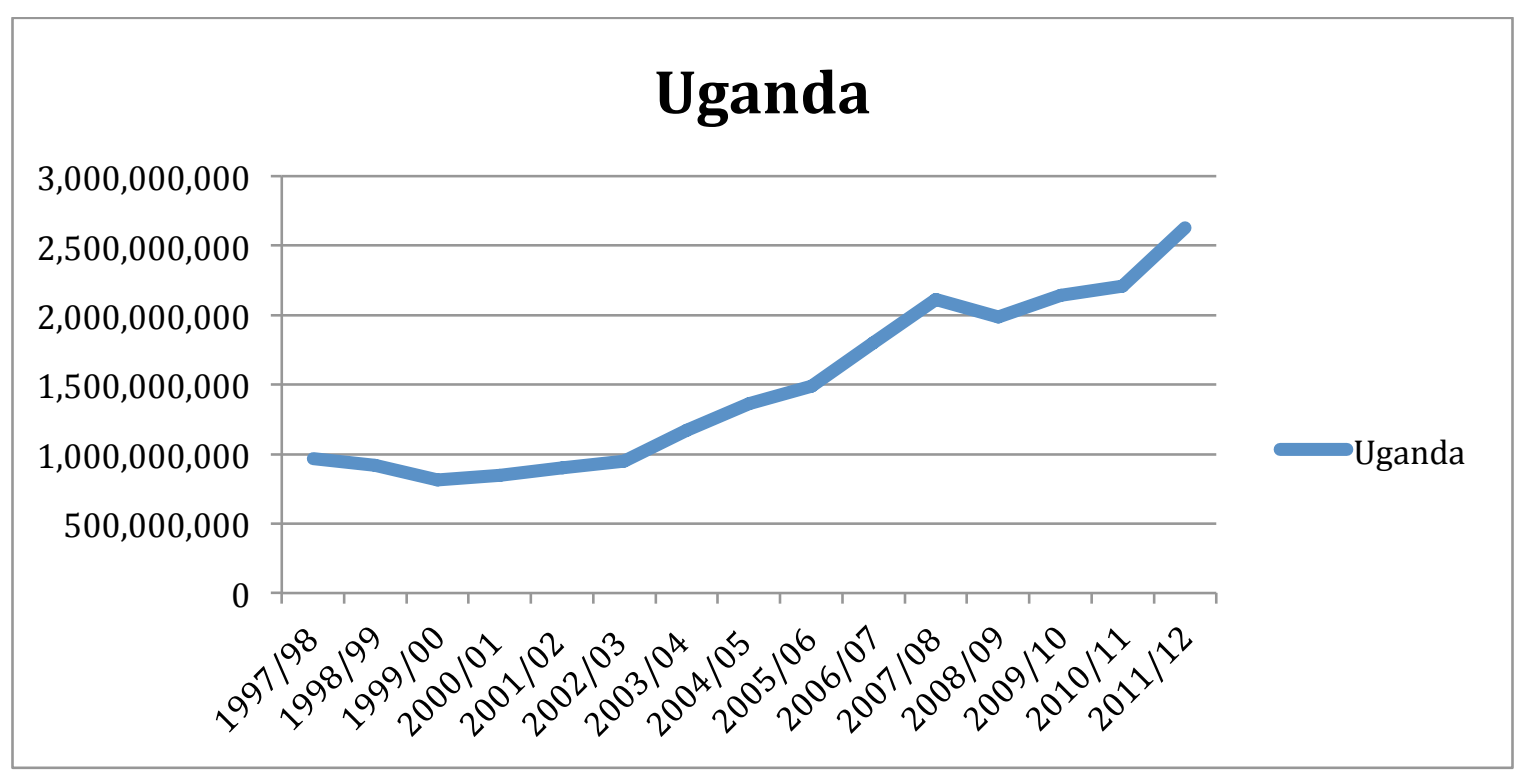

Source: Statistical Abstracts from Uganda Bureau of Statistics 
Figure 2 was created with Uganda tax revenue data found in yearly statistical abstracts, produced by the Bureau of Statistics. Next, Ugandan tax revenue data were converted to US dollars for that year or fiscal year. ${ }^{15}$ Finally, the tax revenues were converted to 2015 US dollars using the inflation calculator found at the US Bureau of Labor website. ${ }^{16}$

Figure 2 shows that tax revenues have been steadily increasing in Uganda from 1997 to 2011, with slight decreases in tax revenues between 2007-08 and 2008-09. Figure 2 suggests that the trends in tax revenues are seemingly positive in this country. Therefore, even if aid reduces tax collection efforts on behalf of the government, it clearly does not eliminate all tax effort. Figure 3 presents the ratio of tax revenues to GDP for the same period of time, which allows for a more direct comparison of tax revenues in the country.

\footnotetext{
15 The Ugandan statistical abstracts only have the exchange rate averages per calendar year, and so the average for the calendar year is used as the exchange rate for the fiscal year (e.g. the exchange rate for 2001 for 2000/01, etc.). For Uganda, the exchange rate values were found in the 2006, 2011, and 2013 statistical abstracts.

16 http://www.bls.gov/data/inflation_calculator.htm. Accessed at 4:22PM on July 14, 2015
} 
Figure 3: Tax-GDP Ratios for Uganda

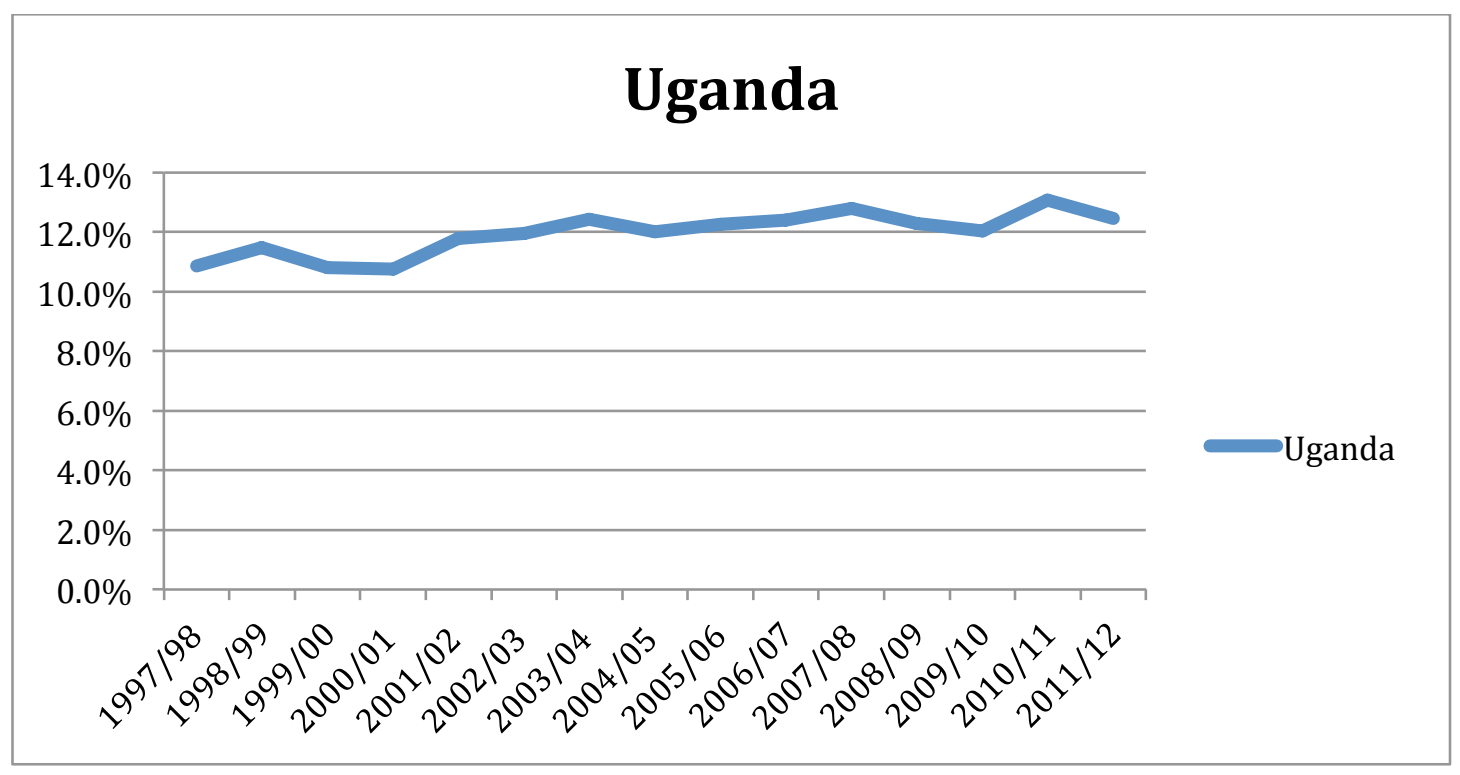

Source: Statistical Abstracts from Uganda Bureau of Statistics

Figure 3 suggests that the tax collection levels as a proportion of GDP in Uganda have been largely stable since 2000 , despite the increase in the tax-GDP ratio from the 1990s. Furthermore, the tax-GDP ratio has been largely stable despite the increase in the net tax revenues in the 2000s. So Uganda has had difficulty in steadily increasing its taxGDP ratio, despite the progress that was made in tax revenue collection during the early to mid-1990s.

The stability of the tax-GDP ratios is surprising, given the (rhetorical) emphasis the state has placed on increasing tax revenues. In the early 1990s, the Ugandan government declared that it would increase taxes by one percentage point per year (Cawley and Zake 2010), a rate that if achieved would have placed the tax-GDP ratio above 20 percent by 2012. Slightly chastened but undeterred, the 2014 National 
Development Strategy for Uganda calls for a .5 percent increase in the tax-GDP ratio over the subsequent years. Despite the stagnation in the growth of the tax-GDP ratio in the late 1990 s, it is worthwhile to explore why the tax-GDP ratio grew in the early to mid-1990s and why the growth ceased in the late 1990s.

\section{Explaining Uganda's Tax Revenues, 1989-1999}

The increases in the tax-GDP ratio between 1989 and 1999 stemmed not only from changes in the level of tax revenue, but also its composition. One typology to understand the composition of tax revenue is to divide taxes by source (domestic or international), and by method of collection (direct or indirect) (Magalasi 2009). Direct taxes are those that the government collects from the taxpayer, and include income taxes and taxes on business profits. Indirect taxes are collected via intermediaries that pass on the cost of the tax to the final consumer. These taxes are typically applied to goods, and examples include customs duties, excise taxes, and a sales tax. The sales tax is applied to the purchase of a good or service, and is borne by the consumer. Domestic taxes typically come from income (either personal or business) or from sales taxes. International taxes are applied to goods that enter or leave the country. Examples of international taxes include customs duties, taxes on goods that are imported into the country, and excise taxes, which are applied to the production of specific goods, such as beer or gasoline.

With these distinctions in mind, the increase in Uganda's tax-GDP ratio is due to policy changes in both how taxes were collected and the composition of tax revenue. The country established an independent revenue authority in 1992, the Ugandan Revenue 
Authority, which helped separate the creation of tax policy in the ministry of finance from the collection of taxes. The increase in the tax-GDP ratio is also due to increases in income taxes and the introduction of a value-added tax (VAT) ${ }^{17}$ (Cawley and Zake 2010, 111). Whereas income taxes contributed $13 \%$ of total revenue in $1991 / 92$, they were contributing some $18 \%$ in $1998 / 1999$, and $29 \%$ in $2006 / 07 .{ }^{18}$ The VAT replaced sales taxes and commercial transaction levies in 1996/97. Sales and commercial transaction levies contributed some $26 \%$ of total revenue in $1991 / 92$, increasing to $31 \%$ of total revenue in 1995/96. While the VAT initially led to a loss in revenue while the policy was becoming established, it contributed $32 \%$ of total revenue in $1998 / 99$, and $33 \%$ in $2002 / 03$. The changes in the composition in tax revenue over time are showcased in figure 4.

\footnotetext{
17 Value-added taxes are taxes that are applied at different stages of production, and have the benefit of not distorting production decisions, unlike standard sales taxes.

${ }^{18}$ Cawley and Zake note that the increase in income taxes is due to both administrative reforms and increases in compliance along with economic growth that increased the overall level of taxable incomes $(2010,123)$.
} 
Figure 4. Composition of Ugandan Tax Revenue, 1988-2003

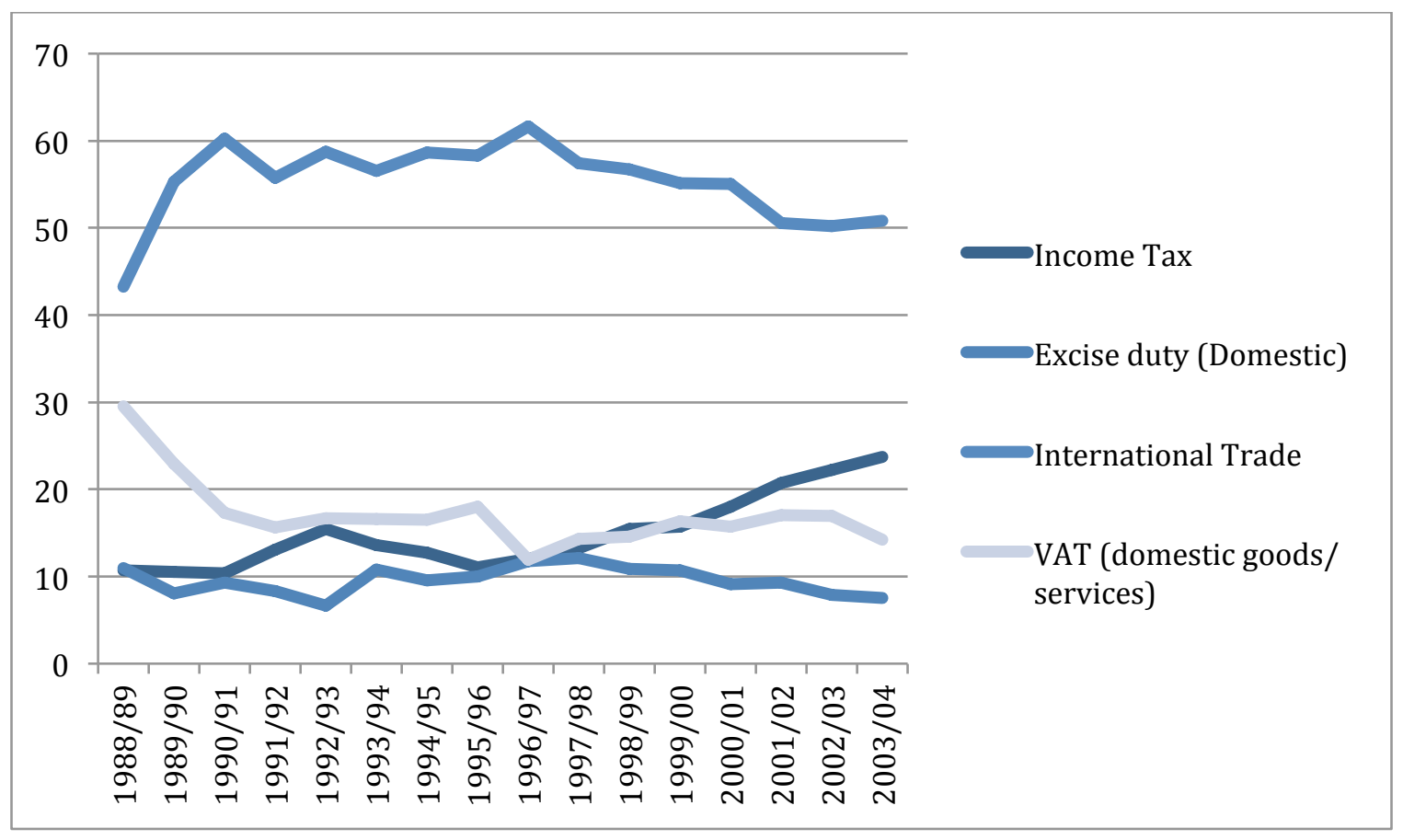

Figure 4 shows the breakdown of the composition of tax revenue between 1988 and 2003. ${ }^{19}$ The categories include income tax, domestic excise duty, international trade, and domestic VAT. ${ }^{20}$ At the beginning of this time period, international trade taxes, made up of petroleum duties, import duties, international excise duties, and VAT on imports, were by far the largest source of tax revenue, constituting $43 \%$ of tax revenue in 1988 and increasing to $60 \%$ in 1991 . After peaking at $62 \%$ of total tax revenue in 1996 , international trade taxes as a percent of total tax revenues begin to decline. By 2003, it is contributing just over 50\% to total tax revenue. The domestic VAT is listed as bringing in

\footnotetext{
${ }^{19}$ The source for the data in figure 4 is Ayoki et al. 2008, 63-64.

${ }^{20}$ Figure 4 oddly has information on VAT dating back to 1988 , when the VAT was only put in place in 1996. It is not clear what these numbers refer to, but one candidate is the sales taxes that the VAT replaced. Note also that there is a domestic VAT, included here, and an international VAT, which is included in the calculation for international trade taxes. Ayoki et al. find that the tax levels are unresponsive to the growth in national income $(2008,49)$.
} 
about $30 \%$ in 1988, but the level of contribution quickly declines in the coming years, decreasing to $12 \%$ at its lowest point in 1996. By 2003, the domestic VAT contributed some $14 \%$ of total tax revenue. Income taxes, including Pay-As-You-Earn and corporate taxes, show considerable growth over this period. They contributed only $10 \%$ of total tax revenue in 1988 , but totaled over $23 \%$ of tax revenue in 2003. Domestic excise duties, like international trade taxes, show a decline over time. Contributing some $10 \%$ to total tax revenue in 1988, the contribution decline to $6 \%$ in 1992 . The contribution recovered to $12 \%$ in 1996 , and then declined again to $7 \%$ by 2003 .

Other policy reforms that affected tax revenues related to international trade. Uganda, like many African countries in the 1990s, underwent structural reforms at the behest of the International Monetary Fund (Whitworth and Williams 2010, 32). One of the components of these reforms is to reduce barriers to trade, such as tariffs and customs duties, so as to promote the free-flow of goods across borders and thereby help to promote growth. As shown in figure 4 above, the contribution of international taxes to overall tax revenue declined from $60 \%$ in 1990 to $50 \%$ in 2001. Thus, Uganda's government relied upon income taxes and VAT to replace the revenue lost to the elimination of international trade taxes.

However, the heavy reliance on income taxes for total revenues in Uganda is problematic. Income taxes can only be reliably collected from companies that pay their employees a salary, and these companies are few in number. Small businesses and the self-employed contribute little in taxation in Uganda (Cawley and Zake 2010) and businesses that operate in the secondary economy, consisting of the 'black market', 
parallel market activities, and informal sector, easily evade taxation. The large black market, along with challenges in curbing non-compliance with taxation and corruption, contributed to the flat-lining of growth in the tax-GDP ratio in the late 1990s:

Firms estimated the informal economy (part of the economy evading taxes, duties, or laws and regulations) to be as high as 43 per cent. In 1998 this perception remained, with tax considered the leading constraint from unfair competition. [Moreover] among the firms that were audited, at least every third firm had to pay additional taxes, while every fourth firm incurred additional costs, such as bribes...All firms whose tax assessment differed by 100 per cent or more 'always'...had to pay bribes to URA officials. [Chen et al. 2001,292-4, cited by Cawley and Zake 2010, 120]

International trade is a particular source of revenue loss through corruption and tax evasion. ${ }^{21}$ Traders have been known to declare having lower quantities of goods and of lower quality of goods to avoid paying their full share of taxes. They have also declared finished products as unfinished, raw materials to similarly avoid paying the required taxes. Traders will claim that the goods originate in a country that may have a lower tariff rate for importing into Uganda if the true country of origin has a higher tariff rate. Goods will sometimes be allowed to enter Uganda under the pretense that the goods are merely to pass through the country en route to another destination, only to be unloaded and sold within the country. Finally, bribery of tax administration officials is used as a means to avoid paying a full share of taxes.

While the government of Uganda has taken steps to combat revenue corruption, the efforts have often been met with public outcry that has led the government to pull back from fully enforcing compliance with the tax laws. To deal with the problem of

\footnotetext{
21 This paragraph draws heavily from Ayoki et al. (2008, 23-24).
} 
smuggling, the government established an Anti-Smuggling Unit (ASU) in 1992. The ASU consisted of 20 officers led by an army colonel, and was seemingly effective in combating smuggling as evidenced by a 0.7 percent increase in non-oil import duties between 1991 and 1995 (Cawley and Zake 2010, 121-122). However, the government disbanded the unit after a public outcry against alleged abuses by the ASU. In 1998, a new unit was established in its place, the Special Revenue Police Service (SRPS), with the mandate of combatting smuggling as well as investigating the bribery of tax administration officials. This unit also met with controversy and was disbanded in 2007.

The examples of the ASU and SRPS are instructive in that the stalled growth in the tax-GDP is in part the result of a political calculation on behalf of the government: When the political costs of tax enforcement become too high, it draws back on its tax enforcement efforts. A similar example is found in the collection of VAT from large taxpaying entities, including private sector companies, called the Large Taxpayer Department (LTD). Established in 1998, the LTD was initially successful in raising tax revenue, and collected 74 percent of domestic tax revenue in its first year of operation (Cawley and Zake 2010,117). However, many large taxpayers began to complain of harassment by LTD officers and seemed to dislike the inspection of their financial affairs by the LTD. Under pressure from powerful domestic interests, the government of Uganda disbanded the LTD in 2001, just three years after it was initially established. 


\section{Summary}

To summarize the main points of this discussion, tax revenue as a proportion of GDP has stayed relatively stable- fluctuating within a few percentage points- for Uganda since the mid-1990s up to the 2012. Previously, Uganda's tax-GDP ratio was low during the late 1980s and early 1990s, but institutional and policy reforms helped the state recover more tax revenues. These policy reforms included drawing an increasingly large share of their tax revenues from income taxes and VAT. Indeed, net tax revenues have increased over time, but the stable tax-GDP ratios suggest that there is not a political interest in increasing tax collection, despite the rhetoric to the contrary in the country.

Figure 3 gives a greater picture for how foreign aid may decrease tax revenues: not by simply eliminating all tax effort, which figure 2 shows to be implausible given the increase in tax revenues over time. However, foreign aid may serve to cap or limit the growth of the tax-GDP ratio within Uganda, rather than decrease it as such. To understand how it may do so, we turn in the next section to an examination of foreign aid flows in Uganda.

\section{Foreign AID Flows to UgAnda}

Uganda has been a recipient of large amounts of foreign aid, and has historically had a strong relationship with the donor community. However, recent corruption scandals that raised concerns of whether aid funds were misused have led the relationships 
between the governments and the donor community to deteriorate. Donors have not necessarily limited funding as a result of these scandals, but have shifted the manner in which aid is delivered. Instead of funding the government directly through budget support, donors are increasingly favoring project aid. The corruption scandals accelerated an ongoing trend to favor project aid over budget support. The lack of funds coming to the government through budget support, may, as argued below, provided the impetus for the state to take more seriously the need to raise domestic revenues.

Figure 5: Total Foreign Aid for Uganda and Sub-Saharan Africa, 1967-2012

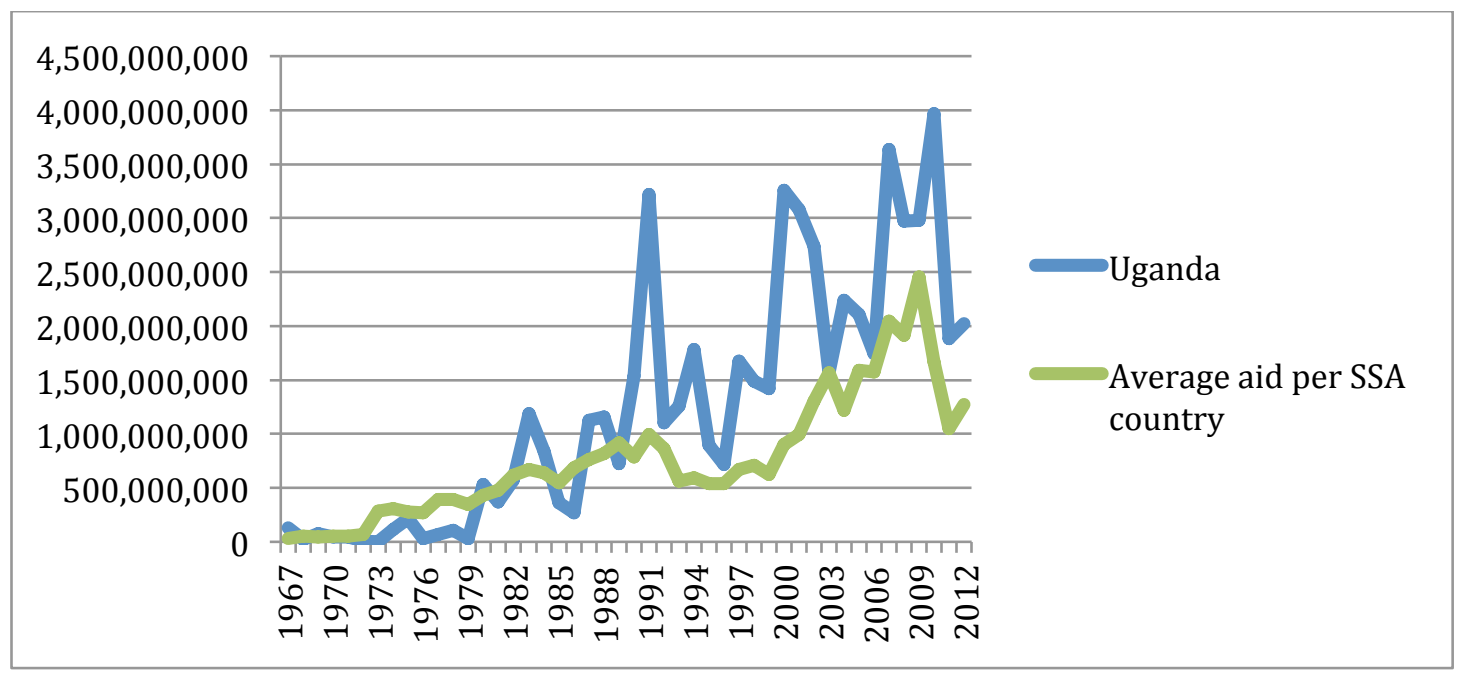

Source: World Bank World Development Indicators, revenue presented in constant 2011 USD

Figure 5 shows total foreign aid flows to Uganda and the average Sub-Saharan country in Africa from 1967 to 2012.22 Aid flows for Uganda in this period totaled $57,401,738,913$ USD, while the aid-GDP ratio for Uganda averaged 22. The aid-

22 The data here begin at 1967 , because earlier years have limited coverage. 
population ratio averaged 54 USD per person per year for Uganda. To provide context for the values for Uganda, figure 5 also includes the yearly average of aid for all sub-Saharan African (SSA) countries per year. ${ }^{23}$ The average amount of aid per SSA country per year is overall less than the average aid per year for Uganda. The average amount of aid delivered per person, per year across sub-Saharan Africa is 53, a value closer to Uganda. Further, the aid-GDP ratio for developing economies in sub-Saharan Africa, $11 \%$, is closer to the Uganda. In sum, the amount of aid delivered to Uganda is more than the average amount per sub-Saharan country, while the amount delivered per person per year in Uganda is closer to the average for people across sub-Saharan Africa.

Figure 6: Aid per Person for Uganda and Sub-Saharan Africa, 1967-2014

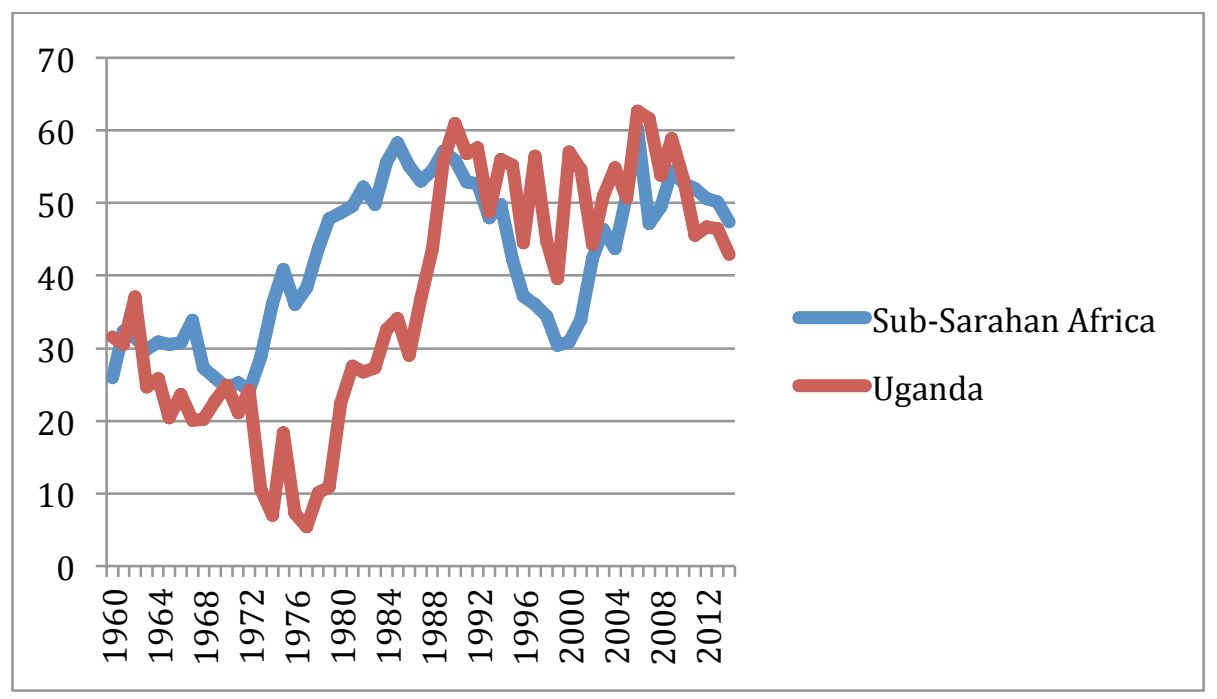

Source: World Bank World Development Indicators, revenue presented in constant 2011 USD

23 To calculate these values, the total aid for sub-Saharan Africa was calculated by year and then those values were divided by the number of countries present in Sub-Saharan Africa by year. North African countries (Libya, Morocco, Algeria, Tunisia, and Egypt) were not included. Six projects were not included in figure 3, because they total an implausibly high amount of aid- these 6 projects total some 7 trillion USD in aid, an amount higher than the 6.8 trillion reportedly delivered in aid since the 1950s (Aiddata). 
Figure 6 provides the average amount of aid person in both Uganda and in SubSaharan Africa (developing countries only) from 1960 to 2014. The trend displayed in figure 6 suggests that for much of the period between 1960 and 1987, Uganda on average received less aid per person than the amount of aid delivered per person in Sub-Saharan Africa as whole. Uganda received the least amount of aid person in 1977, where it received roughly 5.41 USD per person, but from there the amount of aid quickly rises. By 1990 Uganda was receiving about 60.93 USD per person, roughly 5 USD more than the average for Sub-Saharan Africa as a whole (55.83 USD). In the early 1990s the amount of aid per person delivered to Sub-Saharan Africa declined, hitting a low of 30.44 USD per person in 1999. Even during this turbulent decade, Uganda continued to receive more aid per person than Sub-Saharan Africa as a whole- specifically, Uganda received an average of 8.12 USD more person than Sub-Saharan Africa received on average between 1990-1999. By 2005, the difference between the amount of aid per person Uganda received and the amount of aid per person Sub-Saharan Africa had largely disappeared, with Uganda receiving some 50.78 USD and Sub-Saharan Africa receiving 51.06 USD. After fluctuating again for several years, Uganda was receiving less aid per person than Sub-Saharan Africa by 2011. Between 2011 and 2014, Uganda received 4.60 USD less per person compared to Sub-Saharan Africa as a whole. 


\section{CONCLUSION}

What emerges from this chapter is a picture of a country that is a key recipient of donor aid, and has struggled with an inability to increase domestic revenue in terms of its tax-GDP ratio since the late 1990s. Yet relying solely upon domestic sources is a difficult prospect given the costs of taxation, including expanding the tax base, in their agriculturally-based economies. Thus, foreign aid seems associated with a lowered need for the government to develop more fully its own domestic revenues. However, aid did not displace all tax effort, as the governments have taxed at high rates the small formal sectors of the economy. Instead, aid may have enabled the government to avoid the costly and difficult process of finding means to include the large informal sector in the tax base.

The following chapters unpack the relationship between foreign aid and tax compliance by examining one particular country, Uganda, and then generalizing those findings to other developing countries in Africa. Uganda is a useful case for this project because it is in many ways a 'typical' developing country, and so the findings have the potential to speak to the relationship between aid and tax compliance in similar countries. I also helped collect a dataset on local-level aid projects in Uganda, and these data allow for an analysis of the relationship between aid at the local level and individual-level survey responses for a question concerning tax compliance. The next empirical chapter generalizes the relationship between aid and tax compliance by examining a set of 34 countries in sub-Saharan Africa. The last empirical chapter examines the political factors that can shape aid allocation at the local level in Uganda, which helps to examine whether aid goes to areas of greater need or to areas of political convenience for the donor 
country. The last chapter concludes this dissertation by reviewing the findings of each chapter, considering the research projects that would logically follow from this project, and suggesting several policy implications. 


\section{Chapter 2 Aiding Dependency: A Subnational Analysis of Foreign Aid and Tax Compliance in Uganda}

Does aid weaken state capacity, and if so how? One reason why aid may weaken state capacity is by undermining the need for recipient states to develop an effective domestic tax regime. Aid may substitute for domestic taxes as a source of revenue to finance the government, and allow the state to avoid the domestic bargaining that can result in sharing power with the public if they are taxed (Braütigam 2008, Moore 2004, Ross 2004). The lack of sufficient domestic tax revenue, however, keeps the recipient state dependent on foreign aid in order to function and so prevents the capacity of the state from developing over the long term.

While this reasoning is plausible, it focuses primarily on the effects of aid on the state. It leaves unexplored how aid may affect citizen behaviors and attitudes, and more generally on how the provision of aid shapes the social contract between the state and citizen. A growing body of literature examines how the provision of foreign aid affects the relationship between state and society, including democratization (Moore 1998), the accountability of local-level officials to the public (Fjeldstad 2001), the willingness of the government to tax the public (Eubanks 2012), the level of public support for tax-paying as an obligation (Sacks 2012), public support for local leaders (Cruz and Schneider 2014, Guiteras and Mobarak 2014), and public support for the government (Dietrich and Winters 2015). This chapter contributes to this literature by exploring the effects of aid on a particular behavior of the citizenry, tax compliance.

The argument is that aid delivered by donors to citizens undermines the incentives 
on the one hand for the state to enforce tax collection, and on the other for citizens to pay taxes. Aid can disrupt fiscal bargaining between the state and citizens by in some cases substituting for the state, and so lowering the demands that citizens make on the government, while making the government more accountable to donors than to the citizens. At the state level, aid creates the fiscal space that allows the state to be complacent about revenue mobilization and enforcing tax compliance.

The theory thus has two mechanisms that suggest how aid can undermine tax compliance. The first is called the enforcement mechanism, such that aid subsidizes the state and allows the state to withhold enforcing tax compliance. Enforcing tax compliance is both politically and materially costly, and so aid allows the state to avoid incurring those costs. The second mechanism is the substitution mechanism, and points out that aid can fund services that substitute for the state provision of services. Since citizens can receive services from donors without typically having to pay taxes for them, they prefer to receive these services rather than to pay taxes to the state in exchange for services.

The logic underlying these arguments is rooted in the fiscal exchange theory of tax compliance, which posits that tax compliance is a response to government expenditures (Levi 1988, Tilly 1992, Moore 1998, Fjeldstad et al. 2012). In this theory, taxpayers are concerned with the services they receive in exchange for the payment of taxes, and view their obligation to pay taxes as a contractual relationship between themselves and the government. The level that citizens pay in taxes is the product of a bargaining process between themselves and the government, and this bargain is central to 
the accountability of the citizens to the state (Braütigam 2008). While the fiscal exchange theory was initially developed as an explanation for the development of the state in modern Europe, scholars have also begun to apply it in the context of developing countries (Braütigam, Fjeldstad, and Moore 2008). This chapter develops the fiscal exchange theory by considering the possible adverse effects of foreign aid on the fiscal bargain between citizen and state.

New sub-national data on aid projects in Uganda presents an opportunity to investigate the relationship between aid and tax compliance. These data provide information on where aid projects were implemented within these countries. I led a team that geocoded information provided by donor agencies on aid project locations in Uganda under the direction of AidData (Strandow et al. 2011, Tierney et al. 2011) and according to the methodology developed by Strandow et al. (2011). When combined with survey data on tax compliance taken from the 2012 Afrobarometer survey, these data allow for what is, to my knowledge, the first direct examination of the effect of subnational aid flows on individual-level tax compliance. Given that the effects of aid on tax revenue are likely heterogeneous across countries (Morrissey 2015), an in-depth analysis of aid at the sub-national level may help to identify the mechanisms whereby aid in particular contexts undermines tax revenue.

The payment of taxes is important for developing countries because of the close relationship between domestic revenue collection and state capacity (Levi 1988, Hendrix 2010). The more states are able to collect revenue, the more public services that the state can provide to its citizens (or, in the case of corrupt regimes, revenues to use for private 
consumption). Taxation may also promote democratization by providing the public an incentive to keep the government accountable (Ross 2004, Paler 2013, Broms 2015, Martin 2014). Insofar as the bolstering of state capacity and democratization are key development goals, then the study of what supports or undermines tax compliance within developing countries is an important component of these goals for research and policy purposes.

The rest of this chapter proceeds as follows. The next section reviews the literature on the effect of foreign aid on domestic revenue generation and the effect of foreign aid on tax compliance. The next section develops the theory for how aid reduces tax compliance by reducing the incentives for the state to enforce taxation, while also lowering the reliance of citizens on the state by substituting for the state's provision of services. The next section outlines the research design for the analysis as well as the rationale for examining Uganda. The quantitative analysis estimates a model for the effect of aid projects on individual tax compliance. It shows the substantive effects of increases in aid on tax compliance, and also includes a test for whether the results are a result of aid going to areas where refusals to comply with taxation are likely. The paper then concludes with suggestions for future research and the policy implications of these results.

\section{State Capacity, Foreign Aid, and Tax Compliance}

A key question for scholars of foreign aid is how aid affects state capacity. 
Goldsmith (2001) found that foreign aid was associated with a slight improvement in governing capacity, as measured by rule of law and property rights indicators. Many other scholars, however, have found a negative relationship between aid and state capacity. Knack (2001) finds that aid-dependent countries have lower quality of governance, and suggests that aid may fuel corruption through an increase in publicsector employment. Knack and Braütigam (2004) find that donor proliferation decreases state capacity by siphoning off trained government bureaucrats into the aid sector and by over-burdening recipient governments with oversight and compliance requirements.

Other scholars pointed out that aid might undermine the long-term development prospects of states by undermining the need for a state to develop a domestic revenue system (Moss et al. 2006). These scholars argued that aid functions as a source of free money, like natural resources, that undermines the incentives for state elites to raise revenues directly from the citizenry through taxation, which would in turn require the state to cede some powers to the citizenry in exchange for taxation (ibid; see also Therkildsen 2002). For example, Eubanks (2012) argues that the inability of the Somaliland government to receive aid compelled the government to develop a domestic revenue source. Attempting to develop its resources domestically in turn led the government to become more representative so as to secure public consent for taxation.

The effect of foreign aid on the incentives for the state to raise revenues domestically is therefore an issue at the core of the state capacity debate. While not yet conclusive, some cross-national empirical work on the aid-tax revenue relationship has documented a negative effect of aid on tax revenues. Gupta et al. (2004) find that grants 
contribute to lower domestic tax revenues in developing countries because they serve as a source of free money that can substitute for taxes, while loans do not because they must be repaid, thus encouraging the state to develop a functional tax regime. Benedek et al. (2012) replicate this study using a longer time period and reach the same conclusion, with the proviso that the effect is more apparent in weaker states. Clist and Morrissey (2011), however, critique these studies on the basis of questionable data quality and that they use the incorrect temporal framework, while Morrissey (2015) argues that the effect of aid on tax revenue is likely heterogeneous across countries.

Along with the attention given to the state's incentives to collect revenues, a burgeoning body of work examines effect of aid the relationship between the state and citizen. One study argues that aid delivered directly by donors may bolster citizen perceptions of a state's legitimacy because they see the state as attracting aid projects on their behalf, and so increase the moral obligation that citizens feel towards paying taxes (Sacks 2012). The study shows that, cross-nationally, aid is linked to higher levels of state legitimacy, which this study defines as the belief that the state has the right to collect taxes. Interestingly, the study also cites a survey conducted in Zambia that found aid to be linked to higher levels of non-compliance (Sacks 2012, fn. 13). One possible explanation for the contrary sub-national finding is that donors may undermine government legitimacy and foster resistance to taxation if aid decreases the accountability of local authorities to the public (Fjeldstad 2001).

The effect of aid provision on perceptions of government legitimacy is thus important for potential explanations for levels of non-compliance with taxation: If aid 
undermines government legitimacy, and if legitimacy is one reason for compliance with taxation, then aid may undermine tax compliance with a negative effect on legitimacy. The empirical record on this question is not yet conclusive, with aid having no significant effect on perceptions on government legitimacy in one experimental study of USAID projects in Bangladesh (Dietrich and Winters 2015), while another showing that local politicians in the Philippines are able to benefit from taking credit for attracting aid projects, even if the politicians had no influence over where they went (Cruz and Schneider 2014). Other studies have found that if the leader is known by the public to have no influence over where the aid is allocated, however, the leader is not perceived more favorably (Guiteras and Mobarak 2014; Brass 2010, 160-161). Simply knowing that a donor is involved in providing a service does not appear to diminish the legitimacy of the government (Dietrich et al. 2015), perhaps because the high levels of extreme poverty in many developing countries may create a sense of gratitude for having received any services at all, regardless of the source (Brass 2010, 163).

An alternative explanation for individual compliance with taxation other than state legitimacy is the fiscal exchange thesis, which states that individuals pay taxes because of the services they receive in return (Timmons 2005). The fiscal exchange thesis frames the relationship between the citizen and the state as a bargaining process, in which the citizens agree to pay taxes in exchange for services from or representation in the state. As explained by Fjeldstad et al., "governments can increase compliance by providing goods that citizens prefer in a more efficient and accessible manner, or by more effectively emphasising that taxes are necessary for the receipt of government services" 
$(2012,9)$. Yet the fiscal bargain that undergirds tax compliance only holds insofar as the government provides sufficient public services. As Fjeldstad et al. go on to argue,

[the fiscal exchange theory] also means that compliance is always conditional. It will vary as governments vary in their performance, honesty, attention to due process, and other determinants of government reliability. Without a material benefit, compliance becomes less assured. [2012,9]

Some empirical support for this explanation of tax compliance is found in the literature. Two studies of the determinants of tax compliance in Africa using Afrobarometer survey data find some support for the fiscal exchange thesis, in that citizens are more likely to pay taxes if they see the state as responding to their needs and providing services (D'Arcy 2011, Ali et al. 2012). This paper builds upon the fiscal exchange theory of tax compliance by theorizing how aid affects the relationship between the citizen and the state, and extends the analysis of the fiscal exchange thesis to the subnational level in Uganda. As the next section argues, there is reason to believe that aid undermines this relationship by lowering tax compliance.

\section{THEORY}

I argue that foreign aid can upset the fiscal bargain between the citizen and the state by lowering the reliance of citizens on the state for services. Furthermore, the aid can enable the state to underinvest in tax enforcement by serving as an alternate source of funding. In the rest of this section, I unpack these arguments and then derive the main hypothesis that this paper will test. 
According to the fiscal exchange thesis, people pay taxes in exchange for public services, and states provide public services in exchange for taxes. As stated above, the fiscal exchange thesis models the relationship between the state and the taxpayer as a bargaining process in which citizens make demands on the state, and the state sets its policy priorities in accordance with citizen demands. In return for state services, citizens consent to pay taxes. Thus taxes and demands for services can lead to a "virtuous cycle" in which demands for services lead to more efforts by the state to raise taxes in order to provide for those demands, which leads to more demands for services, and so on.

Donors thus serve as a third party that undermines the potential fiscal bargain between states and citizens. Donors in countries like Uganda tend not to be motivated by geostrategic incentives, but rather seek to promote development-related outcomes such as democratization, economic growth, and good governance. Yet their ability to achieve these goals is often hampered by problems relating to donor proliferation- the shear growth in the number of actors providing material resources to development countries and a lack of coordination among donor organizations. Donors tend to fund multiple aid sectors rather than specializing in a few aid sectors and developing a comparative advantage in delivering a particular type of aid. Donors can exhibit 'herding' behavior such that they try to fund the same country if that country has become a valuable target to be seen providing aid to.

So, despite having motives that would otherwise promote development outcomes in line with internationally-accepted standards (such as the Millennium Development Goals or the Sustainable Development Goals) the manner in which aid is allocated can 
undermine aid effectiveness. It also undermines the ability of aid donors to prevent the negative effect of aid on tax compliance at the local level.

Aid can undermine this relationship by substituting for the state as a source of service provision. If citizens come to rely on donors and the non-state actors they fund for services, they are less likely to make demands on the state for services. If citizens are not making demands for services from the state, the state has less of an incentive to engage in taxation since it is does not need to raise taxes in order to pay for services.

Aid may also reduce tax enforcement. First off, tax collection is costly for states. Tax collection is operationally costly, because the state has to invest in a tax collection infrastructure and pay tax collection officers enough to limit the attractiveness of corruption. Tax collection is also difficult in developing countries due to the large informal sectors of the economy and the high proportion of subsistence agriculture. Taxation is also politically costly, as it can lead for greater demands for accountability and transparency (Ross 2004, Martin 2014). Thus, finding alternative sources of revenue to taxation can be very attractive for states. Aid can serve as an alternative source of revenue for states that allows them to avoid the costs of engaging in taxation, while still having the funds needed for the state to function.

These two arguments for how aid can substitute for state services while also reducing tax enforcement imply the following hypothesis:

Tax compliance decreases in areas with more aid projects.

The rest of this paper outlines the research design for a test of this hypothesis and the 
results.

\section{RESEARCh DESIGN}

\section{Country Selection}

Uganda is selected for this study because it is a typical developing country, for the reasons explained in chapter one. It is not a strategically important country, and has a relatively low level of development. If aid is found to have a negative effect on tax compliance in this country, it has troubling implications for other aid-recipient countries.

Uganda is a former British colony, and gained its independence in 1963. While the undermining of democratic institutions began with Apolo Milton Obote, who served as president of Uganda in the late 1960s, the democratic rollback of the country culminated with a military coup launched by an army officer named Idi Amin in 1971. Uganda experienced eight years of brutal dictatorship under Amin's rule that only ended with Tanzania's invasion of the country to depose Amin. After seven more years of civil war, Yoweri Museveni’s National Resistance Movement (NRM) emerged victorious and seized power in 1986, and the NRM has been the governing party since that time.

After coming to power through emerging victorious from civil war, the new Ugandan government initially had warm relations with the donor community because of the political and economic reforms that the government initiated. On the political front, the NRM reintroduced democratic elections over the presidency in 1996, followed by multiparty elections over parliamentary seats in 2006. Uganda also pursued neo-liberal 
economic reforms beginning in the early 1990s that donors viewed favorably, and rewarded the country with high levels of aid, as explored in figures 5 and 6 in chapter one.

Despite the initial warm relations between the country and the donor community, this relationship began to sour in the late 2000s. First, the economic priorities of the Ugandan government began to diverge from those of the donor community, with the government beginning to favor large infrastructure investments instead of investments in social services that donors sought. Secondly, the government of Uganda between 2009 and 2011 debated controversial legislation that discriminated against LGBT individuals, which swiftly led to condemnation by donors and the freezing of foreign aid. The bill, formally called the Uganda Anti-Homosexual Act, initially called for individuals convicted of engaging in same-sex relationships to receive the death penalty, although the version of the bill that was eventually passed by the Uganda legislature called for life imprisonment. Despite the fact that the bill was quickly struck down by the country's constitutional court on procedural grounds, the controversy surrounding the bill contributed to deteriorating relationships between the Ugandan government and donor countries, many of which threatened to suspend aid while the bill was debated and eventually did suspend it after the bill was passed.

Finally, an aid-related corruption scandal in the Office of the Prime Minister was in some ways the final straw in a deteriorating relationship between the government and the donor community. The Ugandan Auditor General revealed in October 2012 that personnel had embezzled funds from a donor-funded program to provide support to areas 
affected by the Lord's Resistance Army, managed by the Office of the Prime Minister. The embezzled funds are estimated at 13 million USD. ${ }^{24}$ Several donors, including the UK, EU, Germany, Ireland, Denmark, and Norway, that had been providing aid directly to the government in the form of budget support shifted to project aid. Given that budget support provided as much as 30 percent of the national budget, the loss of these funds left the Ugandan government scrambling to find alternative sources of revenue. Figure 7 shows the decline in budget support from 2010 to 2014.

Figure 7. Project Aid and Budget Support in Uganda, 2005-2014

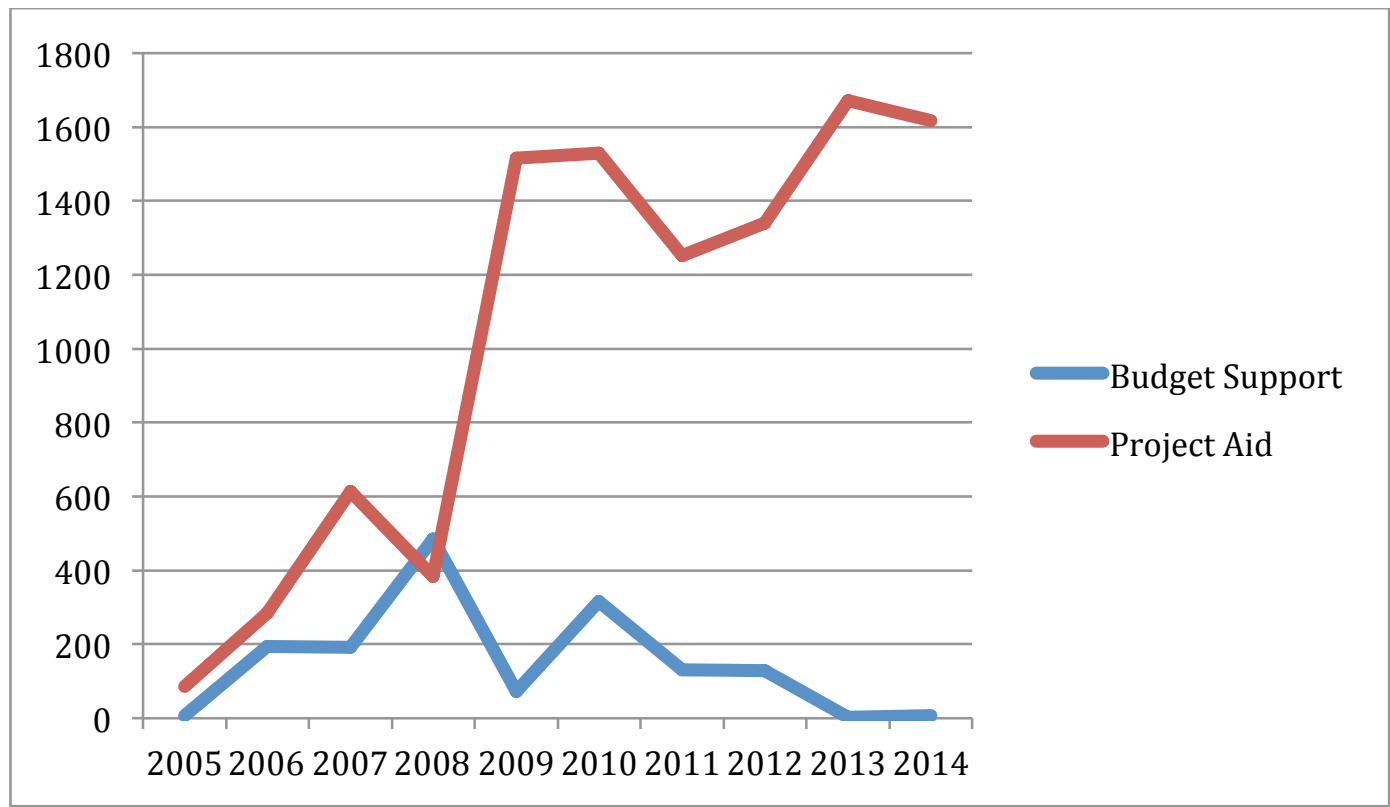

Source: OECD DAC Creditor Reporting System. Data are in constant million USD.

Figure 7 displays the project aid and budget support flows from 2005-2014. The

\footnotetext{
${ }^{24}$ Reuters, "EU Joins National Donors in Freezing Aid to UgandaOver Graft." 4 December 2012, accessed on 28 June 2016 at 4:23PM at: http://www .reuters.com/article/us-uganda-aid-idUSBRE8B30DA20121204
} 
first observation to note about figure 7 is that project aid surpasses budget support for every year except 2008, when donors allocated some 100 million USD more in budget support than in project aid (485 million USD in budget support vs. 384 million USD in project aid). By 2009, project aid is some 20 times larger than budget support (1.5 billion USD vs. 72 million USD). Budget support ticks up to 315 million USD in 2010, and then begins a steady decline to 130 million USD in 2011, 128 million USD in 2012, and then collapsing to 2 million USD in 2013. Budget support had slightly improved in 2014, reaching 7.9 million USD, but nowhere near the levels seen in the late 2000s. At the same time that budget support was collapsing, project aid soared to 1.3 billion USD in 2012 and 1.6 billion USD in 2013. As will be suggested below, the cuts in budget support to the government may have incentivized the state to invest in its tax collection efforts.

Could the aid corruption scandal have undermined the relationship between citizens and the state? It does not appear so. Examining the level of trust in the president in 2008, when the fourth round of the Afrobarometer survey was conducted, to the level of trust in the president in 2012, when the fifth round was conducted, shows no clear change in the level of trust. In 2008 , some $27 \%$ of respondents claimed to trust the president "a lot," while $31 \%$ of respondents answered similarly in 2012. Slightly more respondents claimed to trust the president "not at all" in 2012 compared to 2008 (13\% vs. $11 \%$ ), while fewer claimed to trust the president "just a little" in 2012 compared to 2008 (26\% vs. $29 \%$ ). A slightly smaller percentage of respondents claimed to trust the president "somewhat" in $2012(28 \%)$ as in $2008(29 \%)$. So there is between the survey responses in 2012 and 2008 is the larger percentage that claimed to trust the president "a 
lot" in the more recent survey, more also claimed to trust the president "not at all."

Figure 8. Quality of Governance Measures, 1996-2014

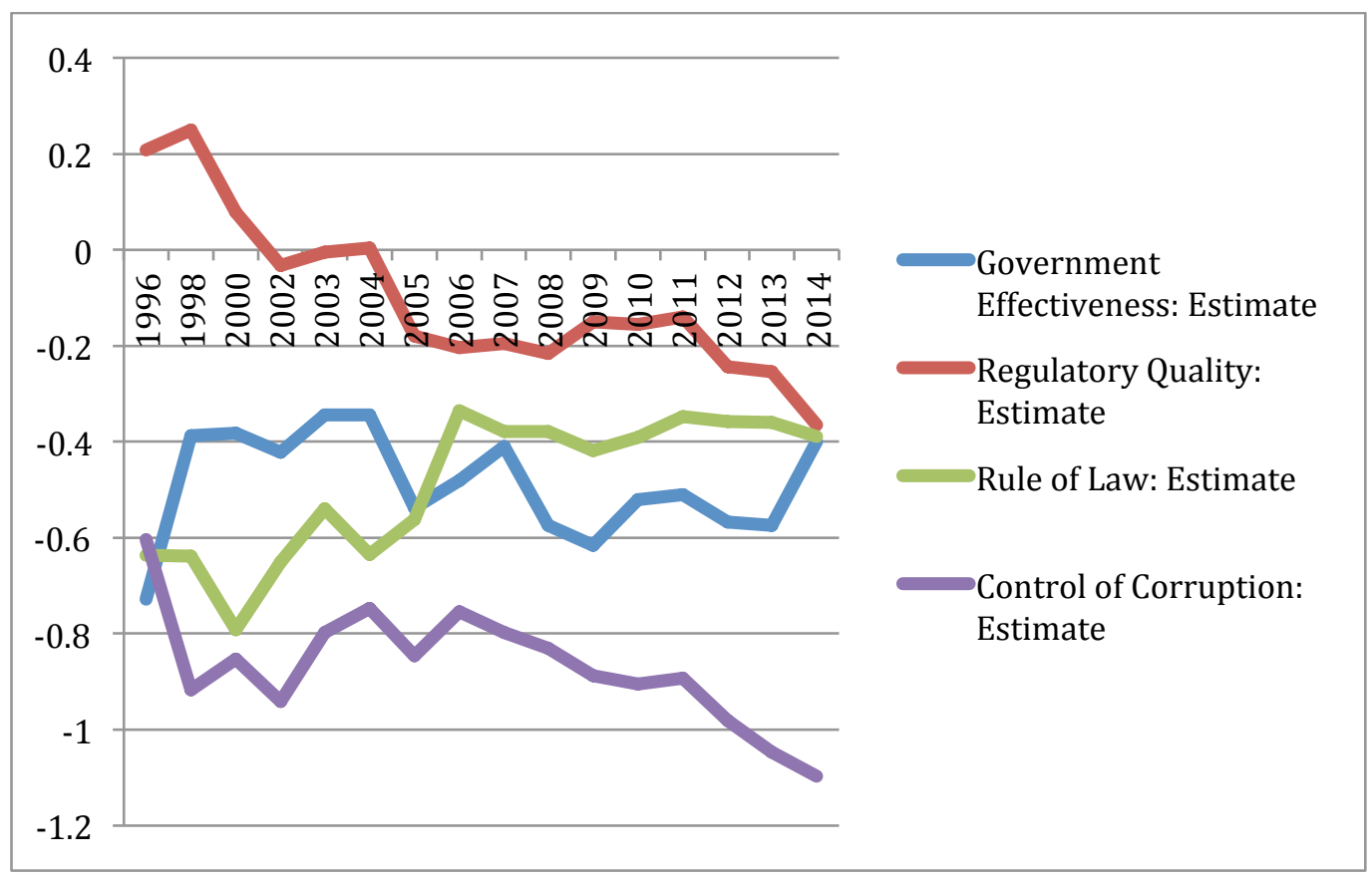

Source: World Bank Worldwide Governance Indicators

It appears that Uganda has had challenges regarding its quality of governance.

Figure 8 shows the quality of governance according to World Bank measures from 1996, the first year that data is available, to 2014. Four measures are presented: Government Effectiveness, Regulatory Quality, Rule of Law, and Control of Corruption. Each of the four measures presented have a maximum range from -2.5 to 2.5 . Of the four measures presented, only one shows signs of improvement: The estimates for the rule of law, are defined by the World Bank as "perceptions of the extent to which agents have confidence in and abide by the rules of society," increases from about -0.6 in 1996 to about -0.4 in 2014. For the remaining three measures, two seemed to have declined over this period of 
time while the third seemed to show no substantive change. Regulatory quality, defined as "perceptions of the ability of the government to formulate and implement sound policies and regulations that permit and promote private sector development," was initially Uganda's most positive measure of quality of governance with an estimate of 0.2 in 1996. Over the proceeding years, however, this estimate declined, reaching a low of 0.3 by 2014 . The other measure to decline is Control of Corruption, defined as "perceptions of the extent to which public power is exercised for private gain, including both petty and grand forms of corruption, as well as "capture" of the state by elites and private interests." Estimates for Control of Corruption declined from an already-low estimate of -0.6 in 1996 to -1.1 in 2014. The fourth and final measure, Government Effectiveness, shows little overall change between 1996 and 2014. Defined as "perceptions of the quality of public services, the quality of the civil service and the degree of its independence from political pressures, the quality of policy formulation and implementation, and the credibility of the government's commitment to such policies," this measure initially increased from -0.7 to -0.4 between 1996 and 1998 . After an initial positive increase, the estimates oscillate over the ensuing years. By 2014, the estimates for Government Effectiveness are again at -0.4 , essentially where they were in $1998 .{ }^{25}$

The remainder of this section describes the respondents who participated in the survey, the independent and dependent variables, the control variables, the interviews conducted in-country, and the empirical models used to test the main hypothesis.

\footnotetext{
${ }^{25}$ All definitions for variables are taken from World Bank Worldwide Governance Indicators.
} 


\section{Respondents}

Table 9. Summary of Respondents

\begin{tabular}{|l|l|l|}
\hline Variable & Mean & Standard Deviation \\
\cline { 1 - 2 } Age & 35 Years & 13 Years \\
\cline { 1 - 2 } Education & 3.3 Years & 1.8 Years \\
\cline { 1 - 1 } Gender & $50 \%$ Female/50\% Male \\
\cline { 1 - 2 } Urban/Rural & \multirow{2}{*}{$14.3 \%$ Urban/85.7\% Rural } \\
\hline
\end{tabular}

Table 9 summaries basic information about the respondents. The average age is 35 years, with a standard deviation of 13 years. Respondents have an average of 3.3 years of education with a standard deviation of 1.8 years. Half of the 2400 total respondents are female, while the other half are male. To account for the fact that the majority of the population lives in rural areas, rural respondents make up $85.7 \%$ of the sample while urban respondents constitute $14.3 \%$ of the total. 
Figure 9. Proportion of Respondents Who Owed Taxes

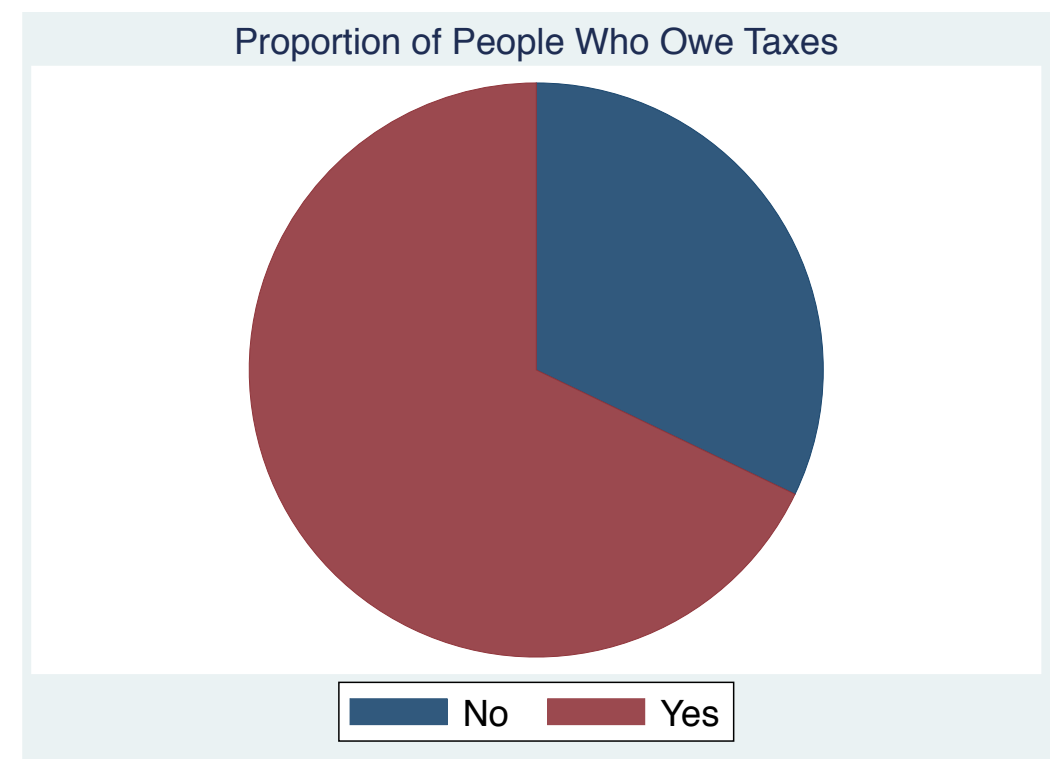

Figure 9 shows the proportion of respondents who owed taxes, with $67.88 \%$ of the respondents claiming to have owed taxes, and $32.12 \%$ claiming to not have owed taxes. The taxes owed include value-added taxes, license fees to the local government, property rates or taxes, income taxes, and self-employer taxes.

\section{The Dependent Variable}

To test the theory, this paper uses survey data for Uganda collected in the fifth round of the Afrobarometer survey (2012). The survey was conducted with 2,400 respondents in 130 counties and municipalities and 63 districts in Uganda, out of a total of 160 counties and municipalities and 77 districts. The Ugandan survey was carried out between December 2011 and February 2012.

The dependent variable is the individual respondent's answer to a question about whether the respondent has refused to pay taxes in the past year: 
Here is a list of actions that people sometimes take as citizens. For each of these, please tell me whether you, personally, have done any of these things during the past year. If not, would you do this if you had the chance: Refused to pay a tax or fee to government?

The answers are recorded as follows: $0=\mathrm{No}$, would never do this, $1=\mathrm{No}$, but would if had the chance, $2=Y e s$, once or twice, $3=Y$ es, several times, $4=Y$ es, often. Table 1 summarizes the responses to this question.

Table 10. Summary of Reported Tax Compliance in Uganda

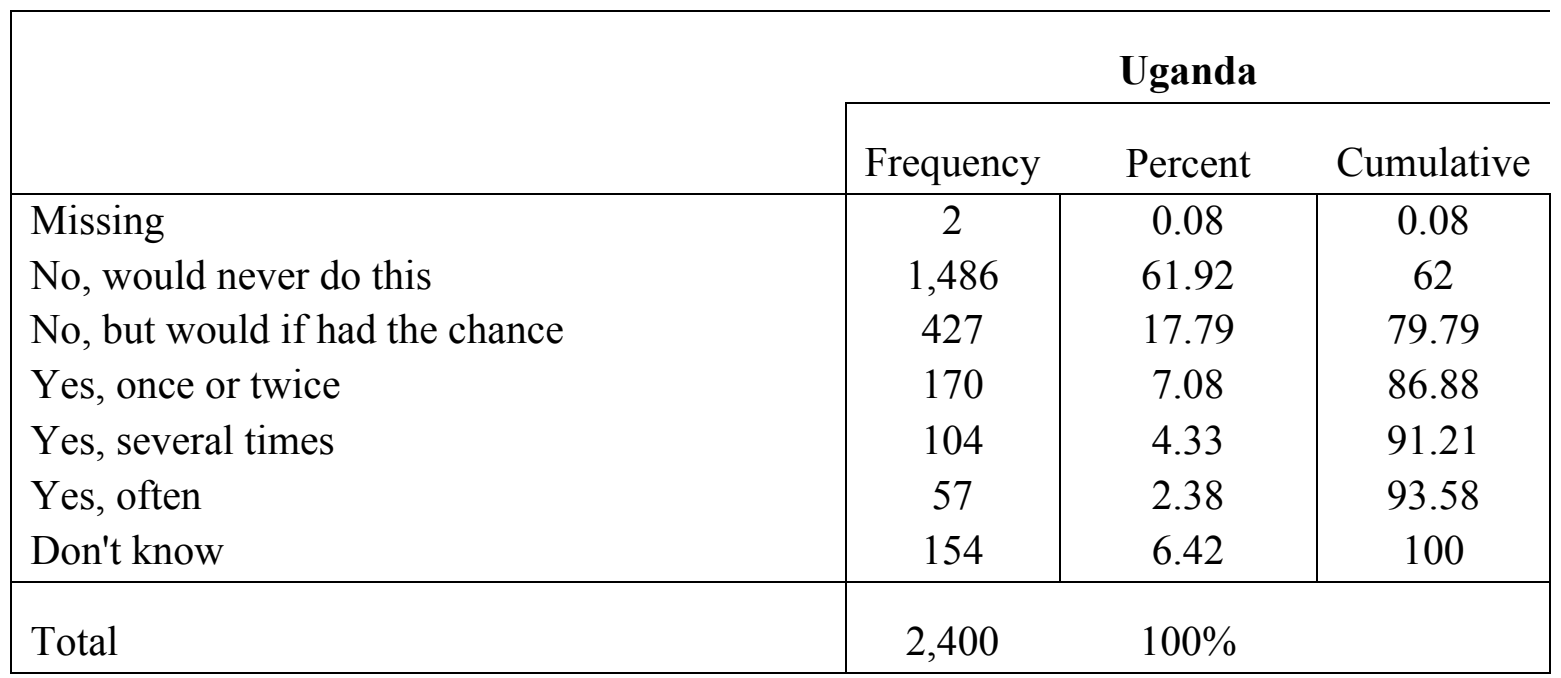

Table 10 shows that of the 2,400 Ugandan respondents in the 2012 Afrobarometer survey, $13.79 \%$ reported having shirked taxes at least once in the past year. Of this $13.79 \%, 69.8 \%$ or 231 of 331 indicated that they owed some kind of tax or fee. The levels of non-compliance in Uganda are higher than average: Across all African countries 
that participated in the fifth Afrobarometer survey, an average of $7.5 \%$ or 3,783 out of 54,404 respondents reportedly refused to pay taxes at least once. ${ }^{26}$

However, the percentages of reported refusals to comply are probably artificially low, given individual incentives to misrepresent the true frequency of refusals to comply with taxation. ${ }^{27}$ One reason why the level of non-compliers in the dataset may be artificially low is if the government is believed to be administering the survey. Respondents, believing that reporting their refusals to comply with taxes would lead to repercussions, would give artificially high levels of compliance. To control for that possibility, the model includes a survey response for whether the respondents think a governmental agency is administering the survey.

\section{The Independent Variable}

The independent variable for this paper is the number of aid project locations within a given administrative area. 'Aid project location' refers to the location where an aid project was implemented, and aid projects can have different numbers of project locations. For example, if an aid project is implemented at seven different locations, each location is treated as having an aid project. I code the number of aid project locations at both the county and district level in Uganda. ${ }^{28}$

\footnotetext{
26 Afrobarometer Online Data Analysis, Afrobarometer Round 5: Refused to Pay Tax or Fee to Government. Found at: http://www.afrobarometer-online-analysis.com/aj/AJBrowserAB.jsp, last accessed on 25 February 2015 at 11:23 AM.

27 Data collected by the author on tax revenues in Uganda suggests that tax revenues decline as the level of reported refusals increase, providing some evidence that lower levels of compliance are associated with lower tax revenues. See Figure A2 in Appendix A.

28 The county is the smallest administrative region in Uganda for which Afrobarometer survey data is publicly available. It is also the third administrative level in Uganda, below the region and the district,
} 
Aid project locations are used because of a large degree of missing data on disbursements and commitments in the Ugandan aid data. Of the 2,458 aid projects recorded in the dataset, 405 or $16 \%$ lack any financial information. ${ }^{29}$ Large donors like the US and the UK lack financial data for $24 \%$ and $30 \%$ of their projects, respectively. The projects that do have financial data have it at the project aggregate level, rather than at the project location level. Thus it is not clear how the project funds are allocated among the project locations. To avoid losing a considerable amount of the aid information in the dataset, this project follows the precedent set by previous studies of sub-national aid allocation (Öhler and Nunnenkamp 2013, Findley and Marineau 2016) by using project locations. Map 1 below shows the distribution of county projects within Uganda.

which is the second administrative level. Coding projects at the county and district includes both projects implemented at the county or districts levels and projects implemented at a lower level (e.g. town, particular place) located within the county or district.

29 To be specific, $16 \%$ of the projects lack information on commitments, disbursements, or both. 
Map 1. County-Level Aid Projects in Uganda

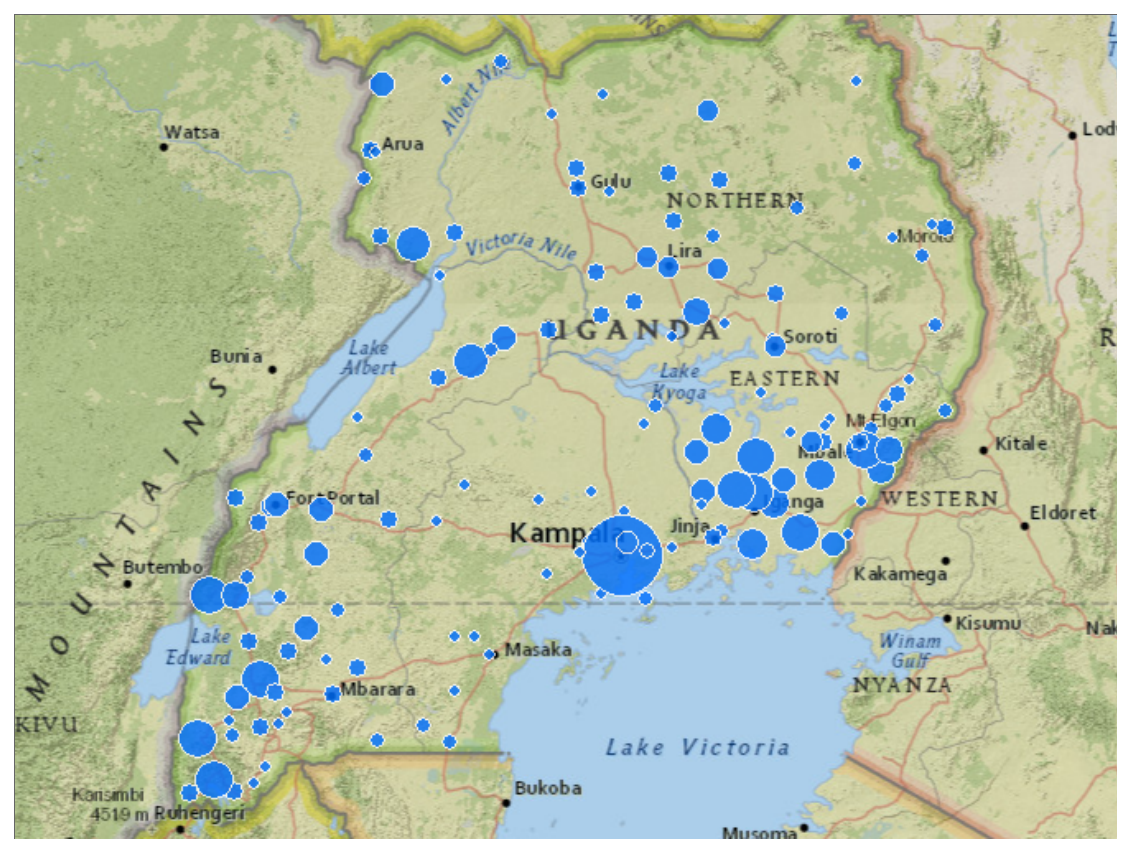

The aid data were collected by AidData (Strandow et al 2011, Tierney et al. 2011) from the Aid Management Platforms (AMPs) for Uganda. The AMP is a software program developed by Development Gateway that allows recipient governments to track the types and amounts of aid that donors allocate to the country. In the case of Uganda, the locations for aid projects listed in the AMP were determined by presenting the list of projects to the donors, and asking the donors to provide information on locations for their respective projects. The locations were then assigned latitude and longitude coordinates according to the geocoding methodology developed by Strandow et al (2011).

The complete dataset for Uganda contains information for 2,458 aid project locations that occurred between 1988 and $2013.70 \%$ of the projects in the dataset 
occurred after 2003 and approximately 50\% since $2008 .{ }^{30} 20 \%$ lack all temporal information. I include projects implemented before 2012, the year in which the Afrobarometer survey was implemented, and so exclude projects for 2012 and those that lack year information. I also exclude projects implemented in counties and districts that were not included in the Afrobarometer survey. As the survey was designed to be random, clustered and stratified at each sampling level, the excluded districts and counties should not bias the final results.

For this quantitative analysis, I use a subset of the dataset that contains subnational information at the county level, totaling some 481 aid project locations in Uganda between 1988 and 2011. The county-level model is used in the primary analysis because there is a likely spatial component regarding the effect of aid projects on tax compliance - the 'closer' the respondent is to an aid project, any potential negative effect of aid on tax compliance is likely to be greater. The more access or exposure a respondent had to a project likely shapes how much that project affects the respondent's relationship with the state. Thus projects implemented in the same county as the respondent are more likely to be more detrimental than projects at the district, regional, or national levels. However, as there are some 1,004 project locations at the district level, which is the next administrative level up from counties for Uganda, I also estimate a version of the model for Uganda using district-level project locations. ${ }^{31}$

\footnotetext{
${ }^{30}$ Note that this because of reporting from donors and the low availability of donor project documents used to code the data, not that the amount of aid changed dramatically.

${ }^{31}$ Uganda has an average of 24 project locations per districts, with a standard deviation of 13 . The country also has an average of 6 project locations per county with a standard deviation of 8 .
} 
Figure 10. Aid Project Locations at County Level by Sector

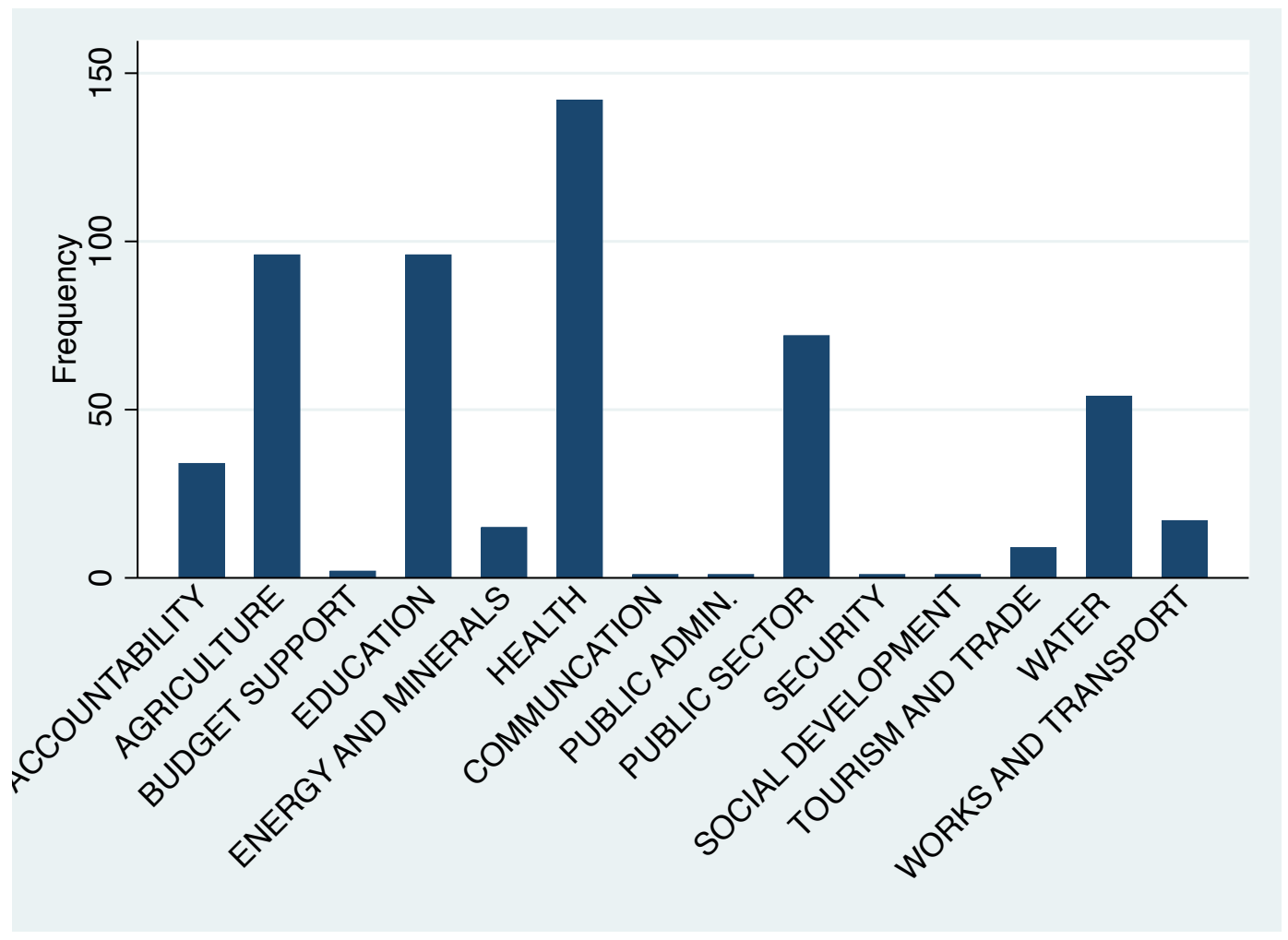

Figure 10 provides a summary of the number of project location counts at the county level by sector. Aid project locations are shown because they are included in the statistical analysis. The patterns of aid projects suggest that donors tend to favor funding social service sectors, including health, education, and agriculture. Health projects make up a plurality of projects at the county level, and make up $26.25 \%$ of the total project locations with 142 project locations. Education and agriculture project locations constitute $17.74 \%$ of the total with 96 project locations each. All of the remaining sectors constitute less than $10 \%$ each of the remaining project locations.

It is also worth noting the types of projects that have very little presence at the county level: Security, for instance, has only one project location. Budget support is only 
recorded as reaching the county level in two instances, suggesting how little budget support is allocated to local - as opposed to the central - government.

Figure 11. Project Commitments by Sector

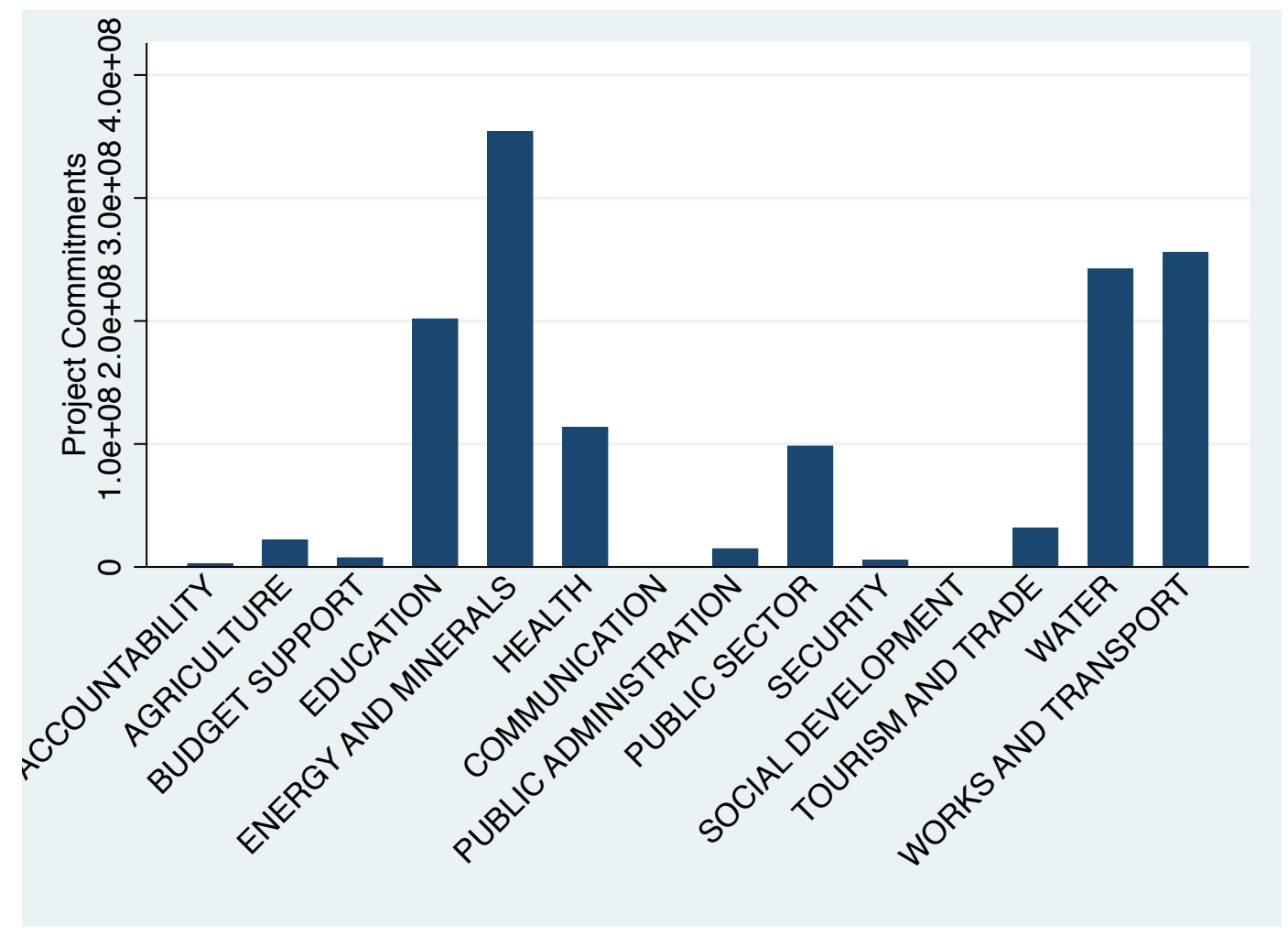

Figure 11 displays project commitments, the amount that a donor pledged to provide for a project. Note that the project commitment sum is calculated by totaling up the project location commitments, and then dividing that sum by the number of project locations. So figure 11 captures the total project commitments, while taking the number of project locations into account so as to not over-count projects that are listed as have the same total commitment per location. 
One immediate different between figure 10 and figure 11 is energy and mineral development has the highest project commitment (354,000,000 USD), despite relatively few project locations (15 or $2.77 \%$ of the total). Water and Works and Transportation also have relatively high project commitments $(242,300,000$ and $255,600,000$ USD respectively) compared to their total project locations (54 locations or $9.98 \%$ of the total versus 17 locations and 3.14\% respectively). Health has relatively a high level of project commitment $(113,400,000$ USD) while also having the highest level of project locations at the county level (142 and $26.25 \%$ of the total county-level project locations, as mentioned above). So the actual project commitments suggest a preference for infrastructural development instead of social service delivery. The next figure explores the extent to which project disbursements match commitments.

Figure 12. Project Disbursements by Sector

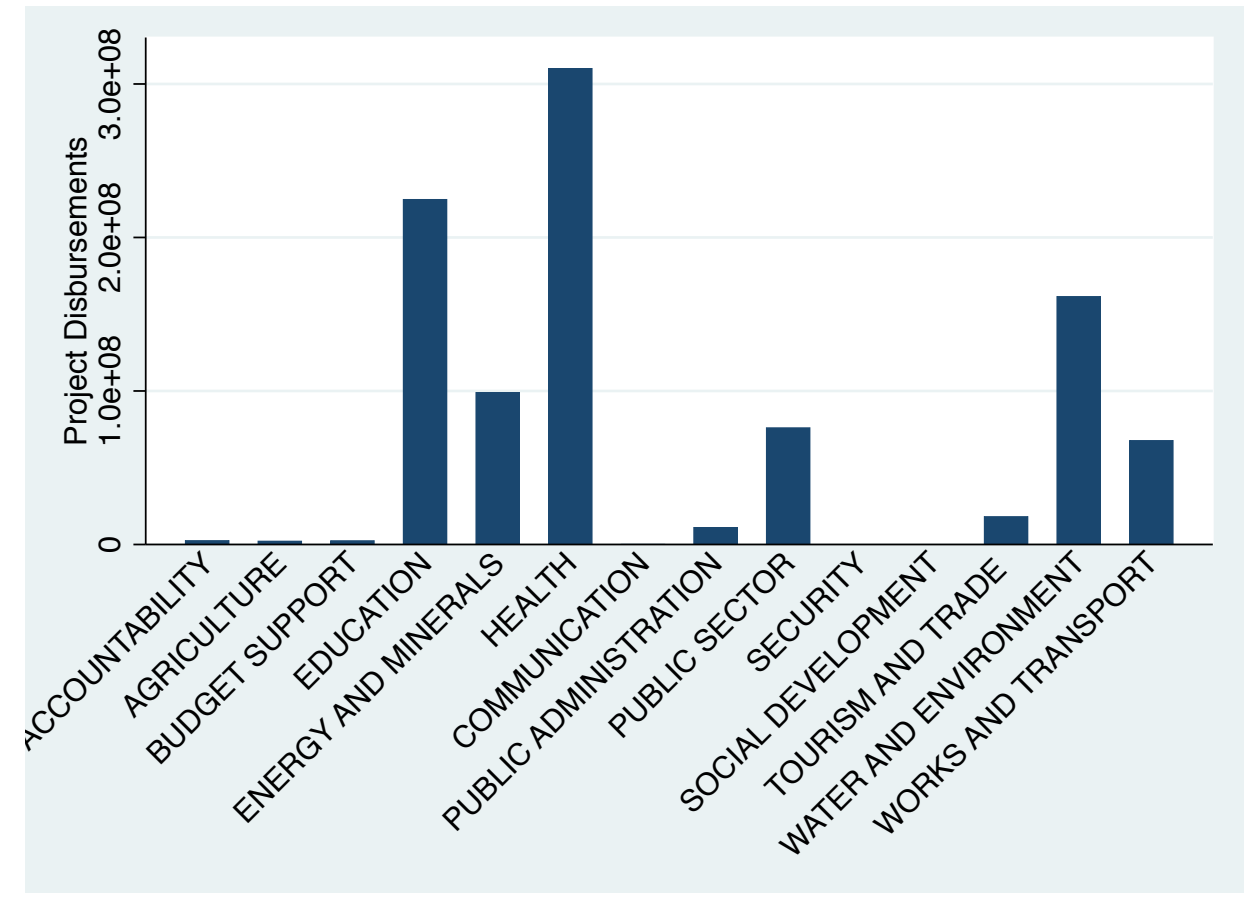


Figure 12 displays project disbursements by sector. While it is useful to compare figure 12 against figure 11, the differences should be viewed with caution because any differences could be due to either donors actually not disbursing aid funds, or from missing information. With that caveat in mind, one of the clearest differences between figures 12 and 11 is that social spending is a higher priority for funds that are actually disbursed compared to committed funds. The sector with the highest amount of recorded disbursed funds is health, with $310,100,000$ USD in disbursed spending. The sector with the second-highest recorded disbursed spending is another social service sector, education, with $224,700,000$. (As an example of the measurement error in using project commitments and disbursements, note that the committed funds for health totaled $113,400,000$ USD, nearly 200 million USD less than the recorded disbursed funds of 310 million.) Energy and mineral development has 98,990,016 USD in recorded disbursed funds, some 250 million less than the recorded committed funds for this project.

The take-away points from figure 10 through 12 is that donors tend to prioritize social service sectors, including education and health, in terms of the number locations that they allocate these projects to at the county level and in terms of the funds that they actually are recorded as disbursing. In terms of project commitments, donors appear to favor infrastructural projects like energy and mineral development, water, and works and transportation, but these preferences are not reflected in recorded project disbursements nor in the number of locations in which these projects appear. 


\section{Individual-Level Controls}

I include several control variables ${ }^{32}$ to account for potential factors that may drive individual tax compliance. The control variables include additional measures related to taxes and variables that capture individual-level factors like education, age, gender, and the job status of the respondent. I now describe these variables in more detail.

\section{Measures of Attitudes towards Taxation}

Along with aid, several other factors may drive individual tax compliance. One obvious factor is whether people know if they owe taxes. As noted above, roughly two thirds of the respondents reported owing taxes. Another factor is whether they believe other people avoid paying taxes or not. A third factor relates to enforcement of taxes by the state and the likelihood of getting apprehended if the respondent refuses to pay taxes. Therefore, I include control variables on the knowledge of taxes that are owed, perceptions of others' tax avoidance, and the ease of evading taxes. Whether the respondent reported that he or she actually owed taxes is used as a control variable. However, the survey does not record which taxes the respondent owed, how much in taxes was owed, or whether the respondent actually paid the specific tax that he or she reportedly owed.

\footnotetext{
32 The wording for the questions used as control variables is included in Appendix A.
} 


\section{Additional Control Variables}

Along with these controls, I control for individual level factors including age, gender ${ }^{33}$, level of education, and whether the respondent reported having full-time employment. Finally, also as mentioned previously, I control for whether the respondent believed the government was administering the survey. I also control for location, including the capital city, Kampala, as the capital receives more aid projects than any other location in the country. Note that this only involves projects actually implemented at the local level in Kampala, rather than projects implemented nationally but that include Kampala as the location by virtue of it being the country's capital. I also control for whether the respondent is in the Northern region of Uganda, as the North has experienced more instability than other regions of the country and has an overall lower level of development compared to other areas. Once all of these control variables are included and observations with missing values are dropped, there are 1,783 total respondents for Uganda.

\section{Addressing Project Location Allocation}

If the goal of this paper, which is to estimate the effect of aid projects on individual tax compliance, is to succeed, attention must be paid to how the locations to which aid projects are allocated may bias the results. One problem is if donors are placing aid projects in areas with a high level of need, this may lead to an artificial relationship between aid projects and tax compliance, in that any positive relationship is driven by the

${ }^{33}$ Gender is coded as follows: $2=$ Female, $1=$ Male. So positive coefficients would suggest that the likelihood tax compliance decreases if the respondent is female, while negative coefficients would suggest that the likelihood tax compliance decreases if the respondent is male. 
fact that places where aid is going already have a low level of compliance. Assuming that refusals to comply with taxation is associated with poorer (i.e. higher need) areas, due to an inability to pay, then this scenario would suggest that the relationship I have proposed overlooks a mechanism that drives both results: high levels of need cause both low compliance and higher aid levels, rather than aid causing low compliance.

To deal with this problem, I estimate a separate model that attempts to show whether aid projects are associated with lower tax compliance even in areas with lower levels of need. I measure 'need' based on the presence or absence of key services and facilities in the areas in which the Afrobarometer survey was implemented. ${ }^{34}$ While administering the survey, the surveyor recorded whether or not the following services and facilities were present and accessible in the sampling unit: electricity, piped water, sewage system, cell phone service, post-office, school, police station, health clinic, and market stall. Each of these variables is coded as dummy variables that indicate the presence or absence of the facility or service in the sampling area. Each of these variables is weighted equally and combined into an index by adding the values on the need-related variables, and then dividing that sum by the total number of need variables. I then reestimate the model using only administrative areas in which the level of need is above the mean, with higher values on the index representing lower levels of need, and lower values representing higher levels of need. If the effects of aid on tax compliance hold in these non-needy areas, it suggests that any underlying effect of need on tax compliance is not driving the results.

34 The wording for the questions used to construct the Need Index are included in Appendix A. 


\section{The Model}

I estimate five main types of models. First, I dichotomize the dependent variable into 'No' answers and 'Yes' answers and estimate a logistic regression with standard errors clustered at the county level. Next, the logistic regression is estimated using only the 'low-need' areas. Again, the logic of using low-need areas is to examine whether the results hold in areas where the ability to pay taxes is likely to be higher. Thirdly, a multilevel model is estimated with random effects at the region, district, and county levels. The fourth model looks only at US aid projects, as the US government is known to channel its aid through non-state actors rather than delivering aid through the central government. Hence, its potential effects on lowering tax compliance through the mechanisms above might be particularly pronounced. Fifthly and finally, I take advantage of the greater level of aid information at the district level by estimating a model using district-level project counts with standard errors clustered at the district level. Finally, to demonstrate the substantive effects of aid on refusals to comply with taxation, the coefficients are displayed in terms of odds ratios for the five models.

\section{Interviews}

In addition to the statistical evidence that demonstrates a relationship between aid and lowered tax compliance levels, I conducted two-dozen interviews in Kampala, Uganda in April and May of 2015. The schedule of interview questions is included in appendix A. The interviews were conducted with aid officials, tax administration 
officers, and civil society members from non-governmental organizations that dealt with tax policy and similar issues. The findings of these interviews are summarized in the section following the presentation of the statistical results.

\section{RESUltS}

Table 11 presents the results of estimating the five models described above. I discuss each in turn. 
Table 11. Logistic Regression Results for Refusal to Comply with Taxation

\begin{tabular}{|c|c|c|c|c|c|}
\hline Variables & $\begin{array}{c}\text { (1) } \\
\text { Main } \\
\text { Results }\end{array}$ & $\begin{array}{c}(2) \\
\text { Low-Need } \\
\text { Areas } \\
\end{array}$ & $\begin{array}{c}(3) \\
\text { Multilevel } \\
\text { Model } \\
\end{array}$ & $\begin{array}{c}(4) \\
\text { US } \\
\text { Projects } \\
\end{array}$ & $\begin{array}{c}(5) \\
\text { District } \\
\text { Projects } \\
\end{array}$ \\
\hline Aid Projects & $\begin{array}{l}0.0801^{*} \\
(0.0219)\end{array}$ & $\begin{array}{l}0.0746^{*} \\
(0.0239)\end{array}$ & $\begin{array}{l}0.0714^{*} \\
(0.0258)\end{array}$ & $\begin{array}{l}0.0688^{*} \\
(0.0203)\end{array}$ & $\begin{array}{l}0.0248^{*} \\
(0.0124)\end{array}$ \\
\hline Population & $\begin{array}{c}2.53 \mathrm{e}-07 \\
(2.62 \mathrm{e}-07)\end{array}$ & $\begin{array}{c}4.31 \mathrm{e}-07 \\
(2.79 \mathrm{e}-07)\end{array}$ & $\begin{array}{c}3.91 \mathrm{e}-07 \\
(6.04 \mathrm{e}-07)\end{array}$ & $\begin{array}{l}3.53 e-07 \\
(3.6 e-08)\end{array}$ & $\begin{array}{c}2.93 \mathrm{e}-07 \\
(1.55 \mathrm{e}-07)\end{array}$ \\
\hline Info. On Taxes & $\begin{array}{l}-0.217^{*} \\
(0.0897)\end{array}$ & $\begin{array}{l}-0.283 * \\
(0.117)\end{array}$ & $\begin{array}{l}-0.211^{*} \\
(0.0860)\end{array}$ & $\begin{array}{l}-0.197^{*} \\
(0.0845)\end{array}$ & $\begin{array}{l}-0.193 * \\
(0.0897)\end{array}$ \\
\hline Others Avoid & $\begin{array}{c}0.534^{*} \\
(0.0820)\end{array}$ & $\begin{array}{c}0.741^{*} \\
(0.0904)\end{array}$ & $\begin{array}{c}0.474^{*} \\
(0.0778)\end{array}$ & $\begin{array}{c}0.478^{*} \\
(0.0784)\end{array}$ & $\begin{array}{c}0.548^{*} \\
(0.0947)\end{array}$ \\
\hline Ease of Evading & $\begin{array}{l}-0.121 \\
(0.103)\end{array}$ & $\begin{array}{c}0.00499 \\
(0.144)\end{array}$ & $\begin{array}{c}-0.146 \\
(0.0903)\end{array}$ & $\begin{array}{c}-0.177 \\
(0.0961)\end{array}$ & $\begin{array}{l}-0.115 \\
(0.113)\end{array}$ \\
\hline Must Pay Taxes & $\begin{array}{l}-0.0839 \\
(0.0594)\end{array}$ & $\begin{array}{l}-0.128 \\
(0.105)\end{array}$ & $\begin{array}{l}-0.130^{*} \\
(0.0482)\end{array}$ & $\begin{array}{l}-0.122^{*} \\
(0.0541)\end{array}$ & $\begin{array}{l}-0.0848 \\
(0.0621)\end{array}$ \\
\hline Owing Taxes & $\begin{array}{l}-0.159 \\
(0.168)\end{array}$ & $\begin{array}{l}-0.215 \\
(0.229)\end{array}$ & $\begin{array}{l}-0.0779 \\
(0.160)\end{array}$ & $\begin{array}{l}0.0120 \\
(0.166)\end{array}$ & $\begin{array}{l}-0.120 \\
(0.175)\end{array}$ \\
\hline Education & $\begin{array}{l}-0.0651 \\
(0.0457)\end{array}$ & $\begin{array}{l}-0.0883 \\
(0.0649)\end{array}$ & $\begin{array}{l}-0.0645 \\
(0.0440)\end{array}$ & $\begin{array}{l}-0.0722 \\
(0.0440)\end{array}$ & $\begin{array}{l}-0.0749 \\
(0.0526)\end{array}$ \\
\hline Age & $\begin{array}{c}0.00251 \\
(0.00708)\end{array}$ & $\begin{array}{l}0.00337 \\
(0.0117)\end{array}$ & $\begin{array}{c}0.0063 \\
(0.0059)\end{array}$ & $\begin{array}{c}0.00527 \\
(0.00610)\end{array}$ & $\begin{array}{c}0.00260 \\
(0.00687)\end{array}$ \\
\hline Gender & $\begin{array}{l}-0.540^{*} \\
(0.157)\end{array}$ & $\begin{array}{l}-0.456^{*} \\
(0.180)\end{array}$ & $\begin{array}{l}-0.605^{*} \\
(0.145)\end{array}$ & $\begin{array}{l}-0.576^{*} \\
(0.132)\end{array}$ & $\begin{array}{l}-0.545^{*} \\
(0.158)\end{array}$ \\
\hline Kampala & $\begin{array}{l}-4.573 * \\
(1.031)\end{array}$ & $\begin{array}{l}-4.607^{*} \\
(1.140)\end{array}$ & $\begin{array}{l}-3.839 * \\
(1.339)\end{array}$ & $\begin{array}{l}-0.286 \\
(0.416)\end{array}$ & $\begin{array}{l}-1.514^{*} \\
(0.417)\end{array}$ \\
\hline Full-Time Job & $\begin{array}{l}-0.218 \\
(0.191)\end{array}$ & $\begin{array}{c}-0.00996 \\
(0.260)\end{array}$ & $\begin{array}{l}-0.214 \\
(0.178)\end{array}$ & $\begin{array}{l}-0.187 \\
(0.165)\end{array}$ & $\begin{array}{l}-0.212 \\
(0.200)\end{array}$ \\
\hline Gov. Interviewer & $\begin{array}{l}0.319^{*} \\
(0.139)\end{array}$ & $\begin{array}{l}0.0599 \\
(0.160)\end{array}$ & $\begin{array}{c}0.183 \\
(0.143)\end{array}$ & $\begin{array}{c}0.229 \\
(0.124)\end{array}$ & $\begin{array}{l}0.320^{*} \\
(0.141)\end{array}$ \\
\hline Northern Region & $\begin{array}{c}0.452 \\
(0.245)\end{array}$ & $\begin{array}{c}0.279 \\
(0.352)\end{array}$ & $\begin{array}{l}0.568^{*} \\
(0.277)\end{array}$ & $\begin{array}{l}0.512^{*} \\
(0.235)\end{array}$ & $\begin{array}{c}0.172 \\
(0.235)\end{array}$ \\
\hline Tax Revenues & $\begin{array}{l}-0.0117 \\
(0.0130)\end{array}$ & $\begin{array}{l}-0.0231 \\
(0.0166)\end{array}$ & $\begin{array}{l}-0.0024 \\
(0.0130)\end{array}$ & $\begin{array}{c}-0.00564 \\
(0.0124)\end{array}$ & $\begin{array}{l}-0.0279 * \\
(0.0138)\end{array}$ \\
\hline Constant & $\begin{array}{l}-0.296 \\
(0.544)\end{array}$ & $\begin{array}{l}-0.333 \\
(0.937)\end{array}$ & $\begin{array}{l}-0.351 \\
(0.601)\end{array}$ & $\begin{array}{l}-0.152 \\
(0.490)\end{array}$ & $\begin{array}{l}-0.337 \\
(0.630)\end{array}$ \\
\hline Observations & 1,783 & 910 & 1,783 & 1,783 & 1,783 \\
\hline
\end{tabular}

Robust Standard Errors in parentheses, $* \mathrm{p}<0.05$ 
Model 1 shows the full results of the effects of aid projects on reported refusals to comply with taxation with standard errors clustered at the county level. The asterisk next to the coefficient for county projects suggests that the effect of aid projects on refusals to comply with taxation is significant, and the coefficient suggests that this effect is positive. For the control variables, the result for access to tax information is negative and significant. This suggests that higher levels of access to tax information are associated with lower levels of refusals to comply with taxation. The 'Others Avoid' variable, which refers to whether other people are seen as avoiding taxation, is positive and significant, providing evidence that there is a sort of social influence on the individual-level decision to pay taxes or not: If others are seen (not) paying taxes, the individual incentive to pay taxes also increases (or decreases). The next significant control variable is gender, and the negative sign on the coefficient suggests that the likelihood of having refused to pay taxes is higher if the respondent is male. People in Kampala are significantly less likely to have refused to pay taxes, as evidenced by the negative sign on the coefficient. Finally, individuals are more likely to have reported that they refused to pay taxes if they believe that the interviewer was a government official. To some up, while substantive effects will be discussed below, the tentative finding is that more aid projects are significantly related to higher levels of reported refusals to comply with taxation.

To account for whether an inability to pay may drive the results shown in model 1, model 2 includes only the respondents found in areas of lower need. The logic is that if the same results are found in areas of lower need, and thus have a greater ability and perhaps incentive to pay taxes, then the effect found in model 1 is not dependent simply 
on an inability to pay. Thus, the significant and positive effect found for county projects in model 2 is further support for the result found in model 1, bolstering the finding that more aid projects are associated with higher levels of reported refusals to pay taxes.

The results for the control variables are similar to those in model 1. Access to tax information is negatively related to reported refusals to pay taxes, suggesting that people are more likely to pay taxes if they know which taxes they are supposed to pay. A positive coefficient for others avoiding taxes suggests that people do not simply chose to pay taxes or not in isolation, but are influenced by the behavior of others around them. Gender is significant, with males less likely to pay taxes than females, while people living in Kampala are less likely to refuse to pay taxes. Unlike model 1, however, the variable for government interviewer is not significant.

Models 1 and 2 cluster standard errors at the county and district levels respectively to account for similarities between respondents who live in the same areas. Another way to account for within-group similarities is a multilevel model, which is estimated by model 3. In model 3, counties are clustered within districts, which are clustered within regions. The positive and significant coefficient for county projects suggests that within group similarities are not driving the overall relationship between more aid projects and higher levels of reported refusals to comply with taxation.

The results for the control variables in model 3 mirror those for models 1 and 2 , they also different in two important respects. The results for access to information, others avoiding taxes, gender, and living in Kamapala match the findings in the first two models. Two additional control variables are significant in this model that were not 
significant in the first two models, however. The first is whether the respondent believes that people had an obligation to pay taxes, and the variable is negative and significant. This suggests that as a belief in an obligation to pay taxes decreases, the likelihood that someone reported refused to pay taxes correspondingly increased. The second variable is one that showed whether the respondent lived in the Northern Region of Uganda, and the finding suggested that people that live in the Northern Region are significantly more likely to have refused to pay taxes.

Not all donors allocate aid similarly, and the US is known to channel its aid through non-state actors. Aid that bypasses the government and is delivered through nonstates may be particularly potent in reducing tax compliance because it allows non-state actors to substitute for the state in service delivery. The positive and significant coefficient for county projects in model 4 suggests that aid delivered by the US is associated with higher levels of reported refusals to comply with taxation.

The results for the control variables in model 4 are largely similar to those for model 3, including the results for the variables for the Northern Region and for whether the respondent believes that people have an obligation to pay taxes. Where it differs from model 3, and indeed differs from the first two models as well, is the result for Kampala. Whether the respondents lived in Kampala is not found to be significantly related to whether the respondent reportedly refused to pay taxes or not in this model.

Thus far, the models have examined aid projects and individuals clustered at the county level. Given that the 'closer' a respondent is to an aid project is likely to have a stronger effect on reported refusals to comply with taxation, these models have focused 
on the lowest level of aggregation available in the survey data. Yet there are more projects at the district level than at the county level, and so model 5 estimates the effect of district-level projects and refusals to comply with taxation. Standard errors are clustered at the district level, similar to the estimation strategy at the county level in models 1,2 , and 4 . The positive and significant effect of district-level projects on reported refusals to comply with taxation provides further support in favor of the hypothesis derived in the theory section.

The results for the control variables for model 5 are most similar to those for model 1. Access to information is negatively related to tax refusals, while the perception that others avoid paying taxes is positively related to the decision to pay taxes. Males again found to be more likely to refuse to pay taxes, while respondents living in Kampala are less likely to refuse to pay taxes. Whether the respondent believes the interview is a government official is positively related to whether they reported having refused to pay taxes. Unlike models 3 and 4, the coefficients for Northern Region and whether the respondent believes there is an obligation to pay taxes are insignificant. Where the results for model 5 differ from models 1-4 is in regards to tax revenues. As tax revenues increase, the likelihood of a respondent having refused to pay taxes decreases.

While the results in table 11 are suggestive of the nature of the relationship between aid projects and refusals to comply with taxation, figure 13 below shows the substantive effects of aid. 
Figure 13. Coefficient Plot of Models 1-5

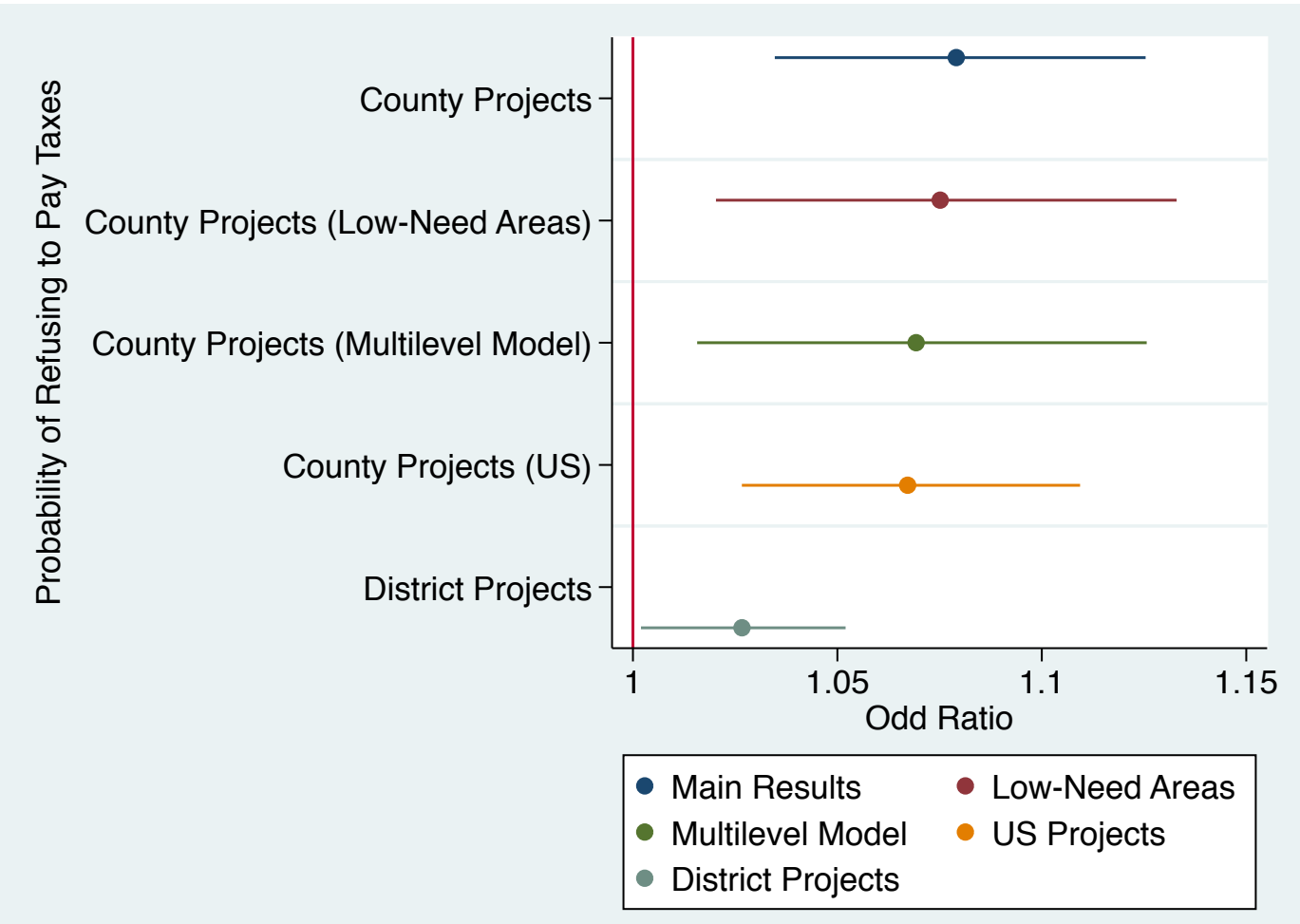

Figure 13 displays the coefficients in terms of odds ratios to aid in the substantive interpretation of the effect of aid projects on refusals to comply with taxation. The fact that the coefficients for county projects are greater than 1 suggests that there is an increased odds that individuals in areas with more aid projects will reported to have refused to pay taxes.

Starting at the top of figure 13 , the odds ratio for the main county project results is just under 1.08. Substantively, this means that the odds of someone having reportedly refused to pay taxes with more than the average number of aid projects are 1.08 greater than for someone with less than the average number of aid projects. The odds ratio for 
projects in low-need area is slightly smaller, calculated at 1.075. The odds ratios for aid projects in the multilevel model and for US-only projects are both just under 1.07, while the odds ratio for district projects is the smallest at just under 1.03.

\section{RELATIONSHIP BETWEen FOREIGN AID AND TAXATION IN UGANDA: FINDINGS FROM INTERVIEWS}

The interviewees were largely aware of the potential problem between foreign aid and taxation. ${ }^{35}$ This is not entirely surprising, as many of the interviewees were economists by training and so understood the theoretical reasons why aid could undermine taxes. The interviewees were more divided on whether aid had a causal effect on taxes, and if so, whether that effect was positive. One interviewee said that

I will be candid. I am an economist, and from my days at school I have believed that ODA is subsidizing the government. It gives government officials the room to steal tax revenue, because ODA replaces what is stolen. We have so many examples of that. [Interviewee 8B, Kampala Uganda, 13 May 2015]

Another interviewee echoed this point, saying that

It is tricky to prove anything, but the hunch is that large aid inflows reduce the incentives to collect domestic revenues. In the late 1990s in Uganda, huge increases in budget support may have depressed the effort the government made to raise domestic revenue. [Interviewee 15A, 2 June 2015. Interview conducted via Skype between Austin, TX and Kampala, Uganda.]

\footnotetext{
35 The interview schedule used to conduct the interview is included in the appendix.
} 
Some interviewees argued that while aid may have had a negative effect in the past, changes in how aid is delivered and targeted have contributed to improvements in tax revenues. One interviewee argued that

At one phase of development cooperation this may have been true, in the early years where everything changed was 1989 with the fall of the Berlin wall. Development cooperation previously was a means of foreign policy, an attempt to keep the countries in their block. In the 1970s and 80s, we had project matrices and project objectives and indicators, but the bottom line was if something didn't work out, as long as the politics were in order, nothing escalated. But that has changed. Since 1990s, these sort of political motivations don't play so much of a role. Still development aid and assistance has some underlying political agendas, and we all have a certain interest that we are following, but that is one argument amongst several. [Interviewee 7A, Kampala Uganda, 12 May 2015]

Some interviewees claimed that any association between low taxes and high aid was not due to a causal relationship, but simply that developing countries that need aid also have low tax revenues. One interviewee stated that "I don't think there is a causal relationship [between aid and taxes], except maybe for the fact that developing countries have a shortfall in generating revenue and therefore have a need for foreign aid and development cooperation” (Interviewee 8A, Kampala Uganda, 13 May 2015).

Finally, other interviewees were more optimistic about the effect of aid on taxes, claiming that aid may have a positive effect on taxes by boosting economic activity. One interviewee argued, for instance, that a road project may bolster economic activity by reducing the cost of bringing goods to markets, and this increased economic activity has a positive effect on tax revenues. ${ }^{36}$ At other times, aid projects can entail fee structures that users have to pay in exchange for the service. These fees serve as a form of tax, even if

\footnotetext{
36 Interviewee 1D, Kampala, Uganda, 4 May 2015.
} 
the fees are collected specifically for the services rendered rather than accruing into the government treasury. Finally, some interviewees claimed that taxes on items and companies implementing donor projects contribute a significant amount of tax revenue. ${ }^{37}$ While the donors themselves may not pay taxes, contractors that implement donor projects or the materials for a donor project would be taxed.

These arguments about how aid can boost tax revenues serve as alternative hypotheses, and ultimately it is an empirical matter to determine which hypothesis is correct. However, even if these interviewees are correct that aid has a small, positive effect on tax revenues via its effect on productivity, aid can still undermine the state's overall tax effort if the state comes to rely on aid as a substitute for domestic revenue mobilization. In other words, any growth-enhancing effects of aid would positively affect tax revenues only if the state tries to collect the taxes. And if aid is directed towards countries that have low domestic revenue, it is an open question of whether aid provides an incentive to avoid raising revenues. One recent evaluation of budget support efforts in Uganda came to this conclusion, stating that

Did the large BS [budget support] in the early period contribute to "crowding out" local revenue mobilization? The answer is probably yes, based on a basic review of the trends in the size of BS aid relative to revenues and expenditures, as well as comparisons with relevant international experience. Uganda is unique among other African countries with substantial BS in that it (i) received exceptionally high levels of BS aid compared with revenues and expenditures in the early part of the period and, yet, (ii) failed to increase domestic revenues substantially during that period and later on. [Joint Evaluation 2015, 21]

\footnotetext{
37 Interviewee 2D, Kampala Uganda, 5 May 2015. However, other interviewees disputed that the government can tax contractors on donor projects due to host country agreements that prevent it. (Interview 3C, Kampala, Uganda, 6 May 2015.)
} 
This evaluation thus concludes that aid, and budget support in particular, lowered revenue mobilization efforts in Uganda. It argues that this relationship is unique to Uganda, yet the evaluation offers no reasons or evidence that the relationship does not exist elsewhere.

The budget support evaluation points to three main ways in particular that tax revenues in Uganda are lower than expected: "large VAT exemptions, clientelism, and culture of non-compliance with tax code, including by top public sector officials who own and operate private businesses with little or no compliance" (Joint Evaluation 2015, 20).

The first point regarding VAT exemptions has to do with the tax holidays that the state grants to attract foreign investment. Investing in Uganda is costly because it is risky, so the state uses the tax holidays as a means for the investors to recoup their investment more quickly and turn a profit. As one interviewee argued, these investments are good for Uganda's economy and state revenue because the investments often create jobs that then are taxed. ${ }^{38}$

Yet these VAT exemptions are controversial because they are perceived as open for abuse by investors. ${ }^{39}$ Some interviewees argued that upon the expiration of the tax holiday, investors sell their investments to another investor, who renames the original investment and then applies for a new tax exemption. Furthermore, these interviewees argued that the exemptions are unfair because they are not granted to local investors.

Regarding clientelism, interviewees argued that people in Uganda tend to view

\footnotetext{
38 Interviewee 2D, Kampala Uganda, 5 May 2015.

${ }^{39}$ Interviewee 1C, Kampala Uganda, 4 May 2015.
} 
state services as an entitlement, but that taxpaying is not viewed as an obligation. One interviewee claimed that "there is a disconnect from government services as a right and taxpaying as an obligation. Whatever shape the aid takes, it comes across as a handout, and people don't see their responsibilities." 40 Another interviewee pointed out that "you don't feel paying taxes as a national obligation or duty. You feel like you are being cheated if you are paying taxes." 41

While these arguments focus on how budget support can lower tax compliance, interviewees described ways that project-based aid can undermine the relationship between the state and society. One interviewee pointed out how the provision of aid can lower the incentive to hold the government accountable:

They have the mindset that UK AID has provided, US AID has provided, they don't feel that they have the right to hold government accountable. It is a free service they have been provided. If they knew that they had to contribute to their development, they would feel more motivated to hold their governments accountable... If people paid taxes, then they would be able to hold the government accountable and demand services. [Interviewee 5B, Kampala, Uganda, 5 May 2015]

Yet the provision of project aid also contributes to the reluctance to pay taxes: "[A]s long as they see that they need some external assistance to build the hospital or the school [they will be reluctant to pay taxes], but in reality they should be contributing to the tax bracket and the revenue basket to influence where the money goes." 42

Some interviewees pointed out that aid can substitute for state services. "If you look at the civil society engagement, civil society has tended to take on the role of

\footnotetext{
40 Interview 2D, Kampala Uganda, 5 May 2015.

41 Interview 5A, Kampala Uganda, 8 May 2015.

42 Interviewee 5B, Kampala, Uganda, 5 May 2015.
} 
government or the state. In my view civil society should be questioning what government is doing, but not superseding what the government is doing" with actions such as drilling

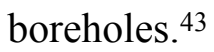

Donors have recognized that superseding the role of the state is problematic for long-term development, but have had difficulty getting the state to step in:

There have been efforts to get the state involved in social service. They can't make their basic capital development requirements unless they keep their people healthy. They basically say that we will leave that to you [i.e., the donors] to do. It is difficult for policy dialogue, and has been so long that our role is providers and givers. [Interviewee 3C, Kampala, Uganda, 6 May 2015]

Yet the lack of engagement of the state in service provision is problematic, because it creates a disincentive for tax compliance:

People ask, why should we pay tax? Money is squandered, misappropriated. As long as there is poor service delivery by the state, infrastructure, schools, etc., people will not understand why they should pay taxes. There is a mismatch between what people pay and the services delivered. People will say, yes we will pay but what do our taxes do? [Interviewee 9A, Kampala, Uganda, 15 May 2015]

Additionally, several of my interviewees pointed to political factors that can induce non-compliance towards taxation. One interviewee explained that

We have a problem with politicians when it comes to taxes. Of course taxes themselves have politics around them. Politicians interfere a lot when it comes to taxes. They will do so many things to undermine domestic revenue mobilization. There are so many cases where certain people are supposed to pay, and politicians interfere with that process. It happens at the local and national level. If the tax is imposed on them, they won't vote for them. They don't appreciate it or understand it, and they don't understand the difference between politics and what is right. [Interviewee 5B, Kampala Uganda, 8 May 2015]

\footnotetext{
${ }^{43}$ Interviewee 2B, Kampala, Uganda, 5 May 2016.
} 
Another interviewee echoed this point while indicating the electoral factors that can undermine tax compliance:

During elections, people don't pay taxes. In this country, the way we have been brought up, is that the money is eaten. Enforcement is low, and if there is a case in court, it will go slowly. Especially the enforcement of taxes will decrease on fisheries, on Lake Victoria and Lake Albert. There are fewer roadblocks and checkpoints, and you are going to see less activity in the commercial divisional court, and fewer tax audits because people use those for politics.... A fisherman for example, may be supposed to pay for a license. Yet if he is a chief and you ask him to pay the license, he will cause an uprising. They don't want that.

[Interviewee 5A, Kampala Uganda, 8 May 2015]

In addition to election-related non-compliance, large companies created by public sector officials contribute to a culture of non-compliance with taxation. Members of parliament are often involved in these large companies, and use their political influence to avoid having to pay taxes.

A scandal concerning the misuse of donor funds occurred in Uganda in late 2011 at roughly the same time, and donors responded similarly. The Ugandan government responded to the loss of donor revenue by focusing more intently on raising domestic revenue. The Ugandan government met the challenge by combining the introduction of new taxes along with new administrative reforms that meant to streamline the process and thus raise revenue. The response of the Ugandan government has been more open to raising revenue more directly, rather than only cutting expenditures and streamlining tax administration. As one report explained,

In 2014, in the context of drastically reduced BS and the need to control fiscal deficit, [the government of Uganda] has taken renewed actions to address the problem. As of 1 July 2014, Parliament approved the elimination of many VAT exemptions. In addition, several zero-ratings for some goods were eliminated and corporate income tax base was expanded. Excise duties were also increased on 
fuels, sugar and money transfers. [Joint Evaluation Draft Report, April 2015, page 20]

While the effectiveness of these tax reforms is yet to be seen, the basic response of the Ugandan is straightforward: In the face of declining donor aid in the form of budget support, the governments have been forced to take steps to account for the loss of revenue.

Yet Uganda has not been able to deliver the revenue needed to make up for the loss of budget support. One basic problem to increasing tax revenues that the Ugandan government faces is the narrow tax base, while expanding the tax base is difficult given the informal nature of the economy. As one interviewee explained,

[O]ur country is working towards increasing the percentage of domestic revenue to finance the budget... [Yet the government is] taxing the same people. The net is too small to include a big proportion of people. There are sectors that have the potential to raise revenue, but are difficult to tax: informal sectors like agriculture, informal businesses. What [the government has] done is pump those individuals they could for several taxes. [Interviewee 5B, Kampala Uganda, 8 May 2015]

In spite the efforts to increase domestic revenue, the government has resorted to cutting expenditures and securing loans to make up the revenue shortfall. The government has even responded to the loss of donor support by cutting expenditures in sectors that have traditionally received high levels of donor support. Instead, the government has been financing its development priorities through loans, often from foreign lenders such as China:

Concessional loans are reducing and come with conditions, so government has opted to go out for other loans. The government now has shifted to getting more money from the Chinese. These loans come without conditions, but the government needs the capacity to pay them back. These loans are funding the 
infrastructure. The World Bank will build hospitals, the African Development Bank is involved in fisheries, while the Chinese will build huge infrastructure projects. [Interviewee 5A, Kampala Uganda, 8 May 2015]

The increasing willingness of the government to turn to non-traditional loans to finance its priorities has been a source of concern among donors who argue that the government should focus on the delivery of social services rather than infrastructure. The government in turn argues that the infrastructure projects will boost economic activity in the long-run, and so sacrificing social services in the short term is acceptable given the government's scarce resources.

\section{CONCLUSION}

In conclusion, this chapter argues that foreign aid lowers tax compliance because it undermines the fiscal bargain between the state and citizen, and makes tax enforcement less likely by the state. By undermining the fiscal bargain, aid may contribute to lowered state capacity. I find empirical support for the hypothesis that higher levels of aid projects correlate with lower levels of tax compliance for Uganda. The interview evidence shows that donors themselves are aware of the potential problem in aid undermining long-term state development, although there was not a consensus that aid was having this effect. The empirical results shown here provide some support for the concern that aid is indeed having a negative impact on state development through its effect on tax compliance.

One future avenue of research on the question of how aid affects revenue generation includes collecting more subnational data on local government budget and 
spending patterns. Currently, I assume that aid projects lead the local governments to consume the portion of funds that would otherwise go to public sector goods. Clearly, future research needs to examine how local government spending and consumption patterns change in relation to local aid flows. Secondly, future research ought to differentiate the effects on tax compliance of subnational aid projects that come in the form of grants from those that are loans. While grants may be more detrimental to revenue generation than loans, so far this proposition has only been tested at the national level (Gupta et al. 2004).

One policy implication from this analysis is, if donors insist upon allocating aid projects at the local level, they need to be sensitive to the effect of aid on the generation of local revenue. Applying conditionality to the disbursement of aid projects, such by requiring matching funds from local governments before disbursing aid, may help to reduce the negative effect of aid on tax compliance.

This chapter provides evidence that at the sub-national level in Uganda, aid is associated with higher levels of refusals to comply with taxation. To determine whether this result is an artifact of Uganda requires examining whether the result holds more broadly or not. The next chapter examines the relationship between aid and tax compliance in a wider set of countries. 


\section{Chapter 3 Aiding Dependency: A Cross-National Analysis of Foreign Aid and Tax Compliance}

Foreign aid is a critical tool employed by the international community to build state capacity in the developing world. The interests of the international community in doing so are clear: weak states are often sources of terrorism, civil war, and other activities that can affect not only their neighbors, but as seen in the example of Syrian refugees fleeing to Europe, the effects of weak states can affect developed countries as well.

Yet the effectiveness of foreign aid in bolstering state capacity is a subject of debate. One school of thought, rooted in the aid dependency literature, has argued that aid creates the incentives to perpetuate the conditions that create the need for foreign aid (Moyo 2009). Thus, rather than bolstering state capacity, aid keeps weak states weak. The other school of thought emphasizes how foreign aid can provide the financial resources and technical assistance to improve state capacity (Moss, Pettersson, van de Walle 2005).

One key mechanism whereby aid might help or hinder the development of state capacity is through its effect on tax revenues. Aid may serve as a source of non-tax revenue that will allow the state to function while avoiding the costs associated with taxation (Morrison 2014). Indeed, a state's ability to raise its own revenues is often used as an indicator of overall state capacity (Hendrix 2010, Young 2009), and is important for a state's long-term political and economic development. 
Yet there is here too an ongoing debate on whether aid lowers tax revenues, increases tax revenues, or has no consistent effect at all (Morrissey 2015). This debate tended to proceed at two levels. The first level is empirical, in that one strain of the literature has attempted to identify whether countries that receive foreign raise less taxes than those that do not receive foreign aid, or at least receive foreign aid at reduced levels. The other level for this debate has been theoretical, and has received much less attention than the empirical debate.

This chapter aims to move the debate forward on aid and tax revenues, and thus the debate on aid and state capacity more generally, by looking at the effect of aid on tax compliance. Tax compliance is an important component of tax revenues and the relationship more generally between state and society. On the one hand, if people are incentivized to not pay taxes either by engaging in so-called "black market" or informal economic activity, the ability of the state to raise its own revenues will be hindered. On the other, the decision of people to pay taxes or not is a key indicator for the nature of the relationship between state and society: People that pay taxes are more likely to demand accountability and representation than those who do not pay taxes (Martin 2014, Ross 2004).

The argument purposed in this paper is that aid undermines tax compliance due to two key mechanisms. First, and building off of the literature cited previously, aid allows the state to underinvest in tax enforcement. Tax enforcement is costly, both operationally in terms of having to fund a tax extraction apparatus that can raise the taxes, and politically due to the likelihood of increasing demands for accountability and 
representation that often accompany higher levels of tax revenues (Ross 2004). Secondly, aid can provide services that substitute for the state-provision of services. This can lead citizens to be less reliant on the state, and thus interrupts the virtuous cycle of citizens making demands on the state, the state responding with taxes and public services, which leads to greater demands, and so on.

However, despite a large literature on aid and tax revenues more generally, the effect of aid on tax compliance remains a remarkably understudied topic. This chapter helps to address this gap by leveraging the fifth round of the Afrobarometer survey, which includes a question that asks the respondent whether she had refused to pay taxes in the past year, and if so how often. The chapter analyzes the effect of foreign aid on reported refusals to comply with taxation. Using a multilevel logistic regression of aid levels on whether respondents reportedly refused to pay taxes at least once in the past year, this paper finds support for the overall argument. The chapter also provides evidence for the causal mechanisms of the argument, by showing that the effect of aid on reducing tax compliance increases as people believe that they will not get caught for refusing to pay taxes and as people are willing to trade lower state services for lower taxes. An instrumental variable analysis is used to show that the observed effect is not due to countries with higher levels of refusals to pay taxes receiving more foreign aid.

\section{LITERATURE REVIEW}

The question of whether aid helps or hinders taxes is important because of the close 
relationship between tax revenues, state capacity, and development more generally. The relationship between the sources of public finance and the nature of governing institutions was powerfully articulated by Joseph Schumpeter, who noted that

The spirit of a people, its cultural level, its social structure, the deeds its policy may prepare - all this and more is written in its fiscal history.... The public finances are one of the best starting points for an investigation of society, especially though not exclusively of its political life. [Schumpeter (1919) 1934: 7]

Tax revenues are also a key component of state capacity: As argued by Besley and Persson, "the power to tax lies at the heart of state development" $(51,2013)$. The power to tax is on the one hand an indicator of state strength, with high tax revenues suggesting that the state has successful penetrated the society it governs and has the bureaucratic efficiency to deliver the tax revenue into the state treasury. On the other, high tax revenues contribute to a stronger state that can deliver on pubic services such as defense and welfare-related spending.

Whether aid helps or hinders tax revenue, and economic more generally, is a debate nearly as old as the international aid regime itself. Nicholas Kaldor argued that developing an indigenous capacity for taxation is necessary for sustainable development, but warned that "foreign aid is likely to be fruitful only when it is a complement to domestic effort, not when it is treated as a substitute for it" $(410,1963)$. Critics of foreign aid pointed out that foreign aid created an incentive for recipient states to perpetuate the need for aid by essentially subsidizing unproductive policies that may serve the shortterm interest of the governing regime, while undermining long-term development (Bauer 1974).

More recent work on this approached this question through the related literature 
on the so-called "resource curse," which posits that the availability of valuable natural resources, such as oil, can have negative consequences for the development of state institutions and political accountability (Ross 2015). Some scholars have treated natural resources and aid as essentially equivalent in terms of their effects on the host states, and provide a source of financial stability that can inhibit political change (Morrison 2014; see also Ahmed 2012), while other scholars find that aid can bolster democratization when the international system is conducive towards democracy promotion (Bermeo 2016).

Aid is claimed to undermine governance by lowering the dependence of the government on local revenue generation, and thus relieving the incentive for the local population to keep the government accountable (Eubanks 2012, Asongu 2015). Experimental evidence has suggested that citizens are more likely to demand accountability from leaders if they are paying taxes and contributing to public goods, while revenue windfalls can decrease the degree to which citizens demand transparency and accountability (Paler 2013, Martin 2014).

Yet if the literature provides some evidence that aid can have a negative effect on governance, identifying the nature of the relationship between aid and taxation has been more elusive. While some research has documented a negative relationship between aid grants and tax revenues (Benedek et al. 2014), some have claimed that the negative relationship is spurious due to poor quality of the data (Pritchard 2016) and that evidence exists of a positive relationship between aid and grants since the 1980s (Clist and Morrissey 2011). In other work, Morrissey has claimed that any effect on aid and taxation 
is country-specific, and precludes any generalizations on the relationship between aid and taxes (2015).

Less work, however, has examined how aid affects the individual taxpayer's decision to comply with taxation or not. One study found that aid bolsters the perception that the government has the right to enforce taxes (Sacks 2012). An experimental study suggested that foreign aid can raise perceptions of government legitimacy (Dietrich and Winters 2015), which may have ramifications for whether people choose to pay taxes or not (Levi 1988). This chapter contributes to this literature by positing a theoretical relationship between aid and tax compliance, and then demonstrating the existence of a negative relationship between aid and tax compliance through statistical analyses.

Specifically, the previous chapter demonstrated that aid at the local level is associated with a higher level of refusals to comply with taxes in Uganda. This chapter expands upon this finding by including the full set of countries that took in the fifth round of the Afrobarometer survey, which included a question on tax compliance. The relationship identified in Uganda on aid and tax refusals is refined by examining if the effect is observed in other developing countries. This chapter also expands upon the previous by analyzing the proposed mechanisms whereby aid may undermine tax compliance, which are described in detail in the next section.

\section{THEORY}


The argument of this chapter is that foreign aid undermines tax compliance in countries that receive it. There are two primary mechanisms that lead aid to lower tax compliance. The first is the enforcement mechanism. The logic behind this mechanism is that when a state receives aid from donors, this aid allows the state to avoid enforcing taxation while retaining its ability to function and finance its operations. Avoiding a reliance on taxation is attractive to the state, because taxation is costly. On the one hand taxation is operationally costly, in that the state has to pay for tax officers and a taxation apparatus in order to extract taxes. Taxation is also difficult in developing countries due to the high proportion of economic activity that is devoted to agriculture, and subsistence agriculture in particular. On the other hand taxation is politically costly, in that citizens are likely to demand greater levels for representation, accountability, and transparency if they are taxed (Ross 2004). Aid, serving as a non-tax source of revenue, thus allows the state to avoid the costs of taxation and the politically costly demands for accountability that are likely to accompany tax revenues.

The second mechanism is the substitution mechanism. The logic of this mechanism is rooted in the fiscal bargaining theory for tax compliance, which states that tax compliance is the product of a bargaining process in which the state provides services that citizens demand in exchange for taxes that citizens pay in order to receive the services (Levi 1988). This mechanism breaks down if citizens can receive services from another actor than the state that does not demand taxation as a condition for receiving the services. Aid can fund service delivery that enables to donors and the non-state actors they fund to substitute for the state and thus serves as an alternative source of service 
delivery for citizens. By substituting for the state, aid can lower the reliance of citizens on services provided by the state, yet donors rarely make tax compliance or tax revenues a pre-condition of aid disbursements. Thus, citizens are less likely to make demands on the state for services, and so the state does not need to tax citizens to fund the provision of services. In other words, foreign aid can interrupt the virtuous cycle of citizens making demands on the state, which would result in the state taxing citizens, which would in turn lead to greater demands for services and accountability, and so on.

Donors thus undermine the relationship between the state and the citizen by serving as a third-party to the bargaining taking place over taxes. Donors undermine this relationship not necessarily because they have strategic motives that end up strengthening the state in relation to the citizens, although that is possible. But even if donors are development-minded, there actions can result in undermining the state-society relation dues to challenges donors have in ensuring aid effectiveness. Donors struggle to achieve the goals outlined in international accords such as the 2005 Paris Declaration for Aid Effectiveness due to problems relating to a lack of coordination among donors, proliferation of donors, and the tendency among donors to allocate aid to various sectors rather than simply specializing in a limited number.

These arguments imply the following hypothesis:

H1: Tax compliance decreases as aid levels increase. 
The enforcement and substitution mechanisms are not mutually exclusive, and indeed both can be operating to cause a lowered level of tax compliance. Nevertheless, both have separate empirical implications that can illustrate how exactly aid effects tax compliance. Thus, this paper will test separate hypotheses that capture whether the enforcement and/or substitution mechanisms are driving the overall relationship between aid and tax compliance.

H2: As aid increases, greater ease of evading taxes increases the refusal to pay taxes.

The logic of hypothesis 2 , following the enforcement mechanism, is that the state under-invests in its tax enforcement capacity as aid level increase. Thus evading taxes is easier in these countries than in countries with lower aid levels, which have to rely on tax enforcement to raise revenues.

H3: As aid increases, the acceptance of lower government services in exchange for lower taxes is positively associated with the refusal to pay taxes.

The logic of hypothesis 3 , following the substitution mechanism, is that aid can provide services through non-state actors that lower the reliance that citizens have on the state. If the citizens are less reliant on the state, they are more willing to accept lower taxes in exchange for lower services, because aid can make up for the lowered level of state services. The citizens can keep for themselves the funds that they would otherwise spend on taxes. 


\section{RESEARCH DESIGN}

\section{Unit of Analysis}

The unit of analysis for this project is the individual survey respondent from a series of surveys conducted by the Afrobarometer project (2012). The particular survey under examination in this study is the $5^{\text {th }}$ round of the survey, which was carried out in 2011 and 2012. The survey was carried out in a total of 34 African countries, with over 51,587 total respondents. The respondents in the survey are clustered into countries and then regions within countries.

\section{Dependent Variable}

The dependent variable is a survey question collected by the Afrobarometer project in 2011 and 2012 on whether the respondent had reportedly refused to pay taxes in the past year, and if so how often. The answers take the form of not having refused to pay taxes, with a follow up answer that either the respondent would never do that or that the respondent would if it were possible. The 'yes' answers then have follow up answers as to the frequency of non-compliance: once or twice, several times, or often.

Thus, the answers are nominal in terms of the answers that the respondents were recorded as giving: one answer suggesting that the respondent had complied and would never refuse, another answer that the respondent had complied but intended to not comply if possible, and then a series of answers that suggest increasing levels of noncompliance. 
For one set of analyses, the answers are dichotomized into either "No" answers or "Yes" answers. The "No" answers are collapsed into a single response because this paper is only concerned with reported behavior, and not reported intentions to behave in one way or another. The "Yes" answers are collapsed to create a single category for refusal to comply. For another set of analyses, a multinomial regression including all of the answers is used as a robustness check.

\section{Explanatory Variable}

The main explanatory variable is logged aid, which was collected AidData project (Strandow et al. 2011, Tierney et al. 2011). Logged aid captures the level of donor funds that are entering a country, while taking into account recipient countries like Nigeria that receive considerably more than the other countries in terms of their aid allocation. ${ }^{44}$

\section{Interaction Terms}

To test hypotheses 2 and 3, dummy variables used from the Afrobarometer survey are used to approximate the level of state enforcement and the degree to which respondents are dependent upon the state for services. The first variable captures the ease

\footnotetext{
44 Appendix B includes a replication of the main analysis using project counts. Project counts are an underutilized measure for the level of donor activity in a country. (Clist 2011, for example, in his review of the literature on aid allocation does not mention project counts). The amount of funds coming into a country is more closely associated with the enforcement mechanism, in that the more funds are coming in, the more that the state is subsidized from need to collect taxes. Project counts are used because, as suggested in other research on aid and state capacity, the volume of transactions that donors engage in with recipient countries can overwhelm and undermine state capacity (Knack and Rahman 2007). Furthermore, citizens are more likely to be aware of the presence of donors when donors are implementing a large number of projects than simply if a high amount of aid funds are entering the country. Thus, project counts are more associated with the substitution mechanism than the enforcement mechanism.
} 
of avoiding property and income tax. The second question asks whether the respondent is willing to accept lower levels of state services if taxes are also lowered. The logic that connects this to foreign aid is that if people are receiving services that are provided by donors, then they are more willing to accept lower services from the state in exchange for lower taxes because the aid-funded services will make up for whatever diminished level of state services they experience.

\section{Instrumental Variable}

To account for possible endogeneity that low tax compliance may fuel the allocation of foreign aid, an instrumental variable for foreign aid is employed. United Nations Security Council (UNSC) membership is found to be associated with higher levels of foreign aid because countries that sit on the council may be willing to trade their votes in exchange for resources (Kuziemko and Werner 2006). Previous studies have used UNSC membership as an instrument for foreign aid, and have established that UNSC membership has negative economic and political consequences for developing states due to the influx of foreign aid (Bueno de Mesquita and Smith 2010). ${ }^{45}$ A dummy variable for UNSC member between 2006 and 2011 is created, and the countries in the dataset that were on the UNSC during this time include Uganda, Burkina Faso, Ghana, and Tanzania.

\footnotetext{
${ }^{45}$ Bashir and Lim (2013) criticize this finding and argue that the negative consequences of UNSC membership are not due to aid but to the decreased likelihood of international sanction.
} 


\section{Control Variables}

This paper uses a series of individual-level and country-level control variables. It controls for the individual respondent's age and education. Using World Development Indicators, ${ }^{46}$ controls variables are included for gross domestic product, the percent of GDP contributed by agricultural production, the infant mortality rate, and the total population. Using data from the International Center for Taxation and Development, it also includes tax revenues as a percent of GDP (Prichard et al. 2014). A control variable for quality of governance is used from the Governance Matters project ((Kaufman, Kraay, and Mastruzzi 2009). ${ }^{47}$

Given the cross-sectional design of the survey, the control variables are included in the dataset as 6-year averages. The averages are used rather than the values for 2011 to take into account any random fluctuations in the variables across years. Thus, the GDP and tax revenue variables are the 6-year average for the measures for 2006, 2007, and so on up to 2012.

\section{Empirical Models}

The paper uses a multi-level logistic regression for the main analysis. The first level is the individual respondent, while the second is the region, and the third is the country. The dependent variable is dichotomized into respondents who provided either of

\footnotetext{
46 The World Bank, World Development Indicators (2016). Retrieved from http://data.worldbank.org/indicator

${ }^{47}$ Kaufman, Daniel, Aart Kraay, and Massimo Mastruzzi. (2009). Governance Matters VI. Available at http://info.worldbank.org/governance/wgi/index.asp.
} 
the 'No' answers and those who replied with the 'Yes' answers. ${ }^{48}$ The first set of results display the effect of country projects and logged aid on the Tax Refusal dummy variable.

The second model used in this paper is a multilevel multinomial logistic regression. Random effects are included at the country and regional levels. In this empirical model, the most numerous category ("No, never") is the baseline against which all of the other categories are measured. This model is estimated using generalized systems of equations.

To test the mechanisms outlined in hypotheses 2 and 3, separate models are estimated using interactions of country projects and logged aid respectively with dummy variables for whether the difficulty of evading taxes is low and whether the respondent is willing to exchange low taxes for low service provision by the state. Multilevel logistic and multilevel multinomial models are estimated using these interaction terms and their constituent variables. The third and final model estimated here is an instrumental variable analysis. Both the first stage and second stage results are displayed.

Marginal effects are calculated to show the effects of the increase of country projects and logged aid on the predicted probability of having refused to pay taxes in the past year.

\section{RESUlTS}

\footnotetext{
${ }^{48}$ Only $3.76 \%$ of the respondents either have missing responses or replied 'don't know.'
} 
Table 12. Multilevel Logistic Regression with Logged Aid

\begin{tabular}{|c|c|}
\hline Variables & Tax Refusal \\
\hline Logged Aid & $\begin{array}{l}0.341^{*} \\
(0.151)\end{array}$ \\
\hline Tax Revenue (\% of GDP) & $\begin{array}{c}1.337 \\
(1.343)\end{array}$ \\
\hline Education & $\begin{array}{c}0.0282^{*} \\
(0.00966)\end{array}$ \\
\hline Age & $\begin{array}{l}0.00549^{*} \\
(0.00129)\end{array}$ \\
\hline Agriculture ( $\%$ of GDP) & $\begin{array}{l}0.0283^{*} \\
(0.0124)\end{array}$ \\
\hline GDP & $\begin{array}{l}-0 \\
(0)\end{array}$ \\
\hline Infant Mortality Rate & $\begin{array}{c}0.00107 \\
(0.00338)\end{array}$ \\
\hline Population & $\begin{array}{c}1.81 \mathrm{e}-09 \\
(6.77 \mathrm{e}-09)\end{array}$ \\
\hline Quality of Government & $\begin{array}{r}-0.0865 \\
(0.181)\end{array}$ \\
\hline Constant & $\begin{array}{c}-11.04 * \\
(3.187)\end{array}$ \\
\hline Country & $\begin{array}{c}0.179 * \\
(0.0663)\end{array}$ \\
\hline Region & $\begin{array}{c}0.622 * \\
(0.0706)\end{array}$ \\
\hline $\begin{array}{l}\text { Observations } \\
\text { Number of groups }\end{array}$ & $\begin{array}{c}48,011 \\
33\end{array}$ \\
\hline
\end{tabular}

Table 12 shows the results for the basic multilevel logistic regression, with one column of the table showing the coefficient for aid projects and the other column showing the coefficient for logged aid. The coefficient for logged aid is significant at the $p<.05$ level. As the coefficient is positive, this suggests that more aid increases the likelihood of refusal to pay taxes. For the control variables, the individual-level controls for age and education along with the agriculture variable are both significant and positive, 
suggesting that they are associated with increased refusals to pay taxes. The results for logged aid provide initial evidence in favor of the first hypothesis.

Figure 14. Marginal Effect of Increasing Logged Aid on Predicted Probability of Tax Refusal



Figure 14 shows the marginal effect of logged aid on the predicted probability of someone reportedly having refused to pay taxes. The shape of the line takes the form of an elongated hour-glass, suggesting that there are relatively fewer observations at the far left and far right of the graph than compared to the middle. The substantive effect of increasing logged aid from the minimum number observed to the maximum observed in 
the dataset is to increase the predicted probability of refusing to pay taxes from about .04 to about .11 .

Testing hypotheses 2 and 3

Figure 15. Interaction of Logged Aid and Ease of Evading Taxes

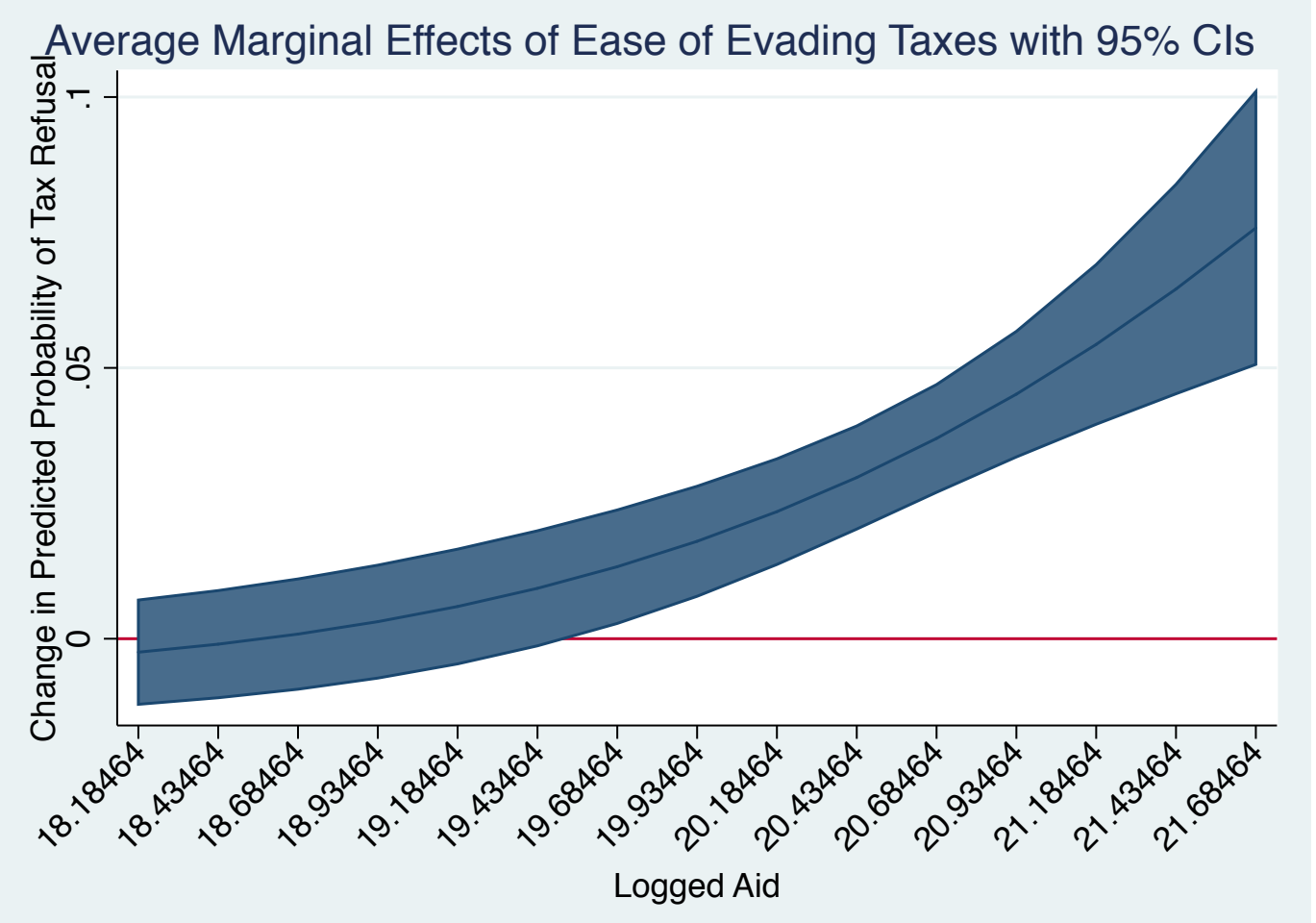

Figure 15 shows the interaction between the ease of evading taxes and logged aid and their effect on the predicted probability of having refused to pay taxes. The effect is not significant across the entire interaction, with the effect becoming significant as logged aid increases to about 19.68. Nevertheless, the results suggest that the predicted 
probability of a respondent having refused to pay taxes increases from about -.01 to about .07 as logged aid and the ease of evading taxes both increase. This is evidence in favor of hypothesis 2 .

Figure 16. Interaction of Lower State Services and Logged Aid

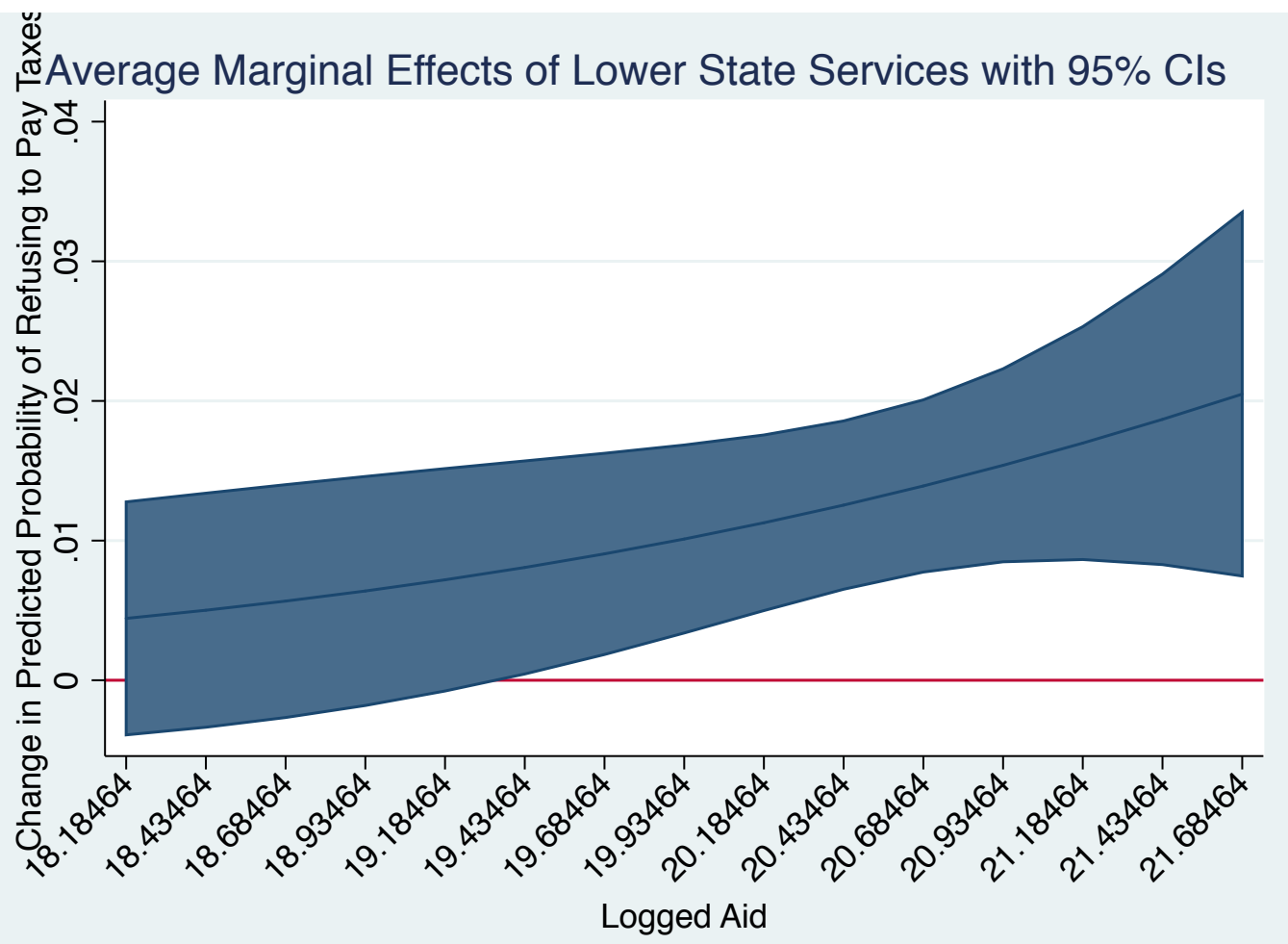

Finally, figure 16 shows the effect of increasing both the willingness to accept lower state services for lower taxes and the amount of logged aid on the predicted probability of refusing to pay taxes. The predicted probability increases from about .005 to just over .02 as both logged aid and the willingness to accept lower state services for lower taxes increase. This is further evidence in support of hypothesis 3. 
Table 13. Multilevel Multinomial Logistic Regression with Logged Aid

\begin{tabular}{|c|c|c|c|c|c|c|}
\hline Variable & No, But Would & Yes, Once or Twice & Yes, Several Times & Yes, Often & Country (Variance) & Region (Variance) \\
\hline \multirow[t]{2}{*}{ Logged Aid } & 0.146 & $0.440^{*}$ & $0.357^{*}$ & $0.449 *$ & & \\
\hline & $(0.167)$ & $(0.104)$ & $(0.128)$ & $(0.188)$ & & \\
\hline \multirow[t]{2}{*}{ Education } & 0.00461 & $0.0285 *$ & 0.000848 & 0.0247 & & \\
\hline & $(0.00692)$ & $(0.0142)$ & $(0.0158)$ & $(0.0161)$ & & \\
\hline \multirow[t]{2}{*}{ Age } & $-0.0107 *$ & -0.00241 & 0.00410 & $0.00745^{*}$ & & \\
\hline & $(0.000954)$ & $(0.00201)$ & $(0.00214)$ & $(0.00216)$ & & \\
\hline \multirow[t]{2}{*}{ Tax Revenue } & 1.211 & 1.590 & $2.742 *$ & 3.061 & & \\
\hline & $(1.449)$ & $(0.934)$ & $(1.129)$ & $(1.605)$ & & \\
\hline \multirow[t]{2}{*}{ Agriculture ( $\%$ of GDP) } & 0.00373 & $0.0342 *$ & $0.0503 *$ & 0.0236 & & \\
\hline & $(0.0137)$ & $(0.00852)$ & $(0.0104)$ & $(0.0151)$ & & \\
\hline \multirow[t]{2}{*}{ GDP } & -0 & -0 & -0 & -0 & & \\
\hline & $(0)$ & $(0)$ & $(0)$ & $(0)$ & & \\
\hline \multirow[t]{2}{*}{ Infant Mortality } & 0.00532 & -0.00195 & 0.00146 & 0.00497 & & \\
\hline & $(0.00383)$ & $(0.00223)$ & $(0.00283)$ & $(0.00430)$ & & \\
\hline \multirow[t]{2}{*}{ Population } & $4.81 \mathrm{e}-09$ & $-9.15 e-10$ & $5.89 \mathrm{e}-09$ & $4.39 \mathrm{e}-09$ & & \\
\hline & $(7.84 \mathrm{e}-09)$ & $(4.25 \mathrm{e}-09)$ & $(5.47 \mathrm{e}-09)$ & $(8.55 \mathrm{e}-09)$ & & \\
\hline \multirow[t]{2}{*}{ Quality of Government } & -0.0894 & -0.138 & 0.0343 & -0.219 & & \\
\hline & $(0.206)$ & $(0.121)$ & $(0.152)$ & $(0.226)$ & & \\
\hline \multirow[t]{2}{*}{ Country } & 1 & -0.0442 & $0.440^{*}$ & $1.018^{*}$ & & \\
\hline & $(0)$ & $(0.136)$ & (0.109) & $(0.118)$ & & \\
\hline \multirow[t]{2}{*}{ Region } & 1 & $1.496^{*}$ & $1.512 *$ & $1.295^{*}$ & & \\
\hline & $(0)$ & $(0.0801)$ & $(0.0755)$ & $(0.0884)$ & & \\
\hline \multirow[t]{2}{*}{ Constant } & -4.789 & $-13.27^{*}$ & $-13.27^{*}$ & $-14.46^{*}$ & $0.288^{*}$ & $0.415^{*}$ \\
\hline & $(3.492)$ & $(2.219)$ & $(2.708)$ & $(3.962)$ & $(0.0852)$ & $(0.0430)$ \\
\hline Observations & 48,011 & 48,011 & 48,011 & 48,011 & 48,011 & 48,011 \\
\hline
\end{tabular}

Standard errors in parentheses

$$
* \mathrm{p}<0.05
$$


Table 13 shows the results for the multi-level multinomial model with logged aid. The coefficient for logged aid is not significant for the "No, but would" answer, similar to the coefficient for country projects in table 12 , while the coefficients for logged aid are all statistically significant and in the direction expected by the theory for the "Yes, once or twice", "Yes, several times", and "Yes, often" answers. For the control variables, the agriculture coefficient is again significant for the "Yes, once or twice" and "Yes, several times" answers, while the age coefficient is significant for the "No, but would" and "Yes, often" answers. The results recorded in tables 12 and 13 provide further evidence in favor of the first hypothesis. 


\section{Robustness checks}

Table 14. Instrumental Variable Results

\begin{tabular}{lc}
\hline Variable & $(1)$ \\
Logged Aid & Second Stage \\
Taxed Revenue & $\left(0.644^{*}\right.$ \\
Education & $2.109)$ \\
& $(1.121)$ \\
Age & 0.0175 \\
& $(0.00997)$ \\
Agriculture & $0.00305^{*}$ \\
GDP & $(0.000934)$ \\
Infant Mortality & 0.00876 \\
& $(0.0107)$ \\
Population & 0 \\
Governance Quality & $(0)$ \\
UNSC & 0.000730 \\
Constant & $(0.00287)$ \\
Sbservations & $-9.87 \mathrm{e}-09$ \\
& $(7.55 \mathrm{e}-09)$ \\
& -0.100 \\
& $(0.132)$ \\
& \\
Stand errors in parentheses. & $* 00.05$ \\
&
\end{tabular}

To provide a robustness check on the main finding that foreign aid increases the refusal to pay taxes, the model in table 12 is re-estimated using United Nation Security Council membership as an instrument for foreign aid. The first stage results are presented. ${ }^{49}$ As shown in table 14, the coefficient for logged aid is positive and

\footnotetext{
${ }^{49}$ See table B3 in appendix B for the full results.
} 
significant, suggesting that the observed effect of logged aid on tax compliance is not due to spurious relationship.

\section{CONCLUSION}

This chapter has argued that foreign aid lowers tax compliance by decreasing the incentive for the state to enforce taxation while also lowering the reliance of citizens on the state. Aid can also subsidize the state and so relieve the state of having to enforce taxation, while aid can substitute for state services and thus interrupt the fiscal bargaining process between the state and the citizenry.

Using a cross-national, multi-level analysis of foreign aid on a survey question regarding tax compliance, this paper finds overall support for the argument that foreign aid lowers reported tax compliance. An instrumental variable analysis of UN Security Council membership and tax compliance provides further support for this overall finding. It also explores the channels by which foreign aid may do so, by showing that increased aid and increased ease of evading taxes are associated with a higher predicted probability of having refused to pay taxes, and that increased aid and increased willingness to accept lower state services for lower taxes are also associated with having refused to pay taxes.

The implications of these findings is that rather than bolstering and indeed increasing state capacity, which is an oft-stated goal for development actors, aid may actually provide the incentive to keep weak states weak. This implication is in line with a 
broader literature that has argued that aid may have had counter-productive effects in recipient countries (Moyo 2009, Easterly 2006).

A future research avenue suggested by this research is to examine when aid actually subsidizes and substitutes for state spending. Such a project would involve examining budgetary data for aid-recipient countries and analyzing for whether aid allocations in a given sector offset state spending on that sector and allow the state to spend its funds on other priorities. If time-series data on budgetary spending could be accumulated, than one could test for the substitutionary thesis by examining whether increases in aid spending in a given sector are met with a corresponding decrease in state spending on that sector. If state spending did not change, it would suggest that the state is not sensitive to donor spending when deciding upon its budgetary priorities, and would provide evidence contrary to the expectation of the substitution thesis. 


\section{Chapter 4 Donor Motives and Aid Allocation in Uganda}

Do foreign aid donors allocate aid strategically or on the basis of need at the subnational level? Recent research has found that donors bypass governments with poorquality institutions and channel the delivery of aid at the subnational level through nonstate actors (Dietrich 2013, Winters 2010). Some have argued that aid can more effectively target areas of need within a country if it bypasses poor-quality government institutions, because governments with poor institutional quality are less able to prevent the misuse of aid through corruption, graft, and rent-seeking (Dietrich 2013). This is despite international efforts such as the 2005 Paris Declaration that called for donors to increase borrower ownership by increasing on-budget aid. Yet it is not clear that even if aid bypasses the central government, it actually targets areas of need at the sub-national level. Examples to the contrary are readily available: other research has found that multilateral donors, such as the World Bank and African Development Bank, in Kenya target electoral constituencies controlled by the governing party coalition (Jablonski 2014, Briggs 2014). Instead, donors may bypass the central government to maintain control over the allocation of the aid at the subnational level, but allocate it to areas controlled by the government to influence the recipient's policy orientation.

The argument of this chapter is that bilateral donors are more likely to deliver aid to government-controlled constituencies than are multilateral donors. Bilateral donors need to justify their aid allocations to domestic publics, and can extract favorable policy concessions from recipient governments if aid is delivered in areas that increase the popularity and support to the recipient government. Multilateral donors are not under this 
constraint, and so can deliver aid on the basis of need. Yet bilateral donors are sensitive to perceptions of aid funding corruption, and by delivering the aid through sub-national channels can maintain more control over the aid rather than if they simply handed over aid funds to the central government. By delivering aid to government constituents, the recipient government can benefit from what serves as a form of 'pork barrel spending' and thus can reciprocate the donors' aid in term of policy concessions.

This chapter tests in the context of a key recipient country, Uganda, the hypothesis that donors target their aid strategically at the subnational level by favoring areas controlled by the governing party of the country. It tests this hypothesis by examining the placement of aid projects following the 2006 and 2011 parliamentary elections to see if aid locations are significantly more likely to be found in governmentheld constituencies. Using new data on subnational aid projects in Uganda, this chapter shows whether donors allocate aid on the basis of need or on the basis of influence at the subnational level. The chapter shows that bilateral and multilateral donor aid allocation patterns are distinct over time, and, of the individual donors examined, the US is found to allocate aid to constituencies held by the governing party in Uganda, the National Resistance Movement (NRM).

Donors may systematically differ in their preferences regarding whether to target areas of influence or areas of need (van der Deen 2011). Some donors may find targeting areas of influence useful if doing so can provide leverage on the recipient government to implement policy reforms wanted by the donor. Other donors may prefer to target need if they are indifferent to policy reforms but are concerned with addressing other goals such 
as poverty reduction and the alleviation of deprivation. Therefore this chapter tests for heterogeneity in donor motivations by first analyzing donor behavior according to whether they are bilateral or multilateral organizations, and then examining the behavior of 4 bilateral and 4 multilateral donors. ${ }^{50}$ Multilateral donors significantly disfavor NRMcontrolled districts, but only after the 2011 elections. Only the US, of all donors examined, is found to significantly favor NRM-controlled areas after both elections.

These findings are substantively important because they show that efforts to target aid directly at the subnational level do not necessarily result in aid that is more targeted on need rather than maximizing strategic influence. While some donors do seem to target aid on need at the subnational level, such as Austria and multilateral organizations like the World Bank and European Union, contrary to the findings in Jablonski (2014) and Briggs (2014), others like the US target their aid strategically. Rather than concluding that donors are simply attempting to maximize strategic influence on the recipient government (Faye and Niehaus 2012), my findings are more consistent with the more nuanced interpretations of donor behavior found in Heinrich (2013) and van der Deen (2011), that donors' motivations over favoring strategic or altruistic uses of aid can shift over time and differ across donors.

\footnotetext{
50 As elaborated further in the research design section, the individual donors are selected according to whether they have sufficient observations to estimate a model after both 2006 and 2011. The bilateral donors examined individually include Austria, Ireland, Japan, and the United States. The multilateral donors examined individually include the African Development Fund, the European Union, the International Development Association, and the United Nations Development Programme. See table 1 for a complete listing of donors in the dataset.
} 


\section{BACKGROUND: AID AND Elections IN UGANDA}

Since its independence from Britain in 1962, Uganda has had only held four multiparty parliamentary elections. The first was the pre-independence elections in 1962 , and elections were not held again until 1980 after Idi Amin, the military dictator who ruled from 1971-1979, had fled the country. The next multiparty parliamentary elections were not held until 2006, despite having held presidential elections in 1996 and 2001. Participation by political parties during these elections was outlawed prior to the 2006 elections, leading some scholars to label Uganda during this period as a "no-party democracy" (Carbonne 2008).

The National Resistance Movement (NRM) is the governing party in Uganda, and has dominated Ugandan politics ever since overthrowing the government of General Tito Okella Lukwa in 1986. The leader of the NRM, Yoweri Museveni, has been the president of Uganda also since 1986, having won election and re-election in presidential elections in 1996, 2001, 2006, and 2011. Museveni won these elections by large margins, garnering $75 \%$ in $1996,69 \%$ in $2001,59 \%$ in 2006 , and $68 \%$ in 2011 . Multiparty elections in Uganda were only reintroduced into the country in 2006. The NRM have been just as successful in recent parliamentary elections, winning 142 out of 205 (69\%) seats in 2006 and 164 out of $263(62 \%)$ seats in 2011.

Despite initially providing support for Museveni, donors' support for the Ugandan president has waned in recent years due to concerns about corruption and laws that criminalized homosexual behavior. During the 1990s, Museveni was considered one of Africa's so-called new leaders who were expected to lead their countries towards 
economic and democratic reforms (Hauser 1999). Donors rewarded Uganda's liberal economic reforms with development aid (ibid). Paradoxically, the support that donors gave to the country undermined their efforts to curb corruption in the country, giving rise to periodic crises surrounding new disclosures of aid-fueled corruption (Tangri and Mwenda 2006). Several European donors, including the United Kingdom, suspended aid to Uganda over concerns that individuals in the prime minister's office were stealing foreign aid funds allocated for poverty alleviation. ${ }^{51}$ The passage of a law that criminalized homosexual behavior led to further aid sanctions against the country (Plaut 2014).

The recent history of democratization in Uganda and the long-standing influence of foreign aid donors in Uganda's politics make it an ideal case to examine the effect of donor motivations on aid allocation. It has been a so-called "donor darling" as a result of not only its democratic reforms, but also its economic reforms that serve to open the economy to international market forces. Additionally, Uganda is in many ways a 'leastlikely' case in which to observe strategic behavior on behalf of donors: it is not a major trading partner with foreign aid donors, nor does it maintain a geographic position of strategic importance. On the other hand, Uganda did maintain a seat on the United Nations Security Council (UNSC) in 2009-2010. Furthermore, Uganda has sent peacekeepers to support the African Union Mission In Somalia (AMISOM) that supports the Federal Government of Somalia's fight against Al-Shabaab militants. So, some strategic behavior may result from donors that attempted to curry favor with Uganda due

\footnotetext{
${ }^{51}$ Reuters. "Britain freezes aid to Uganda over corruption concerns." 16 November 2012.
} 
to its position on the UNSC and its position as a regional security actor. Otherwise, Uganda appears to be a case where strategic behavior among donors is unlikely to be observed.

\section{LITERATURE REVIEW}

Understanding donor motivations for delivering aid is important, as the motivation for giving aid is directly related to how effective aid is in promoting development (Bearce and Tirone 2010; Kilby and Dreher 2010). It is thus not surprising that scholars have been debating where aid goes and why since the beginning of the international aid regime. Early scholars argued that aid was merely an arm of foreign policy, and thus was allocated on the basis of national interests (Schelling 1955). Later scholars argued that a state can have multiple interests, and so aid allocations should be understood as serving different purposes (Morgenthau 1962). The purposes of aid have been reduced down to two: strategic interests and humanitarian principles (McKinlay and Little 1977). The strategic interest of the state as it relates to aid allocation may correspond to variables such as commercial interests in the recipient, national security interests, the influence of the recipient in its region, or the position of the recipient in international organizations like the United Nations Security Council. Secondly, states may allocate aid on the basis of humanitarian principles (Lumsdaine 1993). This perspective argues aid is allocated on the basis of the need of the recipient, which is often measured by poverty. 
Yet all donors need not behave the same in how they allocate aid. Early studies of the US aid allocations determined that its use of aid was primarily to pursue its strategic interest (McKinlay and Little 1977). Studies of individual donor countries had more nuanced results, with one study finding that UK aid followed political, commercial, as well as humanitarian interests (McGillivray \& Oczkowski 1992), while Arab donors were likely to reward poor, Arab, Islamic, or Sub-Saharan countries with aid (Neumayer 2003). The picture that emerges from these studies is that donors give aid for different reasons, which may stem from donor interests, recipient need, or recipient merit (Alesina \& Dollar 2000, Hoeffler \& Outram 2011, van der Deen 2011, Hienrich 2013). Some donors are found to be relatively altruistic (e.g. Nordic counties), some have both egoistic and altruistic motives (UK and US), and some, such as France and Italy, were found to be egoists - such that donors were allocating aid primarily to countries in which they had a strategic interest (Berthélemy 2006).

A key distinction that is employed to explain different preferences and motivations towards aid allocation is between multilateral and bilateral donors. Multilateral donors were traditionally thought to be more responsive to recipient needs than bilateral ones (Maizels \& Nissanke 1984, Frey and Schneider 1986, Tsoutsoplides 1991, Burnside and Dollar 2000). One line of reasoning to support this contention is that because multilateral donors may be less constrained to respond to constituencies and demonstrate benefits of the aid, unlike bilateral donors, multilaterals are able invest aid on the basis of recipient need rather than donor interest. Rodrik has suggests that "multilateral flows are less governed by political considerations than bilateral ones" 
(1996, 176). However, one reason why this argument may not hold is that donors themselves are the constituencies for multilateral agencies, and so the allocation decisions of multilaterals are not immune from the interests of major donors like the US (Stone 2008, Fleck and Kilby 2006; Harrigan, Wang, and El-Said 2006). So whether multilateral aid allocations at the national level are based on need or interest is an open question.

A new line of research on the channel of aid delivery finds that donors allocate their aid differently to countries based on the quality of governance. Winters (2010) finds that the World Bank provides more programmatic and national-level projects in countries that are well-governed, but provides more project and subnational aid to poorly governed countries. Similarly, Dietrich (2013) finds that donors provide aid through non-state actors more frequently when the quality of governance in the recipient country is poor. Both authors assume that sub-nationally allocated aid is delivered on the basis of need, and is isolated from the influence of the recipient government.

However, it is also an open question whether aid that is allocated strategically or on the basis of need at the national level is also allocated or on the basis of need at the subnational level. In other words, inferring donor behavior at the subnational from the motivations for allocation at the national level may suffer from committing an ecological fallacy. For example, Dietrich argues that aid that bypasses the central government is evidence that donors are oriented towards development rather than increasing their strategic influence:

However, if donor governments used aid solely to obtain policy concessions by recipient governments, the use of bypass tactics is puzzling. By definition, bypass reduces the amount of available funds for striking non-developmental bargains with the recipient government. The fact that donors use multiple bilateral aid 
delivery tactics may thus serve as prima facie evidence that donors derive more utility from aid success than the conventional wisdom would want us to believe. [2013, 699]

However, this statement assumes that sub-nationally distributed aid is in fact allocated altruistically within the country. Yet sub-nationally distributed aid may be useful for recipients, if aid that is distributed within government-held electoral districts can provide an advantage for the government during elections by serving as a source of 'pork barrel spending' and public services (Jablonski 2014).

There are only a handful of subnational studies of aid allocation, and the findings on the determinants thereof are mixed. One study of World Bank (WB) and African Development Bank (AfDB) allocations in 27 African countries finds that these donors ignored regional needs but favoritism shaped its placement of aid projects (Öhler \& Nunnenkamp 2013). Jablonski (2014), cited above, also finds that WB and AfDB aid projects are allocated to areas in Kenya that share the ethnic identity of the president, a conclusion also reached by Briggs (2014). Another study found that the quality of bilateral and multilateral aid targeting varies across countries, with some countries having higher quality targeting of aid on need than others (Findley and Marineau 2016).

\section{THEORY}

The question this paper examines is whether donors are more likely to favor constituencies controlled by the Ugandan governing party, the NRM. I argue that allocating aid to government-held electoral districts is evidence of strategic behavior. 
Such aid would benefit the government in several ways: first, by rewarding its constituents for their support of the governing party with aid projects, thus serving as a form of "pork barrel spending." This allows the government to consume for itself the funds that it would otherwise have to pay in rewarding constituents.

Donors can find aid useful if it helps to bring about the policy changes (or the maintenance of policy reforms) that they prefer, such as favorable votes in the $\mathrm{UN}$, economic reforms, and democratization. Donors attempted to use aid as a source of leverage to induce recipients to enact structural adjustment reforms in the 1980s and 1990s, albeit with mixed results. Dollar and Levin (2006) show an increasing tendency for donors to favor countries with democratic institutions and policies that support the rule of law and the protection of private property. Claessens et al. (2009) also show a trend among bilateral donors to greater selectivity to democratization and policy environment of the recipient when making aid allocations.

Foreign aid can enable donors to pursue their preferred policy reforms in recipient countries by serving as both a carrot by serving as a reward for desired behavior and a stick by threatening to remove it. The provision of foreign aid to the constituents of a government can bolster the support for the regime and thus lower the costs for a regime to democratize and serve to stabilize a country undergoing economic shocks. By threatening to take away the aid, and thus deprive the recipient government of a revenue stream that it benefits from, donor governments may have a source of leverage that they might otherwise not have. 
However, the 'carrot' value of aid, or the ability of the aid to appease the recipient and induce the desired behavioral outcome, likely outweighs the 'stick' value of the aid, which is only as strong as the ability of the donors to coordinate and enforce the decision to remove aid. As has been documented thoroughly, the ability of donors enforce conditions on aid is poor (see Svensson 2000 for an analysis of the difficulties with aid conditionality). Furthermore, a recipient government can simply kick out foreign aid agencies if it believes that the agencies are acting in a manner detrimental to its interests. ${ }^{52}$ Thus, appeasement behavior of funding favorable areas is more likely than punishing behavior of funding opposition areas to undermine the NRM.

Allocating the aid sub-nationally ensures that the donor retains some degree of control over how the aid used, unlike a financial transfer like budget support that is more difficult for donors to track. Donors do seem to prefer avoiding the appearance of funding corrupt governments (as evidenced by the fallout from the corruption scandal in Uganda mentioned above), because creating that appearance can result in pressure from domestic publics that prefer not to have their taxes go to such ends. Allocating aid sub-nationally in the form of a service provision is easier for foreign aid agencies to defend to domestic publics, but can still be used by the donor to create leverage with the recipient government by implementing the project in a favorable area.

\footnotetext{
52 For example, the Sudanese government kicked several humanitarian organizations out of the country in 2009 after the Sudanese president, Omar al-Bashir, was indicted by the International Criminal Court. The government of Sudan has suspected humanitarian organizations have provided evidence of alleged misconduct by the Sudanese government to the court. (See New York Times, March 23, 2009, "Aid Groups' Explusion, Fears of More Misery," < http://www.nytimes.com/2009/03/23/world/africa/23darfur.html> accessed January $16^{\text {th }}, 2015$ at 4:44pm.
} 
As discussed above, the literature on the aid allocation policies of multilaterals suggests that while they are not immune from strategic considerations, they are more altruistic than bilateral donors on average. If that finding is correct, the following hypothesis should hold:

H1: Bilateral (multilateral) donors allocate more (less) aid to constituencies controlled by the governing party of Uganda.

The following section outlines the data that is used to test this hypothesis.

\section{RESEARCH DESIGN}

\section{The Unit of Analysis}

The primary unit of analysis is the district in Uganda. Getting accurate information on the number, name, and location of constituencies in Uganda is surprisingly difficult, because the number of constituencies has increased by nearly double since the 2001 parliamentary elections. The Ugandan government has similarly created new districts and divided previously existing districts into multiple parts. For instance, while there were only 56 districts in 2002, 77 existed in 2006 and 112 by 2011 .

A district level rather than constituency level unit of analysis is used for several reasons. District-level covariates are more readily accessible than constituency-level covariates. Furthermore, as described in greater detail below, more subnational aid information is available at the district level than at the constituency level. The 
constituency-level data represent a subset of the total data set, and so relying on it solely for the analysis may bias the results.

\section{The Dependent Variable}

The data for the dependent variable is the aid project location. Under the auspices of AidData (Strandow et al. 2011, Tierney et al. 2011) and according to the methodology developed by Strandow et al. (2011), I led a team of researchers to assign geographic coordinates to the locations of aid projects at the sub-national level in Uganda. Given that I am concerned with the geographical placement of aid projects by donor at the subnational level, I analyze aid project locations. ${ }^{53}$

The dataset is organized into two cross-sections that represent the period following the first multiparty election in Uganda, held on 23 February 2006, and ends on the date of the second multiparty elections, held on 18 February 2011. The second panel covers the period after the second multiparty elections until late $2013 .{ }^{54}$ Given that the analysis focused on the effects of electoral results on aid allocation, the aid projects that were implemented prior to the 2006 elections are not included in the dataset. The temporal information for the aid projects is based on the effective date, which is the project start date at the time of the project's approval, or when that was not available, the

\footnotetext{
53 The aid projects often have multiple locations, and amount of aid committed to each project location is not available. Other studies attempt to estimate the amount of funds that go to individual project locations, but have to adopt assumptions about how donors allocate the funds between multiple locations. For instance, some studies weight the project locations by population at the regional level (Dionne et al. 2013, Jablonski 2014 (see especially fn. 67)), or distribute the aid funds equally among project locations. This study follows Öhler and Nunnenkamp (2013) and examines project location counts.

54 The last project in the dataset set was signed on 31 December 2013.
} 
signature date, the date on which the agreement for the project was signed. If neither date was available, then the project was not included in the analysis.

There are 954 bilateral and 485 multilateral aid project locations in the dataset, for a total of 1,439 aid project locations. 633 bilateral and 286 multilateral aid project locations are recorded after the 2006 election, while 321 bilateral and 199 multilateral aid project locations are recorded after the 2011 election. Table 15 summarizes the aid project locations per donor after the 2006 and the 2011 elections.

Table 15. Summary of Number of Project Locations by Donor

\begin{tabular}{|l|c|c|}
\hline Donor & $\mathbf{2 0 0 6}$ & $\mathbf{2 0 1 1}$ \\
\hline African Development Fund (AfDF) & 46 & 4 \\
Arab Bank for Economic Development in Arica (BADEA) & 6 & 4 \\
Austria & 31 & 26 \\
China & 12 & 2 \\
Denmark & 4 & 0 \\
European Union & 103 & 52 \\
International Bank for Reconstruction and Development (IBRD) & 1 & 0 \\
International Development Association (IDA) & 67 & 53 \\
Ireland & 27 & 15 \\
Islamic Development Bank (IDB) & 13 & 0 \\
Japan & 99 & 60 \\
Netherlands & 38 & 0 \\
Norway & 55 & 1 \\
Spain & 2 & 0 \\
Sweden & 4 & 24 \\
United Kingdom & 128 & 0 \\
United Nations Development Programme (UNDP) & 31 & 86 \\
United States of America & 233 & 193 \\
\hline Total & 919 & 520 \\
\hline
\end{tabular}


Along with estimating models for bilateral and multilateral donors, models are estimated for individual bilateral and multilateral donors. As not every donor has a sufficient number of project locations to be analyzed separately, I estimate individual models for a total of 8 major donors, including 4 bilateral donors (Austria, Ireland, Japan, US) and 4 multilateral donors (African Development Fund, European Union, United Nations Development Programme, and International Development Association). (Note that table 7 above provided information on the total financial flows from these donors, the total number of aid project locations, and the average amount of aid spent per location.)

\section{Explanatory Variables}

The explanatory variables are the proportion of a district controlled by the NRM following the 2006 and 2011 elections. That is, the electoral unit in Uganda is the constituency, and the voters in each constituency vote for a member of parliament to represent them. Districts, in turn are made up of electoral constituencies, and the number of electoral constituencies per district range from 1 to 5 . The independent variable is the sum of the constituencies for which an NRM candidate was elected to parliament divided by the number of constituencies for the district. The proportion of NRM control at the district level is used as the main independent variable because more aid project information is available at the district rather than the constituency level. The data for which party won the constituency for the 2011 elections are gathered from the Electoral Commission of Uganda ${ }^{55}$ and the information on which party won the constituency for

\footnotetext{
${ }^{55} \mathrm{http}: / / w w w . e c . o r . u g /$ eresults.php
} 
the 2006 election was culled from the record of the parliamentary swearing-in ceremony (Uganda 2006). Finally, the log of the proportion of NRM control is calculated (Fox 2008) to create a normalized distribution. (The results of the regressions are not sensitive to whether the proportion is logged or not.)

\section{The Control Variables}

The variables selected as controls are factors that theoretically may also affect how donors allocate aid sub-nationally that the multivariate analysis must 'hold constant' in order to identify any effect that NRM control may have on aid allocation decisions. One set of factors is the urban and rural population of a district, which is taken from the most recent census in Uganda (Uganda Bureau of Statistics 2014). A second set of factors attempts to capture the level of need in a district, and uses two health-related and one education-related measures. It uses the number of health facilities and the immunization rate in a district, along with the ratio of teachers to students (Uganda Bureau of Statistics 2013). The education variable has information for 2009 and 2013, and these data are used in the 2006-2010 and 2011-2013 panels respectively. Finally, district size as measured in thousand hectare units is included as a control variable. District size is measured by aggregating the size of electoral constituencies that make up the district using data from the Global Mapping of Electoral Districts project (Kollman et al. 2014). 


\section{The Model}

The model is estimated with a negative binomial regression. ${ }^{56}$ The negative binomial regression is similar to the Poisson regression in that it is useful for analyzing count data, but unlike the Poisson regression, it allows the conditional variance to exceed the conditional mean (Long 1997, 230-231). Models using the negative binomial regression are each estimated for bilateral and multilateral donors and then for each of the four individual bilateral and multilateral donors.

To aid in the interpretation of the results of the regression analysis, I describe the incident rate ratio (IRR) for each main independent variable along with including the regression coefficients in the regression tables. The IRR for a given explanatory variable shows the expected percent change in the dependent variable above or below a value of 1 . For example, an IRR of 1.50 suggests that with each unit increase in the explanatory variable results in a $50 \%$ increase in the expected counts in the dependent variable. Values for the IRR less than 1 suggest a decrease in the expected counts for the dependent variable.

\section{EXPLORATORY DATA ANALYSIS}

Prior to estimating the negative binomial regression, it is worthwhile to pause and see what can be learned simply by examining the data. Figures $16-19$ are a series of scatterplots with the aid project data for bilateral and multilateral donors on the $y$-axis and

\footnotetext{
56 Specifically, the negative binomial regression model was estimated using the $n b r e g$ command in Stata 13.1. The replication files including the .dta and .do files will be made available at the author's website.
} 
the proportion of NRM control on the $x$-axis after 2006 and then after 2011. For descriptive purposes, a linear regression line is fitted to the data (Berk 2004).

Figure 16. Bilateral Aid and NRM Control after 2006

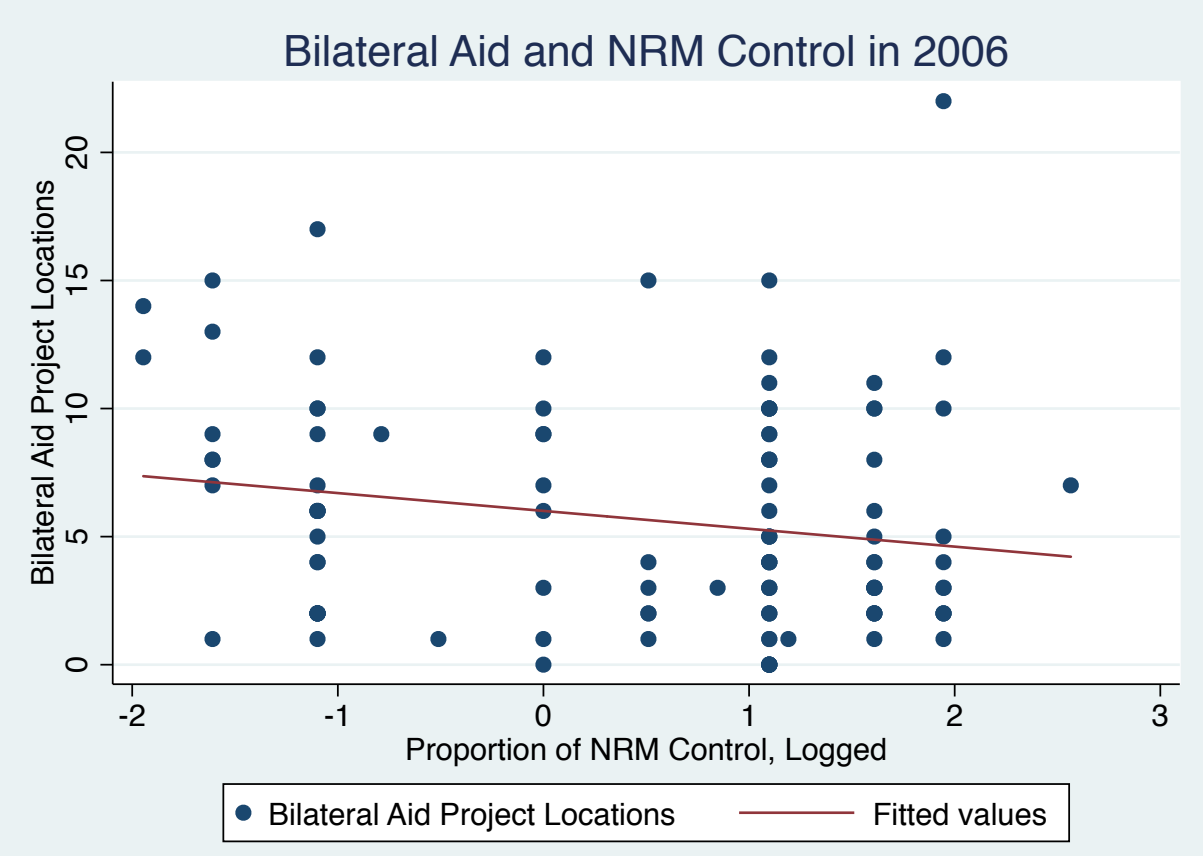

Upon examining figure 16, several trends in the data stand out. First of all, note that there are more points on the right-hand side of the plot than on the left-hand side. This is because the NRM won a majority of the constituencies in the 2006 election and so control a large percentage of the districts. Second, note that the regression line has a negative slope, suggesting that the number of bilateral aid project locations decreases as the proportion of NRM control increases. This initial finding suggests that H1 may not hold for the period following the 2006 election. Next, there appears to be an outlying observation in the upper right-hand corner of the plot. It turns out that this observation is 
Iganga district with some 22 bilateral aid project locations. As the mean number of aid project locations per district is 5.65 and standard deviation is 4.39 , the number of aid proejects in Iganga is some 5 standard deviations above the mean.

Figure 17. Multilateral Aid and NRM Control after 2006

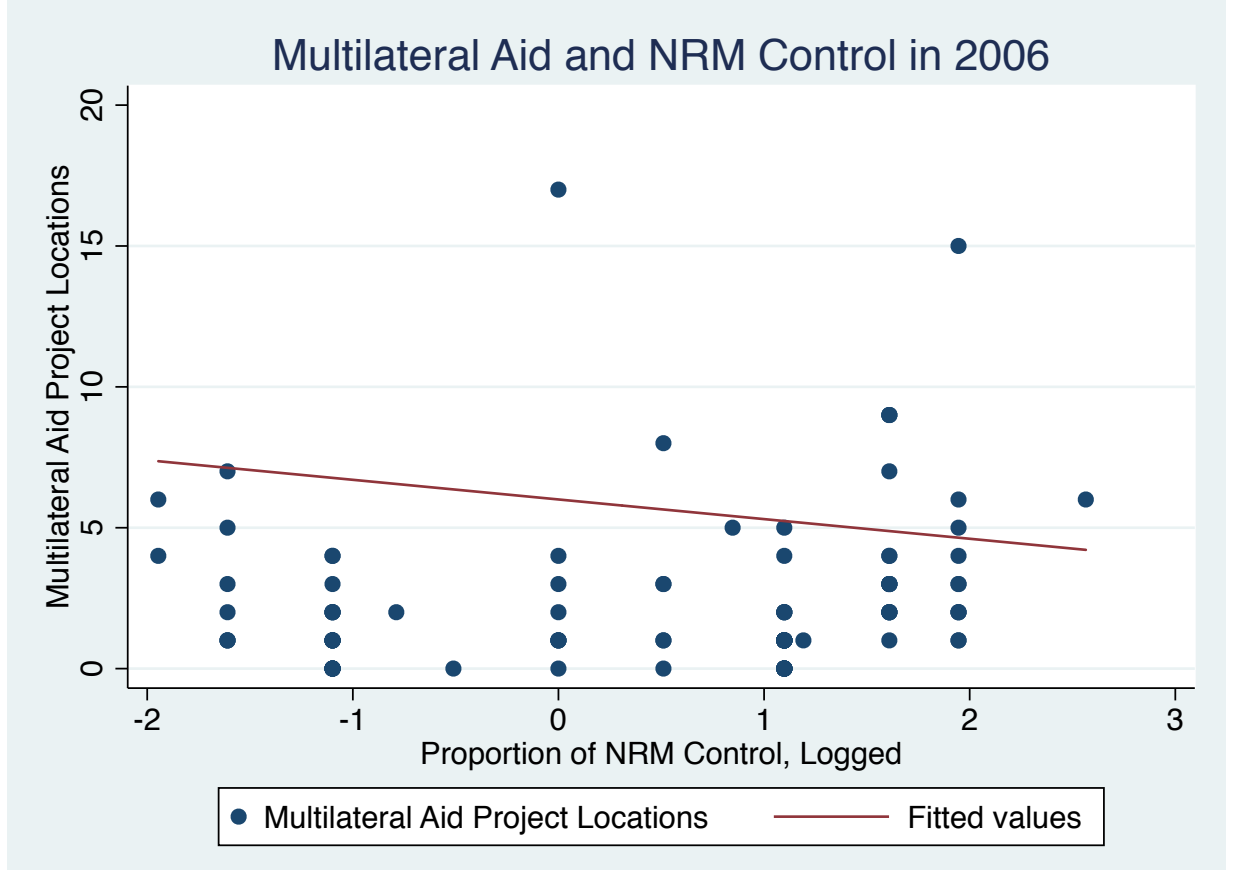

The data for multilateral donors for 2006 follows a similar pattern as for bilateral donors. The regression line fitted to the data has a negative slope, suggesting that multilateral donors may allocate fewer aid project locations in NRM-controlled districts. Additionally, there appear to be two outliers in the data. In this case, the outliers are Kasese district with 17 aid project locations and Kabarole district with 15 project locations. As the average number of multilateral project locations of 2.33 per district and 
the standard deviation is 2.79 , these districts are 6.09 and 5.38 standard deviations above the mean respectively.

Figure 18. Bilateral Aid and NRM Control after 2011

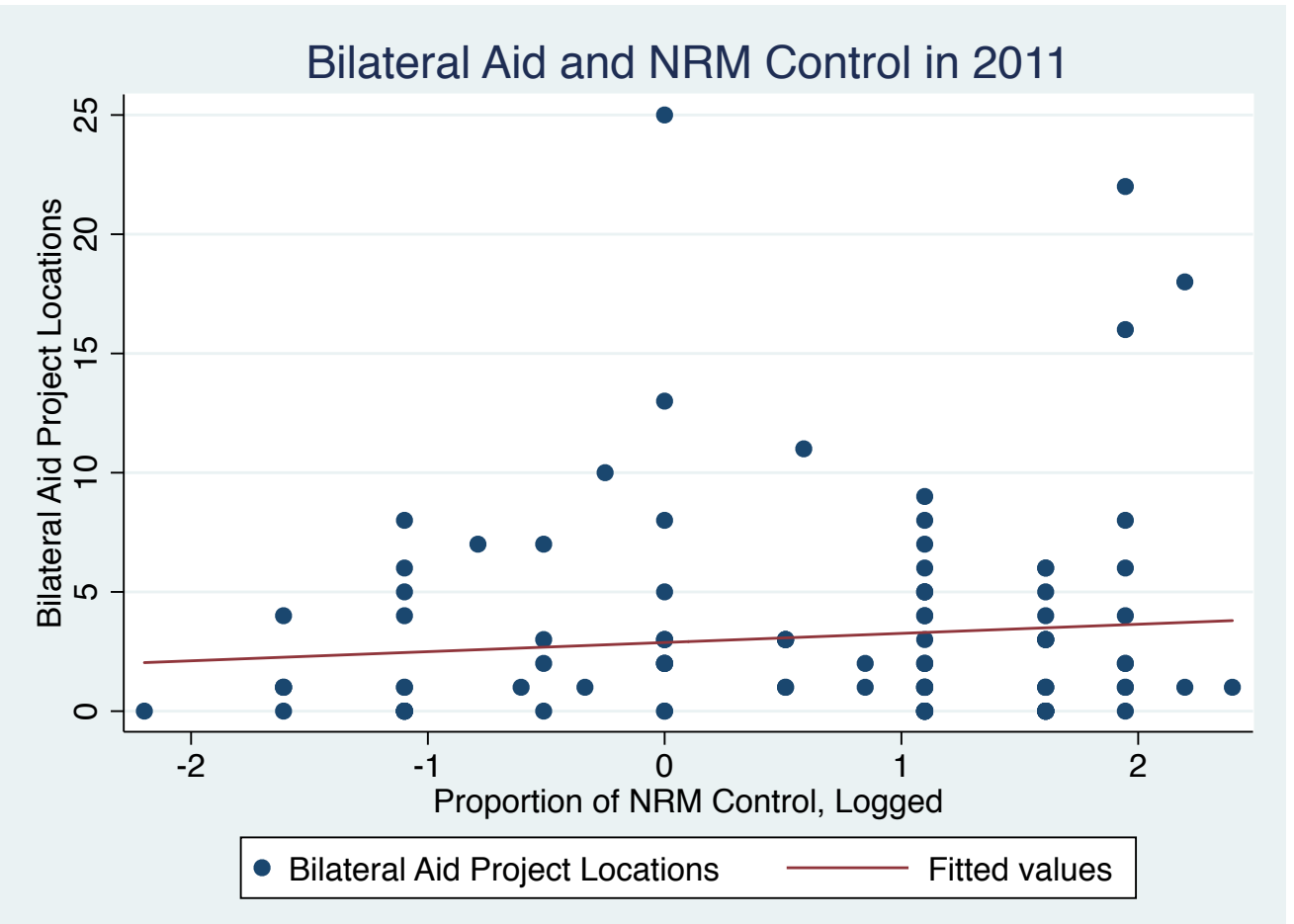

The first and perhaps most important difference between figure 18 and figures 16 and 17 is that the slope of the regression line is now positive. This is the first piece of evidence that bilateral donors favor government-controlled districts. The four dots near the top of the plot suggest potential outliers, including the capital Kampala with 25 project locations, Kisoro district (22), Ntungamo district (18), and Masindi district (16). As the average number of bilateral aid project locations after the 2011 elections is 3.08 with a standard deviation of 4.36 , these districts were 5.73, 5.05, 4.13, 3.67 standard 
deviations above the mean respectively. The data seem to be more prevalent on the righthand side of the plot and seem to fan out towards the top and bottom of the plot, while the data on the left-hand side of the plot are clustered towards the bottom of the plot

Figure 19. Multilateral Aid and NRM Control after 2011

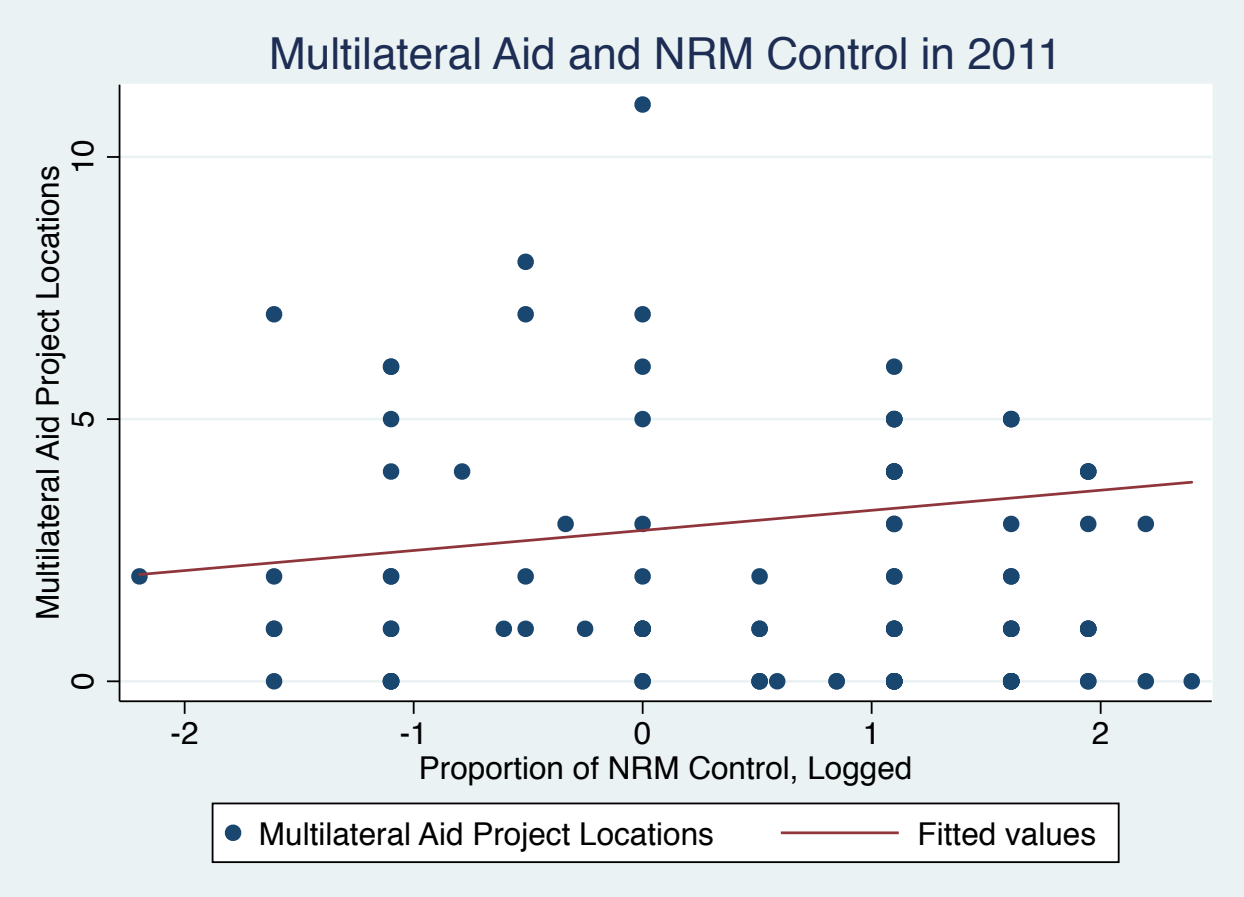

Figure 19 also has the regression line with a positive slope found in figure 18. However, unlike the data in figure 18 that include a number of locations in the upperright-hand part of the plot, the data in figure 19 have a shape that resembles an inverted $\mathrm{U}$. Thus, it is unclear if the regression line in figure 19 describes the trend in the data as well as in the previous figures. The data in figure 19 lack the clear outliers that the other figures seem to have, with fewer observations on the left- and right-hand sides of the plot, and more observations towards the center. 
In summary, the relationships shown in figures 16 and 17 suggest a negative relationship between both bilateral and multilateral aid projects and NRM control after 2006, while figures 18 and 19 show a positive relationship between both types of aid projects and NRM after 2011. These scatterplots provide some initial evidence that contradict $\mathrm{H} 1$ and help to confirm $\mathrm{H} 1$, and suggest that the strategic allocation of aid varies over time.

\section{MAIN RESUlTS}


Table 16. Negative Binomial Results for Bilateral and Multilateral Donors

\begin{tabular}{lcccc}
\hline & $(1)$ & $(2)$ & $(3)$ & $(4)$ \\
VARIABLES & Bilateral & Multilateral & Bilateral & Multilateral \\
& $2006-10$ & $2006-10$ & $2011-13$ & $2011-13$ \\
\hline & & & & \\
NRM 2006, Logged & $-0.117^{* *}$ & 0.0627 & & \\
& $(0.0510)$ & $(0.0714)$ & & \\
NRM 2011, Logged & & & $0.296^{* *}$ & $-0.220^{* *}$ \\
& & & $(0.115)$ & $(0.101)$ \\
Logged Urban Population & 0.0522 & $0.290^{* *}$ & $0.257^{*}$ & $0.363^{* *}$ \\
& $(0.0872)$ & $(0.117)$ & $(0.156)$ & $(0.151)$ \\
Logged Rural Population & 0.0997 & 0.267 & 0.428 & -0.0920 \\
& $(0.171)$ & $(0.227)$ & $(0.304)$ & $(0.259)$ \\
Immunization Rate & 0.000758 & $0.0125^{* * *}$ & 0.00679 & $0.00614^{*}$ \\
& $(0.00223)$ & $(0.00288)$ & $(0.00415)$ & $(0.00325)$ \\
Health Facilities & 0.00413 & 0.00440 & 0.00419 & $-0.0150^{*}$ \\
& $(0.00404)$ & $(0.00430)$ & $(0.00702)$ & $(0.00824)$ \\
Pupil-Teacher Ratio 2009 & $0.0297 * * *$ & 0.000130 & & \\
Pupil-Teacher Ratio 2013 & $(0.00652)$ & $(0.00869)$ & & \\
& & & $0.0158^{*}$ & 0.0109 \\
District Size & & & $(0.00948)$ & $(0.00827)$ \\
& -0.000662 & 0.000445 & $-3.49 \mathrm{e}-05$ & $0.00209^{* * *}$ \\
Constant & $(0.000484)$ & $(0.000667)$ & $(0.000834)$ & $(0.000772)$ \\
& -1.598 & $-6.548^{* *}$ & $-8.551^{* *}$ & -2.846 \\
Lnalpha & $(2.077)$ & $(2.792)$ & $(3.641)$ & $(3.022)$ \\
& $-1.892^{* * *}$ & $-1.804^{* * *}$ & 0.0109 & -0.513 \\
Observations & $(0.333)$ & $(0.452)$ & $(0.207)$ & $(0.314)$ \\
\hline Robust Standard Errors in parentheses, $, * * * \mathrm{p}<0.01, * * \mathrm{p}<0.05, * \mathrm{p}<0.1$ \\
\end{tabular}

The results of the negative binomial regression including four models, one each for bilateral and multilateral aid project locations after 2006 and then after 2011, are displayed in table 16. Model 1, for bilateral aid after 2006, suggests a negative relationship with the level of NRM control. The incident risk ratio (IRR) for NRM control is .88 , suggesting that a one-unit increase in NRM control is associated with a 
$12 \%$ decrease in bilateral aid project locations. Model 2, for multilateral aid after 2006, does not have a significant relationship with NRM control, although the positive value of the coefficient contrasts with the negative slope of the regression line in figure 16. In model 3, the coefficient for NRM control is significant and positive, suggesting that NRM control is positively associated with the number of aid project locations. The IRR for NRM control in model 3 is 1.34 , suggesting that increased NRM control is associated with a $34 \%$ increase in bilateral aid projects locations. In model 4 , and contrary to the slope of the regression line in figure 16, the coefficient for NRM control is negative and significant for multilateral aid. The IRR for NRM control in model 4 is .80 , suggesting that increased NRM control is associated with a $20 \%$ decrease in multilateral aid project locations. 
Table 17. Negative Binomial Regression for Major Bilateral Donors

\begin{tabular}{|c|c|c|c|c|c|c|c|c|}
\hline VARIABLES & $\begin{array}{c}(5) \\
\text { Austria } \\
2006-10 \\
\end{array}$ & $\begin{array}{c}6) \\
\text { Ireland } \\
2006-10 \\
\end{array}$ & $\begin{array}{c}(7) \\
\text { Japan } \\
2006-10 \\
\end{array}$ & $\begin{array}{c}(8) \\
\text { US } \\
2006-10 \\
\end{array}$ & $\begin{array}{c}\text { (9) } \\
\text { Austria } \\
2011-13 \\
\end{array}$ & $\begin{array}{c}(10) \\
\text { Ireland } \\
2011-13 \\
\end{array}$ & $\begin{array}{c}(11) \\
\text { Japan } \\
2011-13 \\
\end{array}$ & $\begin{array}{c}(12) \\
\text { US } \\
2011-13 \\
\end{array}$ \\
\hline NRM 2006, Logged & $\begin{array}{c}-1.466 * * * \\
(0.441)\end{array}$ & $\begin{array}{l}0.0609 \\
(0.206)\end{array}$ & $\begin{array}{l}-0.165 \\
(0.124)\end{array}$ & $\begin{array}{l}0.206 * * \\
(0.0931)\end{array}$ & & & & \\
\hline NRM 2011, Logged & & & & & $\begin{array}{c}-0.583 * * \\
(0.264)\end{array}$ & $\begin{array}{c}3.309 \\
(2.919)\end{array}$ & $\begin{array}{l}-0.0661 \\
(0.190)\end{array}$ & $\begin{array}{l}0.446^{* *} \\
(0.192)\end{array}$ \\
\hline Urban Population & $\begin{array}{c}0.467 \\
(0.475)\end{array}$ & $\begin{array}{l}-0.481 \\
(0.310)\end{array}$ & $\begin{array}{l}0.425 * * \\
(0.213)\end{array}$ & $\begin{array}{l}-0.235 \\
(0.152)\end{array}$ & $\begin{array}{l}0.774^{*} \\
(0.399)\end{array}$ & $\begin{array}{l}-0.214 \\
(0.879)\end{array}$ & $\begin{array}{c}0.195 \\
(0.265)\end{array}$ & $\begin{array}{c}0.393 \\
(0.293)\end{array}$ \\
\hline Rural Population & $\begin{array}{l}-1.054 \\
(1.169)\end{array}$ & $\begin{array}{l}-0.742 \\
(0.698)\end{array}$ & $\begin{array}{c}0.456 \\
(0.429)\end{array}$ & $\begin{array}{c}0.844 * * * \\
(0.293)\end{array}$ & $\begin{array}{l}-0.482 \\
(0.673)\end{array}$ & $\begin{array}{l}-0.572 \\
(1.160)\end{array}$ & $\begin{array}{c}0.549 \\
(0.493)\end{array}$ & $\begin{array}{c}0.531 \\
(0.529)\end{array}$ \\
\hline Immunization Rate & $\begin{array}{l}-0.00816 \\
(0.0181)\end{array}$ & $\begin{array}{c}0.00910 \\
(0.00687)\end{array}$ & $\begin{array}{l}-0.00838 \\
(0.00625)\end{array}$ & $\begin{array}{l}-0.00152 \\
(0.00387)\end{array}$ & $\begin{array}{l}-0.000428 \\
(0.00995)\end{array}$ & $\begin{array}{c}0.0334^{* *} \\
(0.0159)\end{array}$ & $\begin{array}{c}0.00893 \\
(0.00636)\end{array}$ & $\begin{array}{l}-0.00164 \\
(0.00744)\end{array}$ \\
\hline Health Facilities & $\begin{array}{c}0.0336 \\
(0.0264)\end{array}$ & $\begin{array}{l}-0.00966 \\
(0.0266)\end{array}$ & $\begin{array}{c}0.00156 \\
(0.00984)\end{array}$ & $\begin{array}{c}0.00474 \\
(0.00591)\end{array}$ & $\begin{array}{l}0.00319 \\
(0.0153)\end{array}$ & $\begin{array}{c}-0.104 \\
(0.0888)\end{array}$ & $\begin{array}{l}-0.00273 \\
(0.0121)\end{array}$ & $\begin{array}{l}0.00923 \\
(0.0115)\end{array}$ \\
\hline Pupil-Teacher Ratio & $\begin{array}{c}0.0498 \\
(0.0388)\end{array}$ & $\begin{array}{c}0.0126 \\
(0.0155)\end{array}$ & $\begin{array}{c}0.0390^{* *} \\
(0.0155)\end{array}$ & $\begin{array}{l}0.00427 \\
(0.0117)\end{array}$ & $\begin{array}{c}0.0133 \\
(0.0223)\end{array}$ & $\begin{array}{c}0.0262 \\
(0.0351)\end{array}$ & $\begin{array}{c}0.0480 * * * \\
(0.0171)\end{array}$ & $\begin{array}{c}0.0264 \\
(0.0180)\end{array}$ \\
\hline $\begin{array}{l}\text { Pupil-Teacher Ratio } \\
2013\end{array}$ & & & & & 0.0133 & 0.0262 & $0.0480 * * *$ & 0.0264 \\
\hline District Size & $\begin{array}{c}0.00446 \\
(0.00337)\end{array}$ & $\begin{array}{l}0.00386 * * \\
(0.00168)\end{array}$ & $\begin{array}{l}-0.00179 \\
(0.00117)\end{array}$ & $\begin{array}{c}-0.00342 * * * \\
(0.000904)\end{array}$ & $\begin{array}{c}(0.0223) \\
0.00280 \\
(0.00176)\end{array}$ & $\begin{array}{c}(0.0351) \\
0.00393 \\
(0.00345)\end{array}$ & $\begin{array}{c}(0.0171) \\
-0.000887 \\
(0.00136)\end{array}$ & $\begin{array}{l}(0.0180) \\
-0.00227 \\
(0.00160)\end{array}$ \\
\hline Constant & $\begin{array}{c}1.185 \\
(13.30)\end{array}$ & $\begin{array}{c}10.48 \\
(8.906)\end{array}$ & $\begin{array}{c}-11.45^{* *} \\
(5.288)\end{array}$ & $\begin{array}{c}-7.143 * * \\
(3.468)\end{array}$ & $\begin{array}{l}-4.985 \\
(7.418)\end{array}$ & $\begin{array}{l}-0.593 \\
(16.16)\end{array}$ & $\begin{array}{c}-12.44 * * \\
(6.095)\end{array}$ & $\begin{array}{c}-11.76^{*} \\
(6.443)\end{array}$ \\
\hline Lnalpha & $\begin{array}{c}0.378 \\
(0.883)\end{array}$ & $\begin{array}{l}-15.44 \\
(1,004)\end{array}$ & $\begin{array}{c}-0.566 \\
(0.518)\end{array}$ & $\begin{array}{c}-1.089 * * * \\
(0.381)\end{array}$ & $\begin{array}{c}0.481 \\
(0.929)\end{array}$ & $\begin{array}{c}0.908 \\
(0.729)\end{array}$ & $\begin{array}{c}0.347 \\
(0.412)\end{array}$ & $\begin{array}{c}1.118^{* * *} \\
(0.238)\end{array}$ \\
\hline Observations & 75 & 75 & 75 & 75 & 108 & 108 & 108 & 108 \\
\hline
\end{tabular}


The results in table 17 drill down into the behavior of four bilateral donors after 2006 and after 2011 to provide more insight into the findings in models 1 and 3. In model 5, Austria has a negative and significant relationship with NRM control, contrary to H1 above, and with an IRR of .22 and suggesting a 78\% decrease in Austrian aid projects. The next two models for Irish and Japanese aid have no significant relationship with NRM control, although the coefficient for NRM control is negative in the model for Japan. The coefficient for NRM in the model for US aid, however, is significant and positive, providing some evidence in favor of $\mathrm{H} 1$. The IRR is 1.23 , suggesting a $23 \%$ increase in US aid projects as NRM increases. The patterns in models 5-8 are consistent for models 9-12, which cover the period after the 2011 elections. The coefficient for NRM control is negative and significant for Austrian aid, but is positive and significant for US aid. The IRR for Austria and the US is .55 and 1.56 respectively. 
Table 18. Negative Binomial Regression for Major Multilateral Donors

\begin{tabular}{|c|c|c|c|c|c|c|c|c|}
\hline VARIABLES & $\begin{array}{c}(13) \\
\text { AfDF } \\
2006-10\end{array}$ & $\begin{array}{c}(14) \\
\text { UNDP } \\
2006-10\end{array}$ & $\begin{array}{c}(15) \\
\text { EU } \\
2006-10 \\
\end{array}$ & $\begin{array}{c}(16) \\
\text { IDA } \\
2006-10 \\
\end{array}$ & $\begin{array}{c}(17) \\
\text { AfDF } \\
2011-13\end{array}$ & $\begin{array}{c}(18) \\
\text { UNDP } \\
2011-13\end{array}$ & $\begin{array}{c}(19) \\
\text { EU } \\
2011-13\end{array}$ & $\begin{array}{c}(20) \\
\text { IDA } \\
2011-13 \\
\end{array}$ \\
\hline NRM 2006, Logged & $\begin{array}{c}0.136 \\
(0.144)\end{array}$ & $\begin{array}{l}-0.213 \\
(0.355)\end{array}$ & $\begin{array}{l}-0.0601 \\
(0.137)\end{array}$ & $\begin{array}{c}1.087 \\
(0.125)\end{array}$ & & & & \\
\hline NRM 2011, Logged & & & & & $\begin{array}{c}0.843 \\
(0.533)\end{array}$ & $\begin{array}{c}-0.464 * * \\
(0.217)\end{array}$ & $\begin{array}{c}-0.276^{*} \\
(0.151)\end{array}$ & $\begin{array}{c}-0.295 * * \\
(0.117)\end{array}$ \\
\hline Logged Urban Population & $\begin{array}{c}0.466^{*} \\
(0.243)\end{array}$ & $\begin{array}{c}0.128 \\
(0.475)\end{array}$ & $\begin{array}{c}0.306 \\
(0.212)\end{array}$ & $\begin{array}{l}1.499 * * \\
(0.295)\end{array}$ & $\begin{array}{c}0.645 \\
(0.783)\end{array}$ & $\begin{array}{c}0.0718 \\
(0.294)\end{array}$ & $\begin{array}{l}0.486^{*} \\
(0.251)\end{array}$ & $\begin{array}{c}0.715 * * * \\
(0.199)\end{array}$ \\
\hline Logged Rural Population & $\begin{array}{l}-0.163 \\
(0.416)\end{array}$ & $\begin{array}{c}-0.252 \\
(1.388)\end{array}$ & $\begin{array}{c}0.407 \\
(0.450)\end{array}$ & $\begin{array}{c}1.156 \\
(0.390)\end{array}$ & $\begin{array}{c}2.452 \\
(1.713)\end{array}$ & $\begin{array}{r}-0.0859 \\
(0.501)\end{array}$ & $\begin{array}{l}-0.390 \\
(0.372)\end{array}$ & $\begin{array}{l}-0.164 \\
(0.300)\end{array}$ \\
\hline Immunization Rate & $\begin{array}{c}0.00880 \\
(0.00554)\end{array}$ & $\begin{array}{c}0.0515 * * * \\
(0.0168)\end{array}$ & $\begin{array}{c}0.0155 * * * \\
(0.00566)\end{array}$ & $\begin{array}{c}0.999 \\
(0.00566)\end{array}$ & $\begin{array}{l}0.00277 \\
(0.0200)\end{array}$ & $\begin{array}{c}0.0216^{* * *} \\
(0.00644)\end{array}$ & $\begin{array}{l}-0.00698 \\
(0.00560)\end{array}$ & $\begin{array}{c}-0.00129 \\
(0.00460)\end{array}$ \\
\hline Health Facilities & $\begin{array}{r}-0.000855 \\
(0.00791)\end{array}$ & $\begin{array}{l}-0.00925 \\
(0.0337)\end{array}$ & $\begin{array}{c}0.00535 \\
(0.00849)\end{array}$ & $\begin{array}{c}1.006 \\
(0.00592)\end{array}$ & $\begin{array}{c}-0.100 \\
(0.0650)\end{array}$ & $\begin{array}{c}-0.0342 * \\
(0.0196)\end{array}$ & $\begin{array}{c}-0.00842 \\
(0.0121)\end{array}$ & $\begin{array}{c}-0.00640 \\
(0.00783)\end{array}$ \\
\hline Pupil-Teacher Ratio 2009 & $\begin{array}{l}-0.0168 \\
(0.0182)\end{array}$ & $\begin{array}{c}0.0358 \\
(0.0412)\end{array}$ & $\begin{array}{c}0.0126 \\
(0.0167)\end{array}$ & $\begin{array}{c}0.986 \\
(0.0151)\end{array}$ & & & & \\
\hline Pupil-Teacher Ratio 2013 & & & & & $\begin{array}{c}-0.173 * * \\
(0.0827)\end{array}$ & $\begin{array}{c}0.0147 \\
(0.0144)\end{array}$ & $\begin{array}{c}0.0281 * * \\
(0.0129)\end{array}$ & $\begin{array}{l}0.00938 \\
(0.0116)\end{array}$ \\
\hline District Size & $\begin{array}{c}0.000368 \\
(0.00132)\end{array}$ & $\begin{array}{l}0.000236 \\
(0.00335)\end{array}$ & $\begin{array}{c}0.00172 \\
(0.00137)\end{array}$ & $\begin{array}{c}1.000 \\
(0.00112)\end{array}$ & $\begin{array}{l}-0.00328 \\
(0.00459)\end{array}$ & $\begin{array}{c}0.00416 * * \\
(0.00162)\end{array}$ & $\begin{array}{l}0.00168^{*} \\
(0.00101)\end{array}$ & $\begin{array}{c}0.000589 \\
(0.000886)\end{array}$ \\
\hline Constant & $\begin{array}{l}-3.470 \\
(4.932)\end{array}$ & $\begin{array}{l}-5.572 \\
(16.02)\end{array}$ & $\begin{array}{l}-10.53^{*} \\
(5.621)\end{array}$ & $\begin{array}{l}0.00256 \\
(0.0103)\end{array}$ & $\begin{array}{c}-28.60 \\
(18.28)\end{array}$ & $\begin{array}{l}-2.346 \\
(6.101)\end{array}$ & $\begin{array}{l}-2.054 \\
(4.241)\end{array}$ & $\begin{array}{l}-6.119^{*} \\
(3.382)\end{array}$ \\
\hline Lnalpha & $\begin{array}{c}-16.38 \\
(1,457)\end{array}$ & $\begin{array}{c}0.965^{*} \\
(0.519)\end{array}$ & $\begin{array}{c}-0.113 \\
(0.341)\end{array}$ & $\begin{array}{c}8.22 \mathrm{e}-08 \\
(5.40 \mathrm{e}-05)\end{array}$ & $\begin{array}{c}1.080 \\
(1.127)\end{array}$ & $\begin{array}{c}0.610^{*} \\
(0.370)\end{array}$ & $\begin{array}{l}-0.917 \\
(1.035)\end{array}$ & $\begin{array}{l}-14.89 \\
(743.8)\end{array}$ \\
\hline Observations & 75 & 75 & 75 & 75 & 108 & 108 & 108 & 108 \\
\hline
\end{tabular}


Models 13-16 include the results for four multilateral donors after the 2006 elections. None of the coefficients for the NRM control variable are significant, although they are negative for UNDP and EU aid projects. Models 17-20 cover the same donors for the period after the 2011 elections, and in three of these models the coefficients for NRM control are negative and significant. While the coefficients for NRM control are significant for UNDP and IDA are significant at the .05 level, the coefficient in the EU model is significant at the .10 level. The IRR for UNDP, IDA, and EU is .62, .75, and .76 , respectively, and so suggesting decreases of aid projects of $38 \%, 25 \%$, and $24 \%$ as NRM control increases for each of these donors. The results for these models suggest support for $\mathrm{H} 1$, that multilateral donors are less likely to favor areas with greater NRM control.

\section{DISCUSSION}

The results of the foregoing analysis differ considerably from the results of similar studies of subnational aid allocation. Jablonski (2014) finds that World Bank and African Development Bank projects were allocated in regions controlled by the governing coalition in Kenya between 1980 and 2010; Briggs (2014) finds that bilateral and African Development Bank projects were similarly allocated in Kenya between 1989 and 1995; Öhler and Nunnenkamp (2013) find that African Development Bank and World Bank projects between 2005 and 2011 were allocated to regions in which the president was born, and interpret this finding as evidence of favoritism in the allocation of aid projects. 
Here, I find that bilateral allocations were significantly greater in NRM-controlled areas, but only after 2011, while multilateral aid allocations significantly decreased after 2011. Of the individual donors examined, only the US seemed to consistently favor districts with higher level of NRM control and Austria consistently did not favor these areas, while the World Bank, European Union, and UNDP significantly provided less aid after then 2011 elections. (The coefficient for AfDB is positive but not significant.)

The preponderance of the US in terms of the total number of bilateral aid projects seems to explain the different signs on the coefficients for bilateral projects after 2006 (which was negative) and after 2011 (which was positive). Referring again to Table 4, the US with 233 projects after 2006 makes up some $36 \%$ of all bilateral aid allocations. After the 2011 election, however, the US makes up some $60 \%$ of all bilateral aid allocations. The different findings for bilateral donors appear to result from the influence of the US.

Why would the US favor NRM-controlled areas? The US State department notes that

Uganda is a key U.S. strategic partner, particularly through its contribution to the African Union Mission in Somalia. In addition, Uganda and other governments of the region, under the leadership of the African Union and with the support of the United States, have made progress in weakening the LRA and reducing its threat to central Africa. [US State Department 2016] ${ }^{57}$

Thus, the US seems to have strategic interests in Uganda. Of course, whether a donor has strategic interests at the national level does not mean that aid is distributed strategically sub-nationally. An interview with a USAID employee, when asked whether the US directs aid projects sub-nationally to areas controlled by the government, relied "Political

\footnotetext{
57 United States State Department, "U.S. Relations with Uganda." US State Department website, < http://www.state.gov/r/pa/ei/bgn/2963.htm>. Accessed 4 April 2016 at 12:17 pm.
} 
factors have no bearing. It is entirely a-political." ${ }^{58}$ Yet USAID states in its Uganda Country Development Cooperation Strategy 2011-2015, USAID states that it adopts a policy of geographically focusing on some 40-50 districts out of the 112 total districts in the country $(2010,9) .38$ of these districts are selected because they are part of the Government of Uganda's Agricultural Development Strategy (USAID 2012, 5). 19 districts are considered "Mission Focus Districts" (MFDs), in an attempt to boost geographic targeting of aid projects and to coordinate the activities of teams working on different development objectives in alignment with USAID's development strategy (USAID 2012, 5). ${ }^{59}$

While it is not determinative, it is interesting to note that the 19 MFDs selected by USAID have a high average number of NRM MPs in the 2011 elections -- .67. Note again that this score is calculated by dividing the number of NRM MPs per district by the total number of MPs for that district. On the other hand, this high proportion of NRM MPs is close to the overall percentage of NRM MPs following the 2011 elections, who won 263 out of $375(70.1 \%)$ seats in parliament.

What explains the divergent results between this and the previous studies? First off, the previous studies focused heavily on one case, Kenya. The manner in which donors interact with the recipient government and the favor shown to it probably differs across countries. In this analysis, it is likely not coincidental that the downturn in multilateral aid projects after 2011 coincides with highly public corruption scandals that

\footnotetext{
58 Interview, Kampala, Uganda, 1 April 2015.

${ }^{59}$ USAID's development strategy in Uganda includes Economic Growth from Agriculture and Natural Resources, Democracy and Governance Systems, and improved health and nutrition status for focus areas, and a special objective of improved peace and security in Karamoja. (USAID 2012, 5). 
resulted in the suspension of aid and a series of laws criminalizing homosexual behavior that were heavily criticized by Western donors. Yet it is perhaps illustrative of the problems donors face in applying aid sanctions that the US continued aid allocations to NRM-controlled constituencies at the same time that multilateral donors were decreasing these allocations.

\section{CONCLUSION}

The proposition that this chapter explores is whether donors allocate aid strategically at the subnational level. Using subnational aid data for Uganda, I tested whether bilateral or multilateral donors as a group were more likely to allocate aid projects to government-held constituencies following the 2006 and 2011 elections, and also for whether individual bilateral and multilateral donors favored government-held constituencies. Significantly favoring districts with higher proportions of NRM control is interpreted as strategically allocating aid, as these aid projects may benefit the recipient government through constructing popular support for the regime and thereby increasing the leverage donors have over the recipient government.

The findings suggest that donor motivations for aid allocation are heterogeneous. While the US does in fact allocate its aid in a manner open to strategic interpretation, other donors such as Austria do not. The patterns in aid allocation are not constant over time either. The bilateral donors examined as a whole gave less aid to governmentcontrolled constituencies after the 2006 elections, but more after the 2011 elections. 
Multilateral donors significantly favored government-held districts less after 2011, but not after 2006.

The assumption made in this chapter is that the same logic used to test for strategic or altruistic behavior in aid allocations at the national level can be usefully applied to explain donor aid allocations at the subnational level. These findings are consistent with recent research that shows donors allocate aid strategic or altruistic according to the circumstances in the particular country (van der Veen 2011, Heinrich 2013). Instead of approaching the objective function of donors as either strategic or humanitarian, a more useful approach may be to consider how the organizational dynamics of aid agencies affect how they interact with the recipient government and so how they allocate aid. For example, factors such as the average length of tenure of aid agency staff, the length of the aid relationship with the recipient country, the size of the aid agency, the degree to which government personnel are involved in the planning stage of aid projects, the independence of the aid agency office from the central government in the donor country, are fruitful ways of gaining further insight into the sources of heterogeneity in aid delivery among donors.

Additionally, the specific political context of the recipient country can also play a significant role in how donor countries interact with the recipient, and so future analyzes should take into account time-varying factors such as electoral years, membership in the UN Security Council, corruption scandals, and so on. Finally, subnational aid projects are a fruitful subject for spatial dependence models that may be able to capture coordination among donors. For instance, the fact that the US favors NRM-held areas while Austria does not may actually be evidence of coordination among these donors to 
specialize in different parts of the country. Sub-national aid coordination may thus help to explain the heterogeneity of aid allocations by donors. 


\section{Chapter 5 Conclusion}

\section{RECAP OF ARGUMENT AND FINDINGS}

The argument examined in this dissertation is that foreign aid undermines tax compliance by lowering the need for the state to enforce taxation while also substituting for the provision of state services. This is an important issue because, on the one hand, there is a close relationship between the development of the state and its ability to raise its own tax revenue (Levi 1988, Tilly 1992). The provision of state services is contingent on the state's ability to access revenue, while taxation is also linked to greater demands for accountability and representation in the state (Ross 1999, Martin 2014). On the other, states can only raise tax revenue if people actually pay their taxes that are owed. Thus, tax compliance is a key component of state capacity development.

In the introduction, the basic facts about foreign aid and taxation in a key developing country, Uganda, were unpacked. The argument was empirically tested in the second chapter using data on aid projects at the local level in Uganda along with individual-level data on reported tax compliance. The results supported the overall argument on aid undermining tax compliance. These results were then compared to interview evidence collected in Uganda in the spring of 2015. The interviews suggested that donors were aware of the potential problem of aid undermining tax compliance, and the analysis of this chapter suggests that they have valid reasons to be concerned.

The next empirical chapter generalized the study of aid and tax compliance by including all 34 countries that participated in the 2012 Afrobarometer survey. The chapter showed that aid is associated with a higher level of reported refusals to comply with taxes. It also provided evidence for the two causal mechanisms, the enforcement and 
substitution mechanisms, and found that the substantive effect of the enforcement is the larger of the two.

The final empirical chapter showed that aid is not allocated according to need, but instead showed that at least one donor, the United States, allocates aid according to political control at the local level in Uganda. Assuming that need is associated with an inability to pay taxes, the lack of a relationship between the level of need and the placement of aid projects provide evidence that the effect of aid on reported tax compliance is not spurious. Further evidence regarding the relationship between aid and taxes was found through interview and documentation collected in the country during fieldwork in the Spring of 2015.

\section{FUTURE RESEARCH}

At least two research streams are suggested by the project. The first entails moving the dependent variable from local-level tax compliance to local-level tax revenues. This study has focused on tax compliance because it is an important component of the state-society relationship that has largely been overlooked in the debate on the relationship between aid and taxes. Yet there are no tax revenues without tax-payers, so it is important to understand how aid affects the motivations people have to pay taxes. Nevertheless, studying the effect of aid on tax revenues is a logical next step given the close relationship between revenue and compliance, and examining revenues directly has several advantages. Firstly, tax revenues give a clearer picture of the amount of effort the state is putting into tax collections at the local level. Secondly, tax revenues can be disaggregated into different types and sources of revenue, which could have different 
relationships with foreign aid. Integrating the study of aid and tax revenues is a next step in developing a complete picture of the relationship between aid and public financing in developing countries.

A second research area is to examine the relationship between aid and public spending. There has been work on the fungibility of aid (Feyzioglu et al. 1998), examining whether aid spending allows for increased spending on other priorities by recipient countries such as military spending. Less work, however, has examined the fungibility of spending across other state priorities: does increased spending on, say health and education spending by donors, lead the state to work on other sectors, such as transportation and public works projects? Similarly, do recipient states respond to the demands by donors on how to allocate their public funds? Evidence from Uganda suggests that donors and the recipient government can become at odds with each other in terms of the spending priorities of the recipient. Under what cases do these priorities diverge, and when do they converge? When can donors leverage aid in an effort to bring the recipient's spending priorities in line with their own? Answering these questions will help to complete the picture of how aid affects the public financing and public spending priorities of developing countries.

\section{POLICY IMPLICATIONS}

The picture that emerges from this study is that aid can have a negative impact on recipient states, and specifically by undermining tax compliance. One policy implication that a reader may potentially draw is that the solution for increasing tax compliance, then, would include cutting off aid. Yet taking such a step should be measured against other 
potential outcomes of cutting off aid, such as the possibility that shutting off aid wholesale could result in needs not being met that can only be currently met if aid is disbursed. Cutting off aid can also led to political instability and the onset of civil wars (Nielsen et al.2011). Antiretroviral medication, used to combat the effects of HIV, is one example of a need that is entirely supplied by donors (USAID, in fact) that the government of Uganda may not be able to provide if the medication was not funded by foreign aid. Furthermore, donors are unlikely to cut off aid due to the public relations problems they would likely encounter if they did. So simply calling for the cessation of aid flows is an impractical, unlikely solution.

So the more realistic question to ask is, how can practitioners reform aid so as to minimize its harmful effects on tax compliance? I propose several steps donors can take to this end. I suggest donors use aid to:

1. Tie aid disbursements to progress in raising domestic revenue. Donors could set benchmarks for increasing tax revenue as a percentage of GDP that the government would have to meet in order for the subsequent year's aid to be disbursed. Donors can be sensitive to economic shocks that affect the recipient country, such as commodity price shocks, when determining how strictly to enforce the policy. But, tying aid disbursements to increases in domestic revenue is the first step towards encouraging the government to take tax enforcement more seriously. Conditioning aid in this way will be just as much a challenge for donors to enforce effectively as it would be a challenge for the recipient governments to meet, given the problem donors face in coordinating aid flows effectively. The challenges donors face in coordinating aid flows and enforcing aid 
sanctions are well-known, and stem from the different priorities, preferences, and aid allocation systems used by donors.

One way to avoid the coordination problem is for the donors to tie aid disbursements to matching revenues from the recipient government for the particular projects that the donors want to fund, rather than only tying aid to the overall level of domestic revenue mobilized. The recipient government, for example, may be asked to match $15 \%$ of the overall cost of the project with its own funds. The level of matching funds asked for ought to be within the abilities of the recipient government to reasonably match, although donors could have the goal of increasing the percentage of matching funds over time. Yet donors need to stand firm on the threat to not disburse aid for their projects if the recipient government does not in fact match its level of required revenue.

However, there is no reason why donors could not tie aid to both overall increases in raising domestic revenue as well as revenue-matching: For example, donors could "reward" the recipient for successfully meeting its revenue requirements with additional aid disbursements.

2. Widen the tax base. One way to increase domestic revenue and more easily meet revenue-matching requirements is for the recipient government to widen the tax base. Part of the reason for the narrow tax base is that much of the economy is in the so-called informal sector, or the portion of the economy that is untaxed and lies outside of governmental regulation. The operational costs of reaching the informal sector are high, and so donors can play a positive role by subsidizing the operational costs. 
One way that donors can help lower and manage operational costs of taxing the informal sector is to promote taxpayer education. Groups in developing countries, such as SEATINI (Southern and Eastern African Trade Information and Negotiations Institute) in Uganda, have the self-adopted purpose of promoting taxpayer education. The assumption that these groups make is that people are not aware of the taxes that they already pay (because the taxes are factored into the price of goods) and so they can hold the government accountability for how well their tax funds are used. By paying taxes, these groups argue, people can exert influence in the government to respond to their needs. Donors can support the efforts of these groups and can provide the resources to expand them.

The donor community can also support the tax administration by increasing the accessibility of tax stations, either by building new ones or constructing mobile tax stations that can travel to less-serviced parts of the countries. Finally, donors can help strengthen the tax compliance portion of the tax administration: Tax officials in the Uganda Revenue Authority, for example, believe that they are under-staffed and underresourced, which contributes to the problem of effectively enforcing tax compliance. More donor attention in this area could go a long way in increasing tax compliance.

3. Ensure that aid-funded services are managed by the recipient state. Donors should ensure that their activities do not replace or substitute for the state. Insofar as the donorfunded provision of social services runs the risk of allowing the state to pull back from social service provision, donors should recognize the long-term costs of meeting shortterm needs. 
4. Increase donor attention paid to tax issues. Lastly, but most importantly, donors need to devote more attention to tax issues in general. Historically, little donor efforts were made towards increasing tax revenue, instead focusing on large-scale infrastructure investments in the 1960s and 1970s, human capital development in the 1980s, and the restructuring and, indeed, limiting of tax revenues through the structural adjustment plans in the 1990s. In countries like Uganda, donors devoted the majority of their funds towards sectors like agriculture, education, and health, rather than on government administration. While my interviews revealed that donors are becoming more attentive to the importance of ensuring that the recipient government raises revenues, the steps outlined above are concrete ways that donors can pursue that end. 


\section{Appendix A: Interview Schedule}

\section{One-on-One Interview Schedule}

Foreign aid donors have allocated nearly 6 trillion dollars to developing countries to promote development. However, developing countries often suffer from weak state capacity, and in particular low levels of domestic tax revenue. The question this research seeks to answer is: how does foreign aid affect the incentives for the recipient government to raise tax revenues?

Interviews will be fully anonymous, and no identifying information about individuals will be included in any published research without express written consent. The information will be included in the dissertation project and any affiliated research articles and policy briefs that are published from the dissertation.

\section{Introduction}

1. What is your position, and what are your responsibilities?

\section{Aid and Taxes}

2. How does foreign aid shape the tax revenue system in Uganda (or Malawi)?

a. Does the government increase or decrease enforcement depending on whether they receive more or less aid?

b. If there is low aid, how do politicians get enough revenue to cover state expenses?

c. If there are high levels of aid, do they still try to extract taxes?

d. How does this relationship differ at the local government level versus the central government?

e. How do oil futures or expected oil revenues play into the government's fiscal situation?

\section{Aid and State Services:}

3. How does foreign aid affect the public services provided by the state? (If necessary, probe with suggestions like "do they lower services if they receive more aid, or raise services?")

a. How are international aid projects incorporated into the state budget planning process?

b. How much aid goes into the local government planning and output processes?

c. How much of the conditional grants to local governments funded by aid? Do donors have a say in the sectors that the conditional grants are applied to?

d. Does foreign aid spending on one sector lead the state to shift its funds to other sectors?

e. Do politicians follow specific aid projects and/or the overall aid portfolio? (If necessary, probe with "To what extent are politicians knowledgeable about aid projects in their constituencies, and the aid portfolio overall for Uganda and/or Malawi?") 


\section{Aid and Local Politics}

4. How do foreign aid projects affect electoral politics?

a. How do politicians use aid projects in their electoral campaigns and public statements?

b. To what extent do politicians incorporate enforcement of tax collection as a political tool?

c. How do people know when a project is delivered by an aid organization?

d. How do people distinguish when the government is providing services from donorprovided services?

e. How do people reward anyone when they receive services, either from the government or aid donor? What would that reward look like?

\section{Sub-national Aid Projects}

5. What factors influence where aid projects are allocated within countries?

a. If subnational projects vary over the country, does tax collection vary with it?

b. To what extent do donors take into account party control at the local level?

c. Does the government provide suggestions as to where aid projects should go?

d. How are need-related factors taken into account?

e. How does donor coordination play into where aid projects are located?

\section{Channel of Delivery}

6. What are the channels of delivery employed for aid projects, and why?

a. Why does an aid agency choose to implement a project itself or through other non-state actors, rather than giving the aid to the government?

b. Which non-state actors do you deliver aid projects through?

c. When an aid agency implements through a non-state actor, does the state adjust in that area even if it can't touch the funds?

(If time allows) Policy Implications

a. Are you aware of any projects that attempt to condition the disbursement of aid on revenue matching at the parliamentary level and their constituencies?

b. What about district-level governors?

c. Is this sort of conditionality a good idea or not?

\section{Further contacts}

Do you have suggestions as to other individuals in aid agencies, government offices, and CSOs/NGOs with whom I ought to meet? 


\section{Appendix B}

\section{WORDING OF QUESTIONS USED AS INDEPENDENT VARIABLES}

Information on Taxes: "Based on your experience, how easy or difficult is it to do each of the following: To find out what taxes and fees you are supposed to pay to the government?” Answers: 1=Very Easy, 2=Easy, 3=Difficult, 4=Very Difficult (Afrobarometer 2012, 45). ${ }^{60}$ Question 75B.

Other's Avoiding of Taxes: "In your opinion, how often, in this country: Do people avoid paying the taxes that they owe the government?" Answers: $0=$ Never, $1=$ Rarely, $2=$ Often, 3=Always (Afrobarometer 2012, 27). Question 56I.

Owe Taxes: This variable is a combination of several related questions in Afrobarometer, questions 73A-73E: "Regardless of whether you are able to pay them, are you required to pay each of the following, or haven't you been able to find out about this:"

- Value added tax on the food or goods that you buy from shops or traders?

- License fees to local government, for example, for a bicycle, cart, business or market stall?

- Property rates or taxes?

- If you have paid employment, are you required to pay an income tax, that is, a tax deducted from your wages by your employer?

${ }^{60}$ Answers for not applicable, missing, or don't know are not included in the list of answers here because observations with these values are not included in the analysis. 
- If you are self employed, are you required to pay a tax on the earnings from your business or job? (Afrobarometer 2012, 44-45)

Answers: $0=$ No, I am not required to pay, $1=$ Yes, I am required to pay, $7=$ Not applicable.

Ease of Evading of Taxes: "Based on your experience, how easy or difficult is it to do each of the following: To avoid paying the income or property taxes that you owe to government?" Answers: 1=Very easy, 2=Easy, 3=Difficult, 4=Very difficult, 7= Don't have to pay taxes (Afrobarometer 2012, 45-46). Question 75C.

Education: "What is the highest level of education you have completed?" Answers: $0=$ No formal schooling, $1=$ Informal schooling only (including Koranic schooling), $2=$ Some primary schooling, 3=Primary school completed, 4=Some secondary school/ high school, 5=Secondary school completed/high school completed, $6=$ =Post-secondary qualifications, other than university e.g. a diploma or degree from polytechnic or college, $7=$ Some university, $8=$ University completed, 9=Post-graduate (Afrobarometer 2012, 54). Question 97.

Age: "How old are you?" Answers: 18-110 (Afrobarometer 2012, 8). Question 1.

Gender: Assigned by interviewer. 1=Male, 2=Female. Question 101.

Full-Time Job: "Do you have a job that pays a cash income? If yes, is it full-time or parttime? If no, are you presently looking for a job?" Answers: $0=$ No (not looking), $1=$ No (looking), 2=Yes, part time, 3= Yes, full time (Afrobarometer 2012, 54). Question 96. 
Note: Only the answers for "Yes, full time" were used in the analysis.

Government Interviewer: "Just one more question: Who do you think sent us to do this interview?" Answers: $0=$ No one, $1=$ Government (General), $2=$ National/Union government, 3=Provincial/Regional government, 4=Local Government, 5=President/Prime Minister's Office, $6=$ Parliament/National Assembly, $7=$ Government Census/Statistics Office, $8=$ National Intelligence/ Secret Service, $9=$ Education or Social Affairs Department/ Ministry, 10=Tax or Finance Department/ Ministry, 11=Health Department/Ministry, 12=Other Government Department/Ministry, 13=Constitutional Commission, $14=$ National Electoral Commission, $15=$ National Planning Commission, 16=Public Utility Company, 17=NGO, 18=Political Party/Politicians, 19=Research company/ organization/programme (including the Afrobarometer National Partner), 20=Newspapers/Media, 21=University/ school/ college, 22=Private company, $23=$ International organization, $24=\mathrm{God}$ or a religious organization (Afrobarometer 2012, 55). Question 100. Note: Only the answers for "NGO" were used in the analysis.

\section{WORDING FOR QUESTIONS USED IN NEED INDEX}

Electricity: Are the following services present in the primary sampling unit/enumeration area: Electricity grid that most houses could access?

Piped Water System: Are the following services present in the primary sampling unit/enumeration area: Piped water system that most houses could access?

Sewage System: Are the following services present in the primary sampling unit/enumeration area: Sewage system that most houses could access? 
Cell Phone Service: Are the following services present in the primary sampling unit/enumeration area: Cell phone service?

Post Office: Are the following facilities present in the primary sampling unit/enumeration area, or within easy walking distance: Post-office?

School: Are the following facilities present in the primary sampling unit/enumeration area, or within easy walking distance: School?

Police Station: Are the following facilities present in the primary sampling unit/enumeration area, or within easy walking distance: Police station?

Health Clinic: Are the following facilities present in the primary sampling unit/enumeration area, or within easy walking distance: Health clinic?

Market Stalls: Are the following facilities present in the primary sampling unit/enumeration area, or within easy walking distance: Market stalls (selling groceries and/or clothing)?

Answers: $0=$ No, $1=$ Yes, $9=$ Can't determine, -1 Missing

\section{TABLES AND FigureS}


Figure B1. Relationship Between Tax Compliance and Tax Revenue

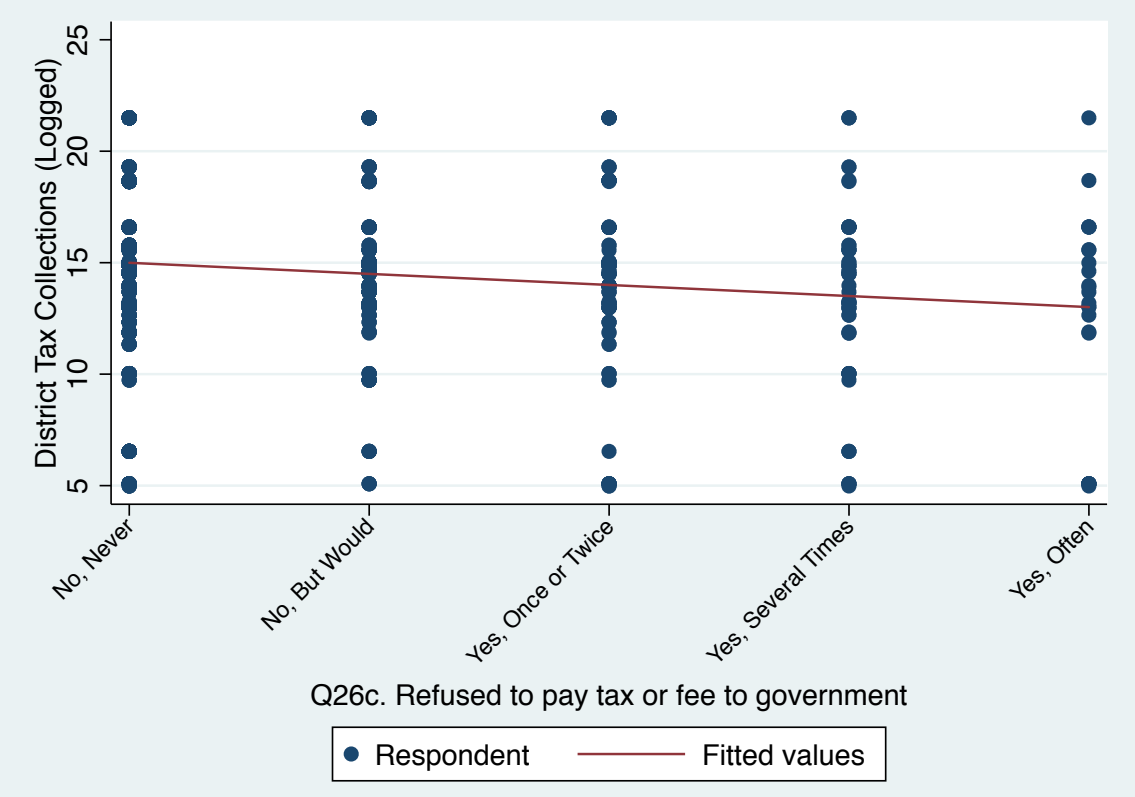

Correlation: -0.1264 
Figure B2. County Aid Projects by Sector

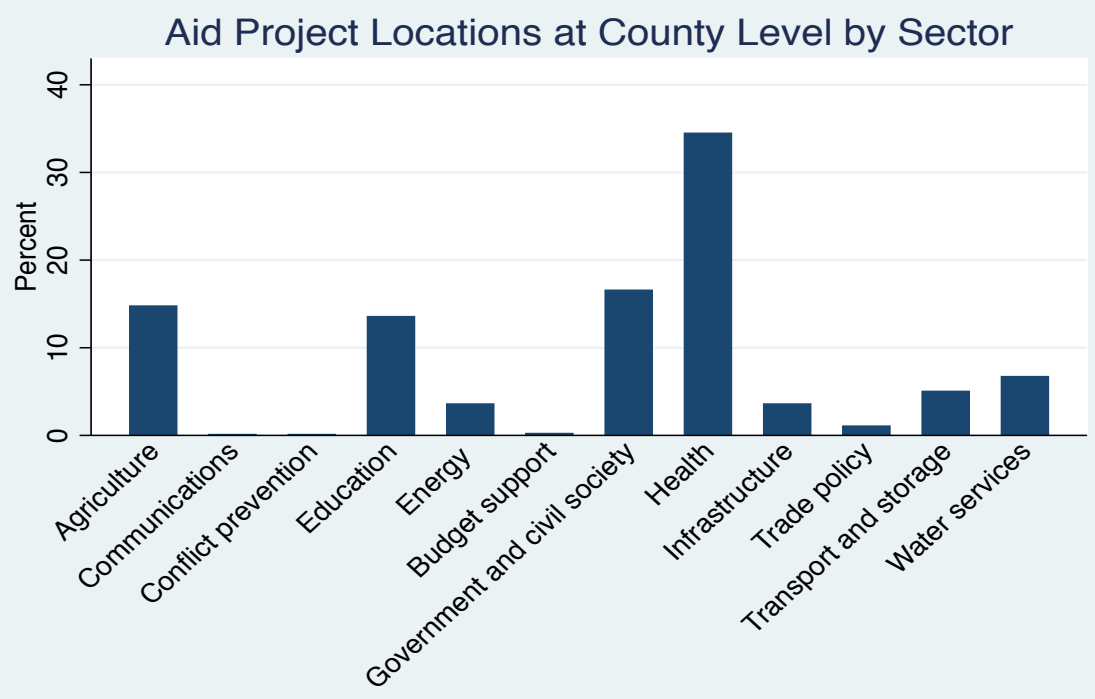




\section{Appendix C}

Table C1. Multilevel Logistic Regression with Country Projects

\begin{tabular}{|c|c|}
\hline Variables & Tax Refusal \\
\hline Aid Projects & $\begin{array}{c}0.000475^{*} \\
(0.000151)\end{array}$ \\
\hline Tax Revenue ( $\%$ of GDP) & $\begin{array}{c}1.229 \\
(1.177)\end{array}$ \\
\hline Education & $\begin{array}{c}0.0281^{*} \\
(0.00966)\end{array}$ \\
\hline Age & $\begin{array}{l}0.00549 * \\
(0.00129)\end{array}$ \\
\hline Agriculture ( $\%$ of GDP) & $\begin{array}{l}0.0296^{*} \\
(0.0114)\end{array}$ \\
\hline GDP & $\begin{array}{l}-0 \\
(0)\end{array}$ \\
\hline Infant Mortality Rate & $\begin{array}{c}0.00142 \\
(0.00316)\end{array}$ \\
\hline Population & $\begin{array}{c}4.60 \mathrm{e}-09 \\
(5.85 \mathrm{e}-09)\end{array}$ \\
\hline Quality of Government & $\begin{array}{c}-0.121 \\
(0.170)\end{array}$ \\
\hline Constant & $\begin{array}{l}-4.711^{*} \\
(0.670)\end{array}$ \\
\hline Country & $\begin{array}{c}0.147^{*} \\
(0.0592)\end{array}$ \\
\hline Region & $\begin{array}{c}0.625 * \\
(0.0711)\end{array}$ \\
\hline Observations & 48,011 \\
\hline Number of groups & 33 \\
\hline
\end{tabular}


Table C2. Multilevel Multinomial Logistic Regression with Country Projects

\begin{tabular}{|c|c|c|c|c|c|c|}
\hline Variables & No, But Would & Yes, Once or Twice & Yes, Several Times & Yes, Often & Country (Variance) & Region (Variance) \\
\hline \multirow[t]{2}{*}{ Aid Projects } & 0.000215 & $0.000608^{*}$ & $0.000555^{*}$ & $0.000438^{*}$ & & \\
\hline & $(0.000189)$ & $(0.000103)$ & $(0.000138)$ & $(0.000193)$ & & \\
\hline \multirow[t]{2}{*}{ Education } & 0.00455 & $0.0296^{*}$ & 0.00124 & 0.0231 & & \\
\hline & $(0.00692)$ & $(0.0142)$ & $(0.0158)$ & $(0.0161)$ & & \\
\hline \multirow[t]{2}{*}{ Age } & $-0.0106^{*}$ & -0.00239 & 0.00413 & $0.00729 *$ & & \\
\hline & $(0.000954)$ & $(0.00201)$ & $(0.00214)$ & $(0.00216)$ & & \\
\hline \multirow[t]{2}{*}{ Tax Revenue } & 1.061 & 1.216 & $2.552 *$ & 2.493 & & \\
\hline & $(1.455)$ & $(0.880)$ & $(1.138)$ & $(1.493)$ & & \\
\hline \multirow[t]{2}{*}{ Agriculture ( $\%$ of GDP) } & 0.000710 & $0.0315^{*}$ & $0.0475^{*}$ & 0.0230 & & \\
\hline & $(0.0139)$ & $(0.00833)$ & $(0.0108)$ & $(0.0143)$ & & \\
\hline \multirow[t]{2}{*}{ GDP } & -0 & -0 & -0 & -0 & & \\
\hline & $(0)$ & $(0)$ & $(0)$ & $(0)$ & & \\
\hline \multirow[t]{2}{*}{ Infant Mortality Rate } & 0.00587 & -0.000928 & 0.00292 & 0.00458 & & \\
\hline & $(0.00395)$ & $(0.00221)$ & $(0.00299)$ & $(0.00412)$ & & \\
\hline \multirow[t]{2}{*}{ Population } & $5.93 \mathrm{e}-09$ & $2.40 \mathrm{e}-09$ & $7.73 \mathrm{e}-09$ & $8.85 \mathrm{e}-09$ & & \\
\hline & $(7.52 \mathrm{e}-09)$ & $(3.82 \mathrm{e}-09)$ & $(5.31 \mathrm{e}-09)$ & $(7.56 \mathrm{e}-09)$ & & \\
\hline \multirow[t]{2}{*}{ Quality of Governance } & -0.133 & -0.212 & -0.0584 & -0.275 & & \\
\hline & $(0.212)$ & $(0.119)$ & $(0.161)$ & $(0.217)$ & & \\
\hline \multirow[t]{2}{*}{ Country } & 1 & 0.0160 & $0.499 *$ & $0.919 *$ & & \\
\hline & $(0)$ & $(0.122)$ & $(0.101)$ & $(0.106)$ & & \\
\hline \multirow[t]{2}{*}{ Region } & 1 & $1.489 *$ & $1.507^{*}$ & $1.351^{*}$ & & \\
\hline & $(0)$ & $(0.0804)$ & $(0.0755)$ & $(0.0876)$ & & \\
\hline \multirow[t]{2}{*}{ Constant } & $-1.967 *$ & $-4.934 *$ & $-6.575 *$ & $-5.650 *$ & $0.310^{*}$ & $0.395 *$ \\
\hline & $(0.825)$ & $(0.502)$ & $(0.651)$ & $(0.860)$ & $(0.0893)$ & $(0.0406)$ \\
\hline Observations & 48,011 & 48,011 & 48,011 & 48,011 & 48,011 & 48,011 \\
\hline
\end{tabular}


Figure C1. Marginal Effects of Increasing Aid Projects

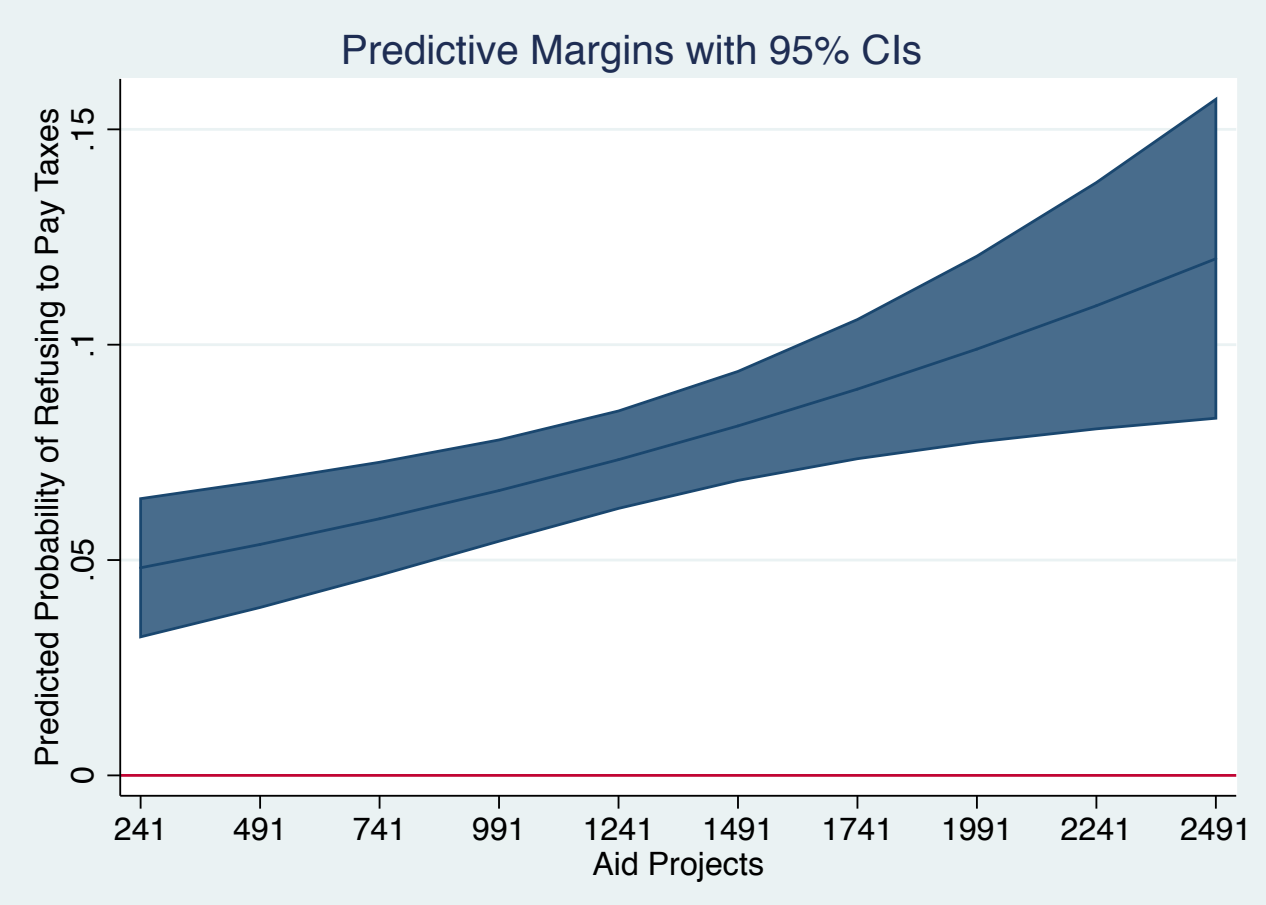

Figure C2. Interaction of Aid Projects and Ease of Evading Taxes

Average Marginal Effects of Ease of Tax Evasion with $95 \% \mathrm{Cls}$




Figure C3. Interaction of Lower State Services and Aid Projects

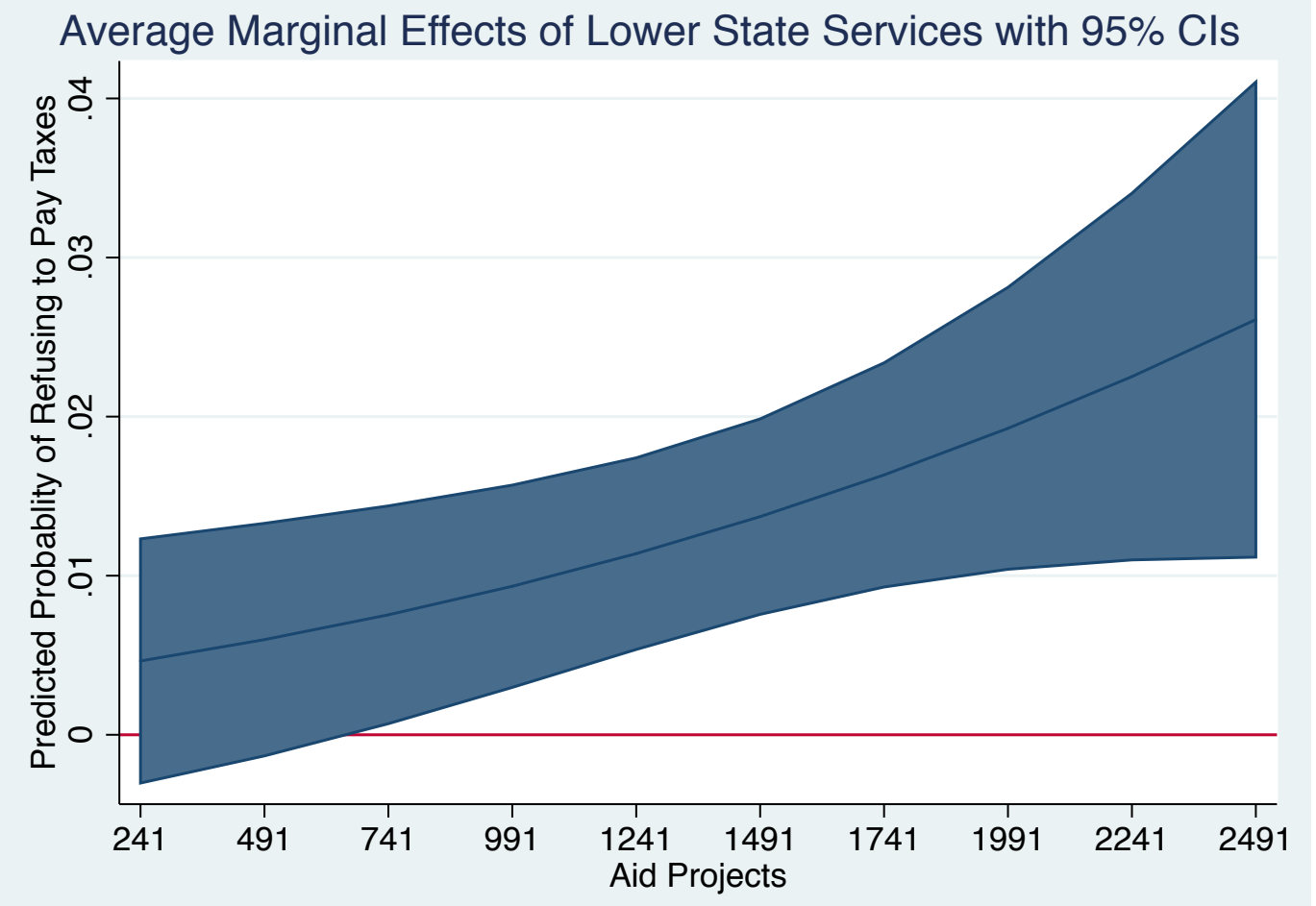


Table C3. Full Instrumental Variable Results

\begin{tabular}{|c|c|c|c|c|}
\hline Variable & $\begin{array}{c}(1) \\
\text { Second Stage } \\
\end{array}$ & $\begin{array}{c}(2) \\
\text { First Stage } \\
\end{array}$ & $\begin{array}{c}(3) \\
\text { athrho2_1 } \\
\end{array}$ & $\begin{array}{c}(4) \\
\text { Insigma2 } \\
\end{array}$ \\
\hline Logged Aid & $\begin{array}{l}0.644^{*} \\
(0.220)\end{array}$ & & & \\
\hline Taxed Revenue & $\begin{array}{c}2.109 \\
(1.121)\end{array}$ & $\begin{array}{l}-2.138 \\
(1.397)\end{array}$ & & \\
\hline Education & $\begin{array}{c}0.0175 \\
(0.00997)\end{array}$ & $\begin{array}{l}-0.00167 \\
(0.0136)\end{array}$ & & \\
\hline Age & $\begin{array}{c}0.00305^{*} \\
(0.000934)\end{array}$ & $\begin{array}{l}-0.00190 \\
(0.00113)\end{array}$ & & \\
\hline Agriculture & $\begin{array}{l}0.00876 \\
(0.0107)\end{array}$ & $\begin{array}{c}0.0150 \\
(0.0146)\end{array}$ & & \\
\hline GDP & $\begin{array}{c}0 \\
(0)\end{array}$ & $\begin{array}{l}-0 \\
(0)\end{array}$ & & \\
\hline Infant Mortality & $\begin{array}{l}0.000730 \\
(0.00287)\end{array}$ & $\begin{array}{l}-0.00264 \\
(0.00411)\end{array}$ & & \\
\hline Population & $\begin{array}{c}-9.87 e-09 \\
(7.55 e-09)\end{array}$ & $\begin{array}{c}1.67 \mathrm{e}-08 \\
(8.73 \mathrm{e}-09)\end{array}$ & & \\
\hline Governance Quality & $\begin{array}{l}-0.100 \\
(0.132)\end{array}$ & $\begin{array}{l}-0.0759 \\
(0.223)\end{array}$ & & \\
\hline UNSC & & $\begin{array}{l}0.628^{*} \\
(0.228)\end{array}$ & & \\
\hline Constant & $\begin{array}{l}-15.00 * \\
(4.362)\end{array}$ & $\begin{array}{l}20.46^{*} \\
(0.674)\end{array}$ & $\begin{array}{l}-0.341 * \\
(0.154)\end{array}$ & $\begin{array}{l}-0.552 * \\
(0.0944)\end{array}$ \\
\hline Observations & 48,011 & 48,011 & 48,011 & 48,011 \\
\hline
\end{tabular}




\section{References}

Afrobarometer Data, Uganda, Round 5, 2012, available at http://www.afrobarometer.org

Afrobarometer Data, Round 5, 2012, available at http://www.afrobarometer.org

Ahmed, Faisal Z. "The perils of unearned foreign income: Aid, remittances, and government survival." American Political Science Review 106.01 (2012): 146165.

Alesina, Alberto, and David Dollar. "Who gives foreign aid to whom and why?" Journal of economic growth 5.1 (2000): 33-63.

Ali, Merima, Fjeldstad, Odd-Helge, and Sjursen, Ingrid H. Factors Affecting Tax Compliant Attitude in Africa: Evidence from Kenya, Tanzania, Uganda and South Africa. Chr. Michelsen Institute, 2012.

Ardant, Gabriel. "Financial Policy and Economic Infrastructure ofModern States and Nations." In The Formation of Nation-State in Western Europe, edited by Charles Tilly. Princeton, NJ: Princeton University Press (1975).

Asongu, Simplice. "On taxation, political accountability and foreign aid: empirics to a celebrated literature." South African Journal of Economics 83.2 (2015): 180-198.

Ayoki, Milton, Marios Obwona, and Moses Ogwapus. Tax Reforms and Domestic Revenue Mobilization in Uganda. Kampala, Uganda: Fountain Publishers. 2008. 
Bashir, Omar S., and Darren J. Lim. "Misplaced Blame: Foreign Aid and the Consequences of UN Security Council Membership." Journal of Conflict Resolution 57.3 (2013): 509-523.

Bauer, Peter T. "Foreign aid forever?" Encounter 42 (1974): 15-29.

Bearce, David H., and Daniel C. Tirone. "Foreign aid effectiveness and the strategic goals of donor governments." The Journal of Politics 72.03 (2010): 837-851.

Benedek, Dora, Ernesto Crivelli, Sanjeev Gupta, and Priscilla Muthoora. Foreign Aid and Revenue: Still a Crowding Out Effect? IMF Working Article WP/12/86, Washington DC: International Monetary Fund, 2012.

Berk, Richard A. Regression analysis: A constructive critique. Sage, 2004.

Berman, Eli, Jacob N. Shapiro, and Joseph H. Felter. "Can Hearts and Minds be Bought? The Economics of Counterinsurgency in Iraq." Journal of Political Economy 119, no. 4 (2011): 766-819.

Bermeo, Sarah Blodgett. "Aid Is Not Oil: Donor Utility, Heterogeneous Aid, and the AidDemocratization Relationship." International Organization 70.01 (2016): 1-32.

Berthélemy, Jean-Claude. "Bilateral donors' interest vs. recipients' development motives in aid allocation: do all donors behave the same?" Review of Development Economics 10.2 (2006): 179-194.

Berthélemy, Jean-Claude, and Ariane Tichit. "Bilateral donors' aid allocation decisionsa three-dimensional panel analysis." International Review of Economics \& Finance 13.3 (2004): 253-274. 
Brass, Jennifer Naomi. Surrogates for government? NGOs and the state in Kenya. Diss. University of California, Berkeley, 2010.

Braütigam, Deborah. "Introduction: Taxation and State-building in Developing Countries." In Taxation and State-building in Developing Countries, Dedborah Braütigam, Odd-Helge Fjeldstad, and Mick Moore (eds), pp. 1-33. Cambridge: Cambridge University Press. 2008.

Braütigam, Deborah, Odd-Helge Fjeldstad, and Mick Moore. Taxation and State-building in Developing Countries: Capacity and Consent. Cambridge: Cambridge University Press. 2008.

Besley, Timothy J., and Torsten Persson. Taxation and development. Working Paper (2013).

Brewer, John. The Sinews of Power: War, Money, and the English State, 1688-1783. Cambridge: Harvard University Press, 1988.

Briggs, Ryan C. "Aiding and Abetting: Project Aid and Ethnic Politics in Kenya." World Development 64 (2014): 194-205.

Broms, Rasmus. "Putting Up or Shutting Up: On the Individual-Level Relationship between Taxpaying and Political Interest in a Developmental Context." The Journal of Development Studies 51.1 (2015): 93-109.

Brun, Jean-François, Gérard Chambas, and Samuel Guerineau. Aide et mobilisation fiscale dans les pays en développement. No. halshs-00556804. 2011.

Bueno De Mesquita, Bruce, and Alastair Smith. "A political economy of aid." International Organization 63.02 (2009): 309-340. 
Burnside, Craig, and David Dollar. "Aid, growth, the incentive regime, and poverty reduction." The World Bank: Structure and Policies 3 (2000): 210.

Carbone, Giovanni M. No-party democracy? Ugandan politics in comparative perspective. Lynne Rienner Publishers, 2008.

Cawley, Gerry and Justin Zake. "Tax Reform." In Uganda's Economic Reforms: Insider Accounts, edited by Florence Kuteesa, Emanuel Tumusiime-Mutebile, Alan Whitworth, and Tim Williamson. Pgs. 103-128. Oxford: Oxford University Press. 2010.

Chen, D., Matovu, J., and Reinikka, R. “A Quest for Revenue and Tax Incidence.” In Uganda's Recovery, edited by R. Reinikka and P. Collier. Pgs. 271-317. Washington, DC: World Bank. 2001.

Clist, Paul and Oliver Morrissey. "Aid and Tax Revenue: Signs of a Positive Effect Since the 1980s." Journal of International Development 23, no. 2 (2011): 165-180.

Clist, Paul. "25 Years of Aid Allocation Practice: Whither Selectivity?" World Development 39.10 (2011): 1724-1734.

Collier, Paul. The Bottom Billion: Why the poorest countries are failing and what can be done about it. New York: Oxford University Press, 2007.

Collier, Paul, Lani Elliot, Anke Hoeffler, Marta Reynal-Querol, and Nicholas Sambanis. Breaking the Conflict Trap: Civil War and Development Policy. World Bank Publications, 2003.

D'Arcy, M. Why Do Citizens Assent to Pay Tax? Legitimacy, Taxation and the African State. Afrobarometer Working Article No. 126, 2011. 
De Luca, Giacomo, and Marijke Verpoorten. From Vice to Virtue? Civil War and Social Capital in Uganda. No. 298. LICOS Discussion Article, 2011.

de Mesquita, Bruce Bueno, and Alastair Smith. "Aid: Blame It All on "Easy Money"." Journal of Conflict Resolution 57.3 (2013): 524-537.

Dietrich, Simone, and Matthew S. Winters. "Foreign Aid and Government Legitimacy." Journal of Experimental Political Science 2.02 (2015): 164-171.

Dietrich, Simone. "Bypass or Engage? Explaining Donor Delivery Tactics in Foreign Aid Allocation." International Studies Quarterly 57, no. 4 (2013): 698-712.

Dollar, David, and Victoria Levin. "The increasing selectivity of foreign aid, 19842003." World Development 34.12 (2006): 2034-2046.

Duponchel, Marguerite. Can Aid Break the Conflict Trap? Unpublished manuscript, 2008.

Easterly, William. The white man's burden: why the West's efforts to aid the rest have done so much ill and so little good. Penguin, 2006.

Economist Intelligence Unit. Democracy Index 2015: Democracy in an age of anxiety. Accessed at http://www.yabiladi.com/img/content/EIU-Democracy-Index2015.pdf on 15 June 2016 at 5:15pm.

Eubank, Nicholas. "Taxation, Political Accountability and Foreign Aid: Lessons from Somaliland." Journal of Development Studies 48.4 (2012): 465-480.

Evans, Peter B., Dietrich Rueschemeyer, and Theda Skocpol. Bringing the State Back In. Cambridge: Cambridge University Press, 1985.

Faye, Michael, and Paul Niehaus. "Political Aid Cycles." The American Economic 
Review 102.7 (2012): 3516-30

Fearon, James D., Macartan Humphreys, and Jeremy M. Weinstein. "Can Development Aid Contribute to Social Cohesion After Civil War? Evidence from a Field Experiment in Post-conflict Liberia." The American Economic Review (2009): 287-291.

Feyzioglu, T., Swaroop, V., \& Zhu, M. "A panel data analysis of the fungibility of foreign aid." World Bank Economic Review, 12.1 (1998): 29-58.

Findley, Michael G. and Josiah F. Marineau. "The swarm principle? A sub-national spatial analysis of donor coordination in Sub-Saharan Africa." Unpublished manuscript (2016).

Fjeldstad, Odd-Helge. "What's Trust Got to Do With It? Non-payment of Service Charges in Local Authorities in South Africa." The Journal of Modern African Studies 42.4 (2004): 539-562.

Fjeldstad, O. H., C. Schulz-Herzenberg, and H. I. Sjursen. Peoples' Views of Taxation in Africa: Theories, Evidence and an Agenda for Future Research. ICTD Working Article, 2012.

Friedman, Eric, Simon Johnson, Daniel Kaufmann, and Pablo Zoido-Lobaton. "Dodging the grabbing hand: the determinants of unofficial activity in 69 countries." Journal of Public Economics 76, no. 3 (2000): 459-493.

Ghura, D. Tax Revenue in Sub-Saharan Africa: Effects of Economic Politics and Corruption. IMF Working Paper 98/135. Washington, DC: International Monetary Fund. 1998. 
Girod, Desha M. "Effective Foreign Aid Following Civil War: The NonstrategicDesperation Hypothesis." American Journal of Political Science 56.1 (2012): $188-201$.

Goldsmith, Arthur A. "Foreign Aid and Statehood in Africa." International Organization 55.1 (2001): 123-148.

Gupta S, Clements B, Pivovarsky A, Tiongson E. 2004. "Foreign Aid and Revenue Response: Does the Composition of Foreign Aid Matter?" In Helping Countries Develop: The Role of Fiscal Policy, B Clements, S Gupta, G Inchauste (eds), pp. 385-405. Washington, DC: Int. Monetary Fund.

Easterly, William R. The white man's burden: why the West's efforts to aid the rest have done so much ill and so little good. Penguin, 2006.

Frey, B. S., \& Stutzer, A. “The economics of happiness.” World Economics, 3:1 (1986): $1-17$.

Fleck, Robert K., and Christopher Kilby. "World Bank independence: A model and statistical analysis of US influence." Review of Development Economics 10.2 (2006): 224-240.

Fleck, Robert K., and Christopher Kilby. "Changing aid regimes? US foreign aid from the Cold War to the War on Terror." Journal of Development Economics 91.2 (2010): 185-197.

Fox, John. Applied Regression Analysis and Generalized Linear Models. $2^{\text {nd }}$ ed. Sage publications, 2008. 
Gibler, Douglas M. 2009. International military alliances, 1648-2008. Version 4.1. CQ Press.

Gupta, Sanjeev, Hamid Davoodi, and Erwin Tiongson. "Corruption and the provision of health care and education services." In The Political Economy of Corruption, Arvind K. Jain, ed. Pgs 111-141. New York: Routlege, 2002.

Harrigan, Jane, Chengang Wang, and Hamed El-Said. "The economic and political determinants of IMF and World Bank lending in the Middle East and North Africa." World Development 34.2 (2006): 247-270.

Harrigan, Jane, and Chengang Wang. "A New Approach to the Allocation of Aid among Developing Countries: Is the USA different from the Rest?" World Development 39.8 (2011): 1281-1293.

Hauser, Ellen. "Ugandan relations with Western donors in the 1990's: what impact on democratisation?" The Journal of Modern African Studies 37.4 (1999): 621-641.

Heinrich, Tobias. "When is aid selfish, and when it is selfless?" Journal of Politics 75.2 (2013): 422-435.

Hendrix, Cullen. "Measuring State Capacity: Theoretical and Empirical Implications for the Study of Civil Conflict." Journal of Peace Research 47.3 (2010): 273-285.

Jablonski, Ryan S. "How aid targets votes: the impact of electoral incentives on foreign aid distribution." World Politics 66.2 (2014).

Joshi, Anuradha and Joseph Ayee. "Associational Taxation: A Pathway Into the Informal Sector?" In Taxation and State-Building in Developing Countries: Capacity and 
Consent. Eds. Deborah Brautigam, Odd-Helge Fjeldstad, and Mick Moore. Pgs. 183-211. Cambridge: Cambridge University Press. 2008.

Kaldor, Nicholas. "Will Underdeveloped Countries Learn to Tax?" Foreign Affairs 41.2 (1963): 410-419.

Kilby, Christopher, and Axel Dreher. "The impact of aid on growth revisited: Do donor motives matter?." Economics Letters 107.3 (2010): 338-340.

Knack, Stephen, and Aminur Rahman. "Donor fragmentation and bureaucratic quality in aid recipients." Journal of Development Economics 83.1 (2007): 176-197.

Kollman, Ken, Allen Hicken, Daniele Caramani, David Backer, Joel Selway, and Fabricio Vasselai. GeoReferenced Electoral Districts Datasets (Beta): Uganda. Ann Arbor, MI: Center for Political Studies, University of Michigan, 2014.

Kuziemko, Ilyana, and Eric Werker. "How much is a seat on the Security Council worth? Foreign aid and bribery at the United Nations." Journal of political economy 114.5 (2006): 905-930.

Levi, Margaret. Of Rule and Revenue. University of California Press, 1988.

Long, J. Scott. Regression Models for Categorical and Limited Dependent Variables. Thousand Oaks, CA: Sage, 1997.

Lumsdaine, David Halloran. Moral vision in international politics: the foreign aid regime, 1949-1989. Princeton University Press, 1993.

Magalsi, Collins V.P. Unmasking the Malawi Tax System. Consultancy Report, Centre for Research on Multinational Corporations. (2009)

Maizels, Alfred, and Machiko K. Nissanke. "Motivations for aid to developing 
countries." World Development 12.9 (1984): 879-900.

Martin, Lucy. "Taxation, Loss Aversion, and Accountability: Theory and Experimental Evidence for Taxation's Effect on Citizen Behavior." Unpublished working paper, Yale University, 2014. Accessed Online at http://sites. duke. edu/2014bmp/files/2014/10/Martin TaxAcc.pdf.

Mauro, Paolo. "Corruption and the Composition of Government Expenditure." Journal of Public Economics 69.2 (1998): 263-279.

McAdam, Doug, Sidney Tarrow, and Charles Tilly. Dynamics of Contention. Cambridge: Cambridge University Press, 2001.

McGillivray, Mark, and Edward Oczkowski. "A two-part sample selection model of British bilateral foreign aid allocation." Applied Economics 24.12 (1992): 13111319.

McKinlay, Robert D., and Richard Little. "A foreign policy model of US bilateral aid allocation." World Politics 30.1 (1977): 58-86.

Moore, Mick. "Revenues, State Formation, and the Quality of Governance in Developing Countries." International Political Science Review 25.3 (2004): 297-319.

Morgenthau, Hans. "A political theory of foreign aid." American Political Science Review 56.02 (1962): 301-309.

Morrison, Kevin. Nontaxation and Representation. Cambridge: Cambridge University Press 2014.

Morrissey, Oliver. "Aid and Government Fiscal Behavior: Assessing Recent Evidence.” World Development 69 (2015): 98-105. 
Moss, Todd, Gunilla Pettersson, and Nicolas Van de Walle. An Aid-Institutions Paradox? A Review Essay on Aid Dependency and State Building in Sub-Saharan Africa. No. 74. 2006.

Moyo, Dambisa. Dead aid: Why aid is not working and how there is a better way for Africa. Macmillan, 2009.

Nielsen, Richard A., Michael G. Findley, Zachary S. Davis, Tara Candland, and Daniel L. Nielson. "Foreign Aid Shocks as a Cause of Violent Armed Conflict." American Journal of Political Science 55, no. 2 (2011): 219-232.

Neumayer, Eric. "The determinants of aid allocation by regional multilateral development banks and United Nations agencies." International Studies Quarterly 47.1 (2003): 101-122.

OECD. The Paris Declaration on Aid Effectiveness. 2005.

OECD. Accra Agenda for Action. 2008.

Öhler, Hannes, and Peter Nunnenkamp. Needs-based targeting or favoritism? The regional allocation of multilateral aid within recipient countries. No. 1838. Kiel Working Paper, 2013.

Öhler, Hannes. Do Aid Donors Coordinate Within Recipient Countries? Unpublished manuscript, 2013.

Organization for Economic Co-operation and Development. Geographical Distribution of Financial Flows to Developing Countries 2014: Disbursements, Commitments, and Country Indicators. 
Ottervik, Mattias. Conceptualizing and Measuring State Capacity: Testing the Validity of Tax Compliance as a Measure of State Capacity. The Quality of Governance Institute Working Paper Series No. 20. 2013.

Paler, Laura. "Keeping the public purse: An experiment in windfalls, taxes, and the incentives to restrain government." American Political Science Review 107.04 (2013): 706-725.

Plaut, Martin. "Uganda donors cut aid after president passes anti-gay law." The Guardian, 25 February 2014. < $\not$ http://www.theguardian.com/globaldevelopment/2014/feb/25/uganda-donors-cut-aid-anti-gay-law $>$. Accessed at 6:38pm on June $2^{\text {nd }}, 2014$.

Prichard, Wilson, Jean-François Brun, and Oliver Morrissey. Donors, aid and taxation in developing countries: an overview. ICTD Work Paper 6 (2012).

Prichard, W., A. Cobham, and A. Goodall. ICTD Government Revenue Dataset. ICTD working paper 19. Institute of Development Studies, Brighton (2014).

Prichard, Wilson. "Reassessing Tax and Development Research: A New Dataset, New Findings, and Lessons for Research.” World Development 80 (2016): 48-60.

Rodrik, Dani. “Why Is There Multilateral Lending?” In Annual World Bank Conference on Development Economics, edited by M. Bruno, B. Pleskovic. Pgs. 167-193. Washington, DC: International Bank for Reconstruction and Development. 1995. Rose-Ackerman, Susan. Corruption and Government: Causes, Consequences, and Reform. Cambridge: Cambridge University Press, 1999.

Ross, Michael L. "Does Taxation Lead to Representation?" British Journal of Political 
Science 34.2 (2004): 229-249.

Ross, Michael L. "What Have We Learned about the Resource Curse?." Annual Review of Political Science 18 (2015): 239-259.

Sacks, Audrey. Can Donors and Non-state Actors Undermine Citizens' Legitimating Beliefs? World Bank Policy Research Working Article 6158, 2012.

Schelling, Thomas C. "American foreign assistance." World Politics 7.4 (1955): 606-626.

Smith, Alastair. "The perils of unearned income." The Journal of Politics 70.03 (2008): 780-793.

Stone, Randall W. "The scope of IMF conditionality." International Organization (2008): 589-620.

Strandow, Daniel, Michael G. Findley, Daniel L. Nielson, and Joshua Powell. 2011. "The UCDP and AidData Codebook on Geo-referencing Aid. Version 1.1." Uppsala Conflict Data Program, Article No. 4. Available at http://www.pcr.uu.se/research/ucdp/publications/ucdp_articles.

Schumpeter, Joseph. "Crisis of the Tax State." International Economic Papers (1934 [1919]): 5-8.

Svensson, Jakob. "Foreign Aid and Rent-Seeking." Journal of International Economics 51 (2000): 437-461.

Tangri, Roger, and Andrew M. Mwenda. "Politics, donors and the ineffectiveness of anticorruption institutions in Uganda." Journal of Modern African Studies 44.1 (2006): 101.

Therkildsen, Ole. "Keeping the State Accountable: Is aid no better than oil?" IDS Bulletin 
33.3 (2002): 41-49.

Tierney, Michael J., Daniel L. Nielson, Darren G. Hawkins, J. Timmons Roberts, Michael G. Findley, Ryan M. Powers, Bradley Parks, Sven E. Wilson, and Robert L. Hicks. "More dollars than sense: Refining our knowledge of development finance using AidData." World Development 39, no. 11 (2011): 1891-1906.

Tilly, Charles. Coercion, capital, and European states, AD 990-1992. Wiley-Blackwell, 1992.

Timmons, Jeffrey F. "The Fiscal Contract." World Politics 57 (2005): 530-67.

Tierney, Michael J., Daniel L. Nielson, Darren G. Hawkins, J. Timmons Roberts, Michael G. Findley, Ryan M. Powers, Bradley Parks, Sven E. Wilson, and Robert L. Hicks. "More Dollars than Sense: Refining our Knowledge of Development Finance using AidData." World Development 39.11 (2011): 1891-1906.

Tsoutsoplides, Constantine. "The determinants of the geographical allocation of EC aid to the developing countries." Applied Economics 23.4 (1991): 647-658.

Uganda Bureau of Statistics. 2013 Statistical Abstract.

Uganda Bureau of Statistics. National Population and Housing Census 2014: Provisional Results.

United Nations Development Programme. Human Development Report 2013:The Rise of the South: Human Progress in a Diverse World. New York: New York, 2013.

United States Agency for International Development. Uganda Country Development Cooperation Strategy, 2011-2015. Working Extract, 2010. Available at: < https://www.usaid.gov/sites/default/files/documents/1860/Uganda_Country_Deve 
lopment Cooperation Strategy 2011-2015.pdf $>$. Accessed at 1:09pm on 4 April, 2016.

United States Agency for International Development. Uganda Country Development Cooperation Strategy, 2011-2015: Performance Management Plan, vol. 1: Mission PMP. May 2012.

van der Veen, A. Maurits. 2011. Ideas, Interests and Foreign Aid. Cambridge:

Cambridge University Press.

Whitworth, Alan and Tim Williamson. "Overview of Uganda Economic Reform since 1986.” In Uganda's Economic Reforms: Insider Accounts, edited by Florence Kuteesa, Emanuel Tumusiime-Mutebile, Alan Whitworth, and Tim Williamson. Pgs. 134. Oxford: Oxford University Press. 2010.

Winters, Matthew S. "Choosing to Target: What Types of Countries get Different Types of World Bank Projects." World Politics 62.3 (2010): 422-458.

World Bank Independent Evaluation Group (IEG), the European Commission (DG DEVCO Evaluation Unit) with the Government of Uganda (Ministry of Finance, Planning, and Economic Development, and Office of the Prime Minister), Ireland (Department of Foreign Affairs and Trade) and the UK (DFID). Joint Evaluation of Budget Support to Uganda. Draft Final Report, Vol. 2. April, 2015.

Young, Joseph K. "State capacity, democracy, and the violation of personal integrity rights." Journal of Human Rights 8.4 (2009): 283-300. 


\section{Vita}

Dr. Josiah Franklin Marineau is an Assistant Professor of Political Science at Campbellsville University. He received his PhD in Government from the University of Texas-Austin in the summer of 2016. Previously, he received a Master's of Arts in International Studies from the University of Denver in 2010 and a Bachelor's of Arts in Political Science from the University of Alaska, Fairbanks in 2007.

Permanent address (or email): josiah.marineau@gmail.com

This dissertation was typed by Josiah Franklin Marineau. 